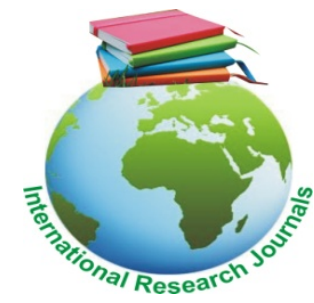

\title{
Type 2 diabetes mellitus, drug addiction, bipolar disorder and epilepsy display overlapping aetiopathogenic mechanisms: Implication for prevention and pharmacotherapy
}

\author{
Stephen Oriaifo* ${ }^{* 1}$ Nicholas Oriaifo ${ }^{2}$, Esther Okogbenin ${ }^{3}$, Eric Omogbai ${ }^{4}$ \\ ${ }^{1}$ Dept. of Pharmacology and therapeutics, Ambrose Alli University, Ekpoma, Edo State, Nigeria \\ ${ }^{2}$ Dept. of Obstetrics and Gynaecology, Irrua Specialist Teaching Hospital, Irrua, Edo State, Nigeria \\ ${ }^{3} \mathrm{HOD}$, Dept of Psychiatry, Irrua Specialist Teaching Hospital, Irrua and Ambrose Alli University, Ekpoma \\ ${ }^{4}$ Dept. of Pharmacology and Toxicology, University of Benin, Benin-City, Edo State \\ ${ }^{*}$ Corresponding Author's E-mail: stephenoriaifo@yahoo.com
}

\begin{abstract}
The prevalence of diabetes and co-morbid diseases, especially in developing countries, may have already exceeded estimates. Accumulating reports indicate considerable underpinnings in the mechanisms of the aetiopathogenesis of metabolic syndrome, bipolar disorder, epilepsy and, recently, substance addiction. Continuing evidence incriminates dysfunction in genetic, mitochondrial and inflammatory cascade mechanisms as contributory factors to the dysregulation of neurotrophic, serotonergic, dopaminergic, adrenergic, glutamatergic, GABAergic and autophagic pathways. There may also be co-incident dysregulation of the global anti-oxidant network, the endogenous digitalis system, the vasopressin signalling and the hypothalamo-pituitary-adrenal axis. Nuclear factor-kappa B (NF-kappa B) signaling and reactive oxygen species lead to activation of the mammalian target of rapamycin complex I (mTORCl) and this process may be central to the aetiopathogenesis of drug addiction, obesity, foetal programming, diabetes mellitus, epilepsy and bipolar disorder. Antiglycaemics such as cannabinoid CB2 agonists, metformin, artesunate and valproate; insulin-mimetics such as glucagon-like peptide-I (GLP-I) and its analogues; phytomedicines from garlic and curcumin are now shown to exhibit neuroprotective effects. These agents which may down-regulate inflammatory cytokines, upregulate endothelial nitric oxide (eNOS) and peroxisome proliferator-activated receptor alpha (PPAR- $\alpha$ ) signalling, attenuate mitochondrial dysfunction, enhance the actions of glucagon-like peptide-I (GLP-I), inhibit mTOR, NF-kappa B, interleukin-I $\beta$ and glycogen synthase kinase-3 $\beta$ stand to be of benefit in these illnesses which demonstrate considerable overlay in their aetopathogenic mechanisms. Underpinnings and bidirectional relationships between the metabolic syndrome and mental health disorders may pave way for common new fronts to drug development in translational cardiovascular psychiatry and neurology.
\end{abstract}

Keywords: Metabolic syndrome, Bipolar disorder, Drug Addiction, Epilepsy, Mechanisms, Overlap

\section{INTRODUCTION}

Globally, type 2 diabetes mellitus is increasing in epidemic proportions (King and Rewers, 1991). According to $\mathrm{WHO}$, the prevalence of diabetes mellitus in adults worldwide was estimated to be $4.0 \%$ in 1995 and is predicted to rise to $5.4 \%$ by the year 2025 . This means the number of adults with diabetes mellitus in the world would rise from 135 million in 1995 to 300 million in the year 2025. Additionally, hypertension affects one billion 
people worldwide and it is estimated that by 2025 , up to 1.56 billion adults worldwide will be hypertensive. There is an association between hyperinsulinaemia and essential/genetic hypertension but not with secondary hypertension (El-Atat et al., 2004).

Diabetes and hypertension exert a significant burden resulting in increased morbidity and mortality (Moller, 2001), decreased life expectancy and reduced quality of life. For example, according to WHO, the life expectancy of Nigerians fell from 51-56 years in 2000 to 47.56 years in 2011 due to the epidemic of the metabolic or insulin resistance syndrome (Mohan et al., 2013; Awosan et al., 2013; Udenze et al., 2013). In tandem, the prevalence of epilepsy (Osuntokun et al., 1987; Olubunmi, 2006) and of drugs of abuse in Nigerians (Chikere and Mayowa, 2011; Ekpeyong, 2012), factors that may upregulate the inflammatory cascade, may also be on the upward trend.

Investigators have reported links between bipolar disorder, the insulin resistance syndrome, obesity and drug addiction (D'Mello et al., 2010; Kemp and Fan, 2012; Nousen et al., 2013; Kenny, 2011; Baik, 2013). The rate of the metabolic syndrome in bipolar disorder varies from $17 \%$ to $67 \%$ depending on sample size (Grover et al., 2012). Evidence suggests that (molecular) defects associated with the development of diabetes also contribute to an increased risk of all types of neuropsychiatriac illnesses including affective disorders (Nousen et al., 2013; Wahlqvist et al., 2012; Cole et al., 2007). This could represent a pathway for new drug development with the biguanide metformin and some phytomedicines (Licinio J, 2011; Stein D, 2012; Berk, 2012; Wahlqvist et al., 2012; Patel et al., 2012).

Additionally, hypoxia-dependent amyloidogenesis, a sequelae of hypertension, could lead to Alzheimer's disease, creating the cerebrovascular-Alzheimer's disease spectrum that may be responsive to some antihypertensives such as carvedilol and valsartan that have neuroprotective effects (Wanget al., 2011; Jin et al., 2014; Valenzuela et al., 2012; Alexander et al., 2011; Wang et al., 2007).

These revelations point to new, unsuspected association of cardiovascular disorders with bipolar mood disorders (Manev, 2009A $2009_{\mathrm{B}}$, Skaper et al., 2009; Yanev et al., 2013; Nichols, 2009; Omar et al., 2012). The possible mediators of this association, such as polymorphism in the matrix metalloproteinase-9 (MMP9) gene (Rybakowski, 2009), microRNA-regulated pathways (Zhu et al., 2013; Hebert, 2009) and dysfunction in eNOS signalling (O'Sullivan et al., 2014), are being unravelled. Immune/inflammatory and cardiometabolic risk factors may be common endophenotypes of both physical and psychiatric illnesses including drug addictin (Krishnadas et al., 2014; Kovacs, 2012; Kenny, 2011; Mclntyre et al., 2009).Importantly, the metabokinesATP-NGF and BDNF are now known to mediate trophobiological effects through immunotrophic to metabotrophic effects involved in pathogenesis of various neuropsychiatric and metabolic diseases when dementia, depression, type 2 diabetes and obesity may express a common phenotype and existence (Gray et al., 2006; Li, 2007; Chaldakov et al., 2009; 2014; Yanev et al., 2013). NGF and BDNF are involved in synaptogenesis and pancreatic $\beta$-cell survival. Included in the list of selected NGF- and BDNF-related diseases are obesity, metabolic syndrome, atherosclerosis, bipolar spectrum disorders, eating disorders, diabetic neuropathy and retinopathy, epilepsy and Alzheimer's disease.

\section{Metabolic Syndrome}

Metabolic syndrome is a cluster of cardiometabolic risk factors which include insulin resistance, prediabetes, type 2 diabetes mellitus, central obesity, dyslipidaemia, hypertension, atherosclerotic cardiovascular disease, hypercoagulability and microalbuminuria (WHO, 1999; Alberti et al., 2005; El-Atat et al., 2004; Awosan et al., 2013).

High-fat diet and obesity may be linked to type 2 diabetes mellitus and epilepsy through the Notch signalling pathway (Li et al., 2013; Liu et al., 2014), thus creating the diabesity spectrum (Chaldakov et al., 2014). Inhibition of Notch signalling pathway promotes browning of white adipose tissue by increasing number of beige fat cells which inproves glucose homeostasis (Bi et al., 2014; $\mathrm{Li}$ et al., 2013). Interleukin 4/13 induction and M2 macrophages activation are required for biogenesis of beige fat (Qiu et al., 2014; Rao et al., 2014). In addition, targeted disruption of transforming growth factor-beta (TGF- $\beta$ ) superfamily receptor, activin receptor-like kinase 7 (ALK7), alleviates diet-induced catecholamine resistance in adipose tissue, thereby reducing obesity (Guo et al., 2014). Obesity may also be linked to type 2 diabetes by an absent protein, nuclear ubiquitous casein and cyclin-dependent kinase substrate (NUCKS). NUCKS is a positive transcriptional regulator of insulin signalling (Qui et al., 2014) and works by regulating chromatin and RNA polymerase II recruitment to the promoters of insulin receptor and other insulin pathway modulators. NUCKS is down-regulated in individuals with a high body mass index and in high fat fed mice. Its levels increase upon starvation. Additionally, variants of the demethylase, the fat mass and obesity-associated (FTO) gene (Fraying et al., 2007) have been positively correlated with obesity, metabolic syndrome and Alzheimer's disease in humans. In the same vein, high fat diet feeding which can also be induced by drugs of abuse such as morphine (Will et al., 2006) produces brain insulin resistance, synaptodendritic abnormalities and altered behaviour in mice (Arnold et al., 2014). It also reduces brain neuropeptide $\mathrm{Y}$, brain-derived neurotrophic factor and cyclic adenosine monophosphate response element binding protein levels with reduced cell proliferation and neuroblast differentiation in the dentate 
gyrus (Yoo et al., 2011; Azoulay et al., 2008). High fat diet also increases blood uric acid levels and reduces brain docosahexaenoic acid levels (Sharma et al., 2014). Elevated serum uric acid is a strong predictor of the development of the metabolic syndrome (Choi et al., 2014) and impulsivity (Sutin et al., 2014). Uric acid, which upregulates the sterol regulatory element binding protein (SREBP-1c) (Choi et al., 2014), may be a biological marker for the differentiation of unipolar and bipolar disorders (Kesebir et al., 2014). Its levels are increased in drug-naïve subjects with bipolar disorder during a first manic episode (Salvadore et el, 2010) and decreased by metformin (Barskova et al., 2005; 2009) and anti-epileptic drugs (Krause et al., 1987).

Work in our clinic recently shows that the insulinmimetic garlic (Sakurai and Adachi, 2005; Patel et al., 2012) significantly enhanced the actions of metformin in reducing alcohol craving and body weight implicating a relationship between mechanisms regulating substance craving and appetite/body weight. This supports previous reports that constituents from garlic such as allicin and diallyl disulphide activate transient receptor potential cation channel, subfamily I, member I (TRPIA) (Emery et al; 2015; Bautista et al., 2005) to decrease body weight and alcohol craving while enhancing cognition most probably by activating glucagon-like peptide-I (GLP-I) and heme oxygenase-I (HO-I)/nuclear factor (erythroidderived 2)-like 2 (Nrf2) (Engel and Jerlhag, 2014; Sarkaki et al., 2012; Ambati, 2013; Shirazi et al., 2013; Zeng et al., 2013). Ferdaoussi et al (2008) have reported that the GLP-I agonist exendin-4 antagonises interleukin-I beta that may be associated with diabetes as well as drug addiction (Cearley et al., 2011; Zhang et al., 2015). Additionally, agents such as GLP-I agonists, garlic, Icysteine and $\mathrm{N}$-acetyl-cysteine that enhance hydrogen sulphide which inhibits NF-kappa B (Oh et al., 2006; Dai et al., 2013) in tissues may prevent drug reinstatement (Selley et al., 2014; Baker et al., 2003; Peana et al., 2010) especially when combined with metformin which also inhibits NF-kappa $\beta$ (Isoda et al., 2006) that regulate structural and behavioural plasticity to drugs of abuse such as cocaine (Russo et al., 2009). Additionally, a dysregulated NF-kappa $\beta$ signalling may be a core characteristic of bipolar disorder (Elhaik and Zandi, 2015), diabetes mellitus (Kiechi et al., 2013); temporal lobe epilepsy (Teocchi et al., 2013) and Alzheimer's disease (Granic et al., 2009).

\section{Lipotoxicity}

Lipotoxicity refers to cellular dysfunctions caused by elevated free fatty acid levels playing a central role in the development and progression of obesity related diseases. Saturated fatty acids cause insulin resistance and reduce insulin production in pancreatic cells. The underlying endoplasmic reticulum (ER) stress-response can lead to beta-cell death (lipoapotosis) (Simon-Szabo et al., 2014). Fructose is a cause of insulin resistance and lipotoxicity (Chen et al., 2001; Elliot et al., 2002; Khitan and Kim, 2013). Fructose administration induces the rise of glucose, insulin, total cholesterol, triglyceride, free fatty acids and methylglyoxal (Lu et al., 2013) and may also lead to decreased neurogenesis in the hippocampus (van der Borght et al., 2011). Methylglyoxal is a highly reactive dicarbonyl generated during glucose and fructose metabolism. It is a major precursor of advanced glycation end-products (AGE) and induces activation of the reninangiotensin system (Dhar et al., 2013). Ten percent fructose administration for three to five weeks induces the metabolic syndrome with over-expression of proinflammatory cytokines such as tumor necrosis factoralpha (TNF- $\alpha$ ), interleukin-6, transforming growth factor beta-I, plasminogen activator inhibitor-I (PAI-I) and monocyte chemoattractant protein I (Yang et al., 2014; Shalam et al., 2006). From our experience and probably due to species differences, this may not be uniformly replicated in all laboratories. Chronic fructose feeding is reported to lead to lower insulin receptor mRNA with attendant decrease in insulin sensitivity in skeletal muscle and hyperinsulinaemia. There is then not only hypertriglyceridaemia but aslo hyperuricemia probably due to upregulation of sterol regulatory element binding protein-lc by peroxisome proliferator-activated receptorgamma-coactivator-I beta (PGC-Iß) (Nagai et al., 2009). Fructose undergoes phosphorylation by fructokinase to fructose-I-phosphate (using ATP), a reaction that has no negative feed-back mechanisms (Abdulla et al., 2011) unlike glucokinase and phosphofructose. Accumulation of the phosphorylated substrate and depletion of ATP leads to high uric acid levels, a cause of the metabolic syndrome (DeBosch et al., 2014). Mice lacking the enterocyte uric acid transporter, GLUT 9, develop earlyonset metabolic syndrome.

Free fatty acids from stored triglycerides or dietderived chylomicrons increase cardiometabolic risk. Free fatty acids, acyl-CoAs, ceramides, and diacylglycerol increase PKC, C-Jun N-terminal kinase (JUNK) and the inhibitor of IK $\beta \alpha$, which is IKK kinase and related kinases. These then impair insulin signalling by increasing the inhibitory serine phosphorylation ofinsulin receptor substrate (IRS) (Qatanani and Lazar, 2007).

\section{Free Fatty Acids Activate Toll-Like Receptors}

In addition, free fatty acids activate Toll-like receptor 4 (TLR 4) (Nguyen et al., 2014); increase endoplamic reticulum (ER) stress, mitochondrial dysfunction to cause insulin resistance, and decrease peroxisome proliferatoractivated receptor gamma-coactivator- I alpha (PGC I $\alpha$ ) important for modulation of dopaminergic activity (Ciron et al., 2010). The activities of TLRs are regulated by glycogen synthase kinase (Martin et al., 2005; Wang et 
al., 2011) whose non-specific inhibitors such as the cannabinoids (Martin-Moreno et al., 2012) and metformin (Sag et al., 2008) may suppress the production of interleukin-I $\beta$, interleukin-6, interleukin-12 and tumor necrosis factor whilst enhancing production of interleukin10. Mice lacking TLR 4 are protected from the ability of lipids to induce insulin resistance. TLR 4 is target gene of CCAAT/enhancer binding protein delta which regulates inflammatory responses (Balamurugan et al., 2012) and modulates obesity-induced inflammation and insulin resistance (Jia et al., 2014) through PKC activation (Loegering and Lennartz, 2011), for example, PKC epsilon which may play a critical role in mediating fatinduced insulin resistance (Samuel et al.,2007). Genetic variations of TLR-4 may be associated to bipolar disorder (Oliveira et al., 2014) and epilepsy (Gan et al., 2013).

Specific alterations in TLR agonist-mediated cytokine release contribute to the evidence of immune dysfunction in bipolar disorders (McKernan et al., 2011) and epilepsy (Maroso et al., 2010). The AMPK activator, metformin, may acutely and chronically suppress TLR 4 signaling (Soraya et al., 2014) which may also be upregulated by morphine released by activated neuroglia during drug addiction (Kovacs,2012), providing support for a relationship between cardiometabolic and neuropsychiatric disorders.

\section{Bipolar Disorder}

Bipolar disorder (BPD), which is associated with the highest suicide rate among all disorders (Malhi et al., 2010), is a severe neuropsychiatric disease. It is characterised by recurrent episodes of mania, pathologically energised states with misguided volition and behaviour. The mood state is of intoxicating euphoria (or irritability) and depressions that are low moods with compromised energy, volitional states and also diminished cognitive capacity (Chen et al., 2014). It affects $1 \%$ of the population.

Family and twin studies show bipolar disorder has a strong heritable component (Lohoff et al., 2006). In bipolar disorder I, there is mania and major depression in ratio of 1: 3 . Bipolar disorder II has hypomania and major depression in ratio of 1: 40. Bipolar disorder (BPD) III or cyclothymic disorder has hypomania and depression in ratio of I: I. Bipolar disorder IV (BPD IV) is mania or hypomania induced by antidepressant therapy. BPD $\mathrm{V}$ consists of only major depression and there is a family history of bipolar disorder. Bipolar spectrum disorder includes depression (especially treatment-resistant depression), impulsivity disorder, substance abuse disorder, eating disorders, personality disorders and childhood behavioural disorders.

\section{A link between mood disorders and substance abuse}

Nearly $60 \%$ of individuals with bipolar dsorder have a co- occurring substance use disorder (Verduin et al., 2005) or drug addictiondefined as a chronic, relapsing brain disease that is characterised by compulsive drug seeking and use despite harmful consequences (Volkow, 2014). This implicates a link between mood disorders and substance abuse or dependence disorders and a genetic link between alcoholism and bipolar disorder has been suggested (Brady and Lydiard, 1992; Sonne and Brady, 2002; Merikangas and Gelemter, 1990; Merikangas et al., 2008). Individuals with manic symptoms may be at greater risk for the later onset of alcohol and cannabis dependence.

\section{Bipolar Disorder is related to Type 2 Diabetes Mellitus}

The relationship between bipolar disorder and type 2 diabetes mellitus has been noted to be more than just comorbid disorder (Calkin et al., 2013; Mclntyre et al., 2009)). Metabolic disturbances in bipolar disorder appears to be a cluster of diseases that demonstrate insulin resistance as their common aetiologic factor (Yumuru et al., 2012). There is insulin resistance in bipolar disorder (Gomes et al., 2010); and type 2 diabetes or even pre-diabetes may be risk factors for smaller hippocampal and cortical volumes in bipolar disorder (Hajek et al., 2014). Shared pathophysiology linking the two disorders include hypothalamic-pituitaryadrenal and mitochondrial dysfunctions, inflammation, excititoxicity, glucocorticoid signalling, common genetic links, and epigenetic interactions which increase cardiometabolic risk with effects on the CNS.

These adaptations and the physiological toll equate to Sallostatic load (McEwen, 2003; Brietzke et al., 2011) while the significant depressive symptoms in bipolar disorder could be termed 'metabolic syndrome type II' (McIntyre et al., 2007). Patients with bipolar disorder and type 2 diabetes mellitus have more severe course of illness and are more refractory to treatment. Maina et al (2008); Rogenold et al (2002) had observed that there is increased prevalence of type 2 diabetes mellitus and significant correlates of overweight in drug-naïve patients with bipolar disorder. Overall results point to the presence of an association between bipolar disorder and metabolic syndrome as well as between their subcomponents (Czepielewski et al., 2013; Brietzke et al., 2011; Mclntyre et al., 2010). In support of this stance is the finding that the elevated insulin-like growth factor-I (IGF-I) in bipolar disorder may be a trait marker for the disease (Kim et al., 2013).

\section{Bipolar disorder is also related to Alzheimer's disease}

Several similarities have also been observed between 
bipolar disorder (bipolar spectrum disorder) and Alzheimer's disease in terms of clinical presentation, temperament and neurobiology. Both pathologies respond to drugs that decrease cortisol or block glutamate receptors and Alzheimer's disease may be termed bipolar type VI (Akiskal et al., 2014). Brain insulin resistance is an early and common feature of Alzheimer's disease (Talbot et al., 2012) and is associated with IGF-I resistance, insulin receptor substrate-I (IRS-I) dysregulation and cognitive decline. Alzheimer's disease shows many age-related pathophysiological features of type 2 diabetes mellitus which include insulin resistance, disrupted glucose metabolism in non-neuronal tissues, peripheral oxidative and inflammatory stress, amyloid aggregation, neural atrophy and cognitive decline. Alzheimer's disease may now be termed type 3 diabetes mellitus (de la Monte, 2012; Yanev et al., 2013; Chaldakov et al., 2014). In selected cardiometabolic diseases (type 2 diabetes mellitus, metabolic syndrome, obesity, atherosclerosis) and neuropsychiatric diseases (Alzheimer's disease, Huntington's disease, Parkinson's disease, epilepsy, bipolar spectrum disorder, depression, schizophrenia, primary headache, diabetic retinopathy, rett syndrome), the levels of brain derived neurotrophic factor (BDNF) and nerve growth factor (NGF) are low (Chaldakov et al., 2014; 2009; Nousen et al., 2013). The neuronal glucose transporter (GLUT 3) and adenosine monophosphate-activated kinase (AMPK) are reduced in Alzheimer's disease (Khatri and Man, 2013). The energy sensor, AMPK, when activated by insulin sensitizers such as metformin + exenatide ( $\mathrm{Li}$, 2007) reduces oxidative stress, improves mitochondrial dysfunction, improves glucose uptake in Alzheimer's disease (AD) and slows down the main amloidogenic protein, $A \beta$, accumulation extracellularly and intracellularly or tau hyperphosphorylation intracellularly (Kim et al., 2011). Though metformin alone is recommended not to be used for Alzheimer's disease because it may upregulate BACEI (beta-secretase) transcription (Chen et al., 2009), Whitmer (2013) has reported that metformin cuts ADlinked dementia rates more than insulin, thiazolidinediones or sulphonylureas. Moreover, the initial report by Chen et al (2009) has also been contradicted by recent investigations by Hettich et al (2014) who showed that the biguanide, metformin, reduces BACEI enzyme levels making it of value in treating or preventing AD. Metformin decreases neuronal insulin resistance and is associated with neurogenesis (Wang et al., 2012). It also protects against vascular dementia. Metformin, not rosiglitazone, attenuates the increasing plasma levels of the new cardiovascular/ bipolar disorder I marker, fibulin-I (Skov et al., 2014; Greenwood et al., 2012).

\section{Hyperglycaemia is linked to Epilepsy}

The International League Against Epilepsy (ILAE) (Fisher et al., 2014) classifies epilepsy as a disease of the brain defined by the following conditions, 1) at least two unprovoked (or reflex) seizures occurring > 24 hours apart; 2) one unprovoked (or reflex) seizure and a probability of further seizures similar to the general occurrence risk (at least 60\%) after two unprovoked seizures occurring over the next 10 years; 3 ) diagnosis of an epilepsy syndrome. The most common type (60\%) of seizures are convulsive (Algreeshah et al., 2013).

People with hyperglycaemia tend to have focal or local seizures (Maccario et al., 1965; Alajbegovic et al., 2002; Moien-Afshari and Tellez-Zenteno, 2009) and seizure may be the first presentation of diabetes mellitus (Omar et al., 2012) where hyperosmolality and dehydration may increase the metabolism of gamma-amino-butyric acid (GABA) and decrease seizure threshold (Ghasemi et al., 2010). Diabetic hyperglycaemia is associated with the severity of epileptic seizures in adults (Huang et al., 2008; Kirchner et al., 2006; Schwechter et al., 2003). While high glucose concentrations are associated with pro-convulsant effects, glucose depletion contributes to an arrest of epileptiform activity in the system of the entorhinal cortex-hippocampus network. Calorie restriction inhibits seizure susceptibility in epileptic mice by reducing blood glucose (Greene et al., 2001).

There is increased expression of Notch I in temporal lobe epilepsy (Liu et al., 2014) and diabetes (Li et al., 2013). High-fat diet also reduces brain-derived neurotrophic factor (BDNF)-neuropeptide $\mathrm{Y}$ (NPY) signalling (Azoulay et al., 2008; Yoo et al., 2011) important for attenuation of seizures and neuroprotection (Kuromitsu et al., 2001; Loscher et al., 2010; Silva et al., 2007; Urabe et al., 2013).

Additionally, there is accumulating evidence that chronic epilepsy and prolonged use of present antiepileptic drugs are associated with atherogenesis due to their resultant hypercholesterolaemia, dyslipidaemia, hyperhomocysteinaemia and hyperuricaemia (Hamed and Nabeshima, 2005) which are factors of the metabolic or insulin resistancesyndrome (Alberti et al., 2005). Cases of familial hyperinsulinaemia associated with epilepsy have been described (Idris et al., 2004).

\section{Epilepsy is linked to bipolar disorder and is associated with drug addiction}

About $34 \%$ of patients with epilepsy have mood disorders (Algreeshah et al., 2013). Bipolar disorder like Alzheimer's disease and type 2 diabetes mellitus may be an age-related disorder where brain structural changes, cognitive deficits, oxidative stress imbalance, $A \beta$ deposits, immunosenescence, telomere shortening and neurotrophin deficiency are important pathophysiogic canges (Rizzo et al., 2014) and metformin is reported to prevent premature senescence associated with agerelated illnesses (Oriaifo et al., 2015) and able to correct 
the pathophysiologic changes. Animal models support a potential role of pathogenic mechanisms of mood disorders in the development of epileptic seizures and epileptogenesis (Kanner et al., 2014). Depression and manic episodes are described in bipolar disorder and in epilepsy (Kudo et al., 2001; Epps et al., 2012) underlining a bidirectional relationship. Manic attacks in dogs seem to resemble epileptic seizures (Phillips, 2005). Also, epileptic seizures are linked to use of substances of abuse (Alldredge et al., 1989; Personal Communication, 2006).

\section{Epilepsy and Alzheimer's disease}

There is accelerated brain ageing in severe chronic epilepsy who may have features resembling Alzheimer's disease (Thorn et al., 2011) with increased prevalence of $A D$ in drug-resistant epilepsy. The insulin sensitizer, metformin (ClinicalTrials.gov Identifier: NCT 01965756; Gupta et al.,2011; Mathieu-Costello et al., 2003), attenuates Alzheimer's disease biomarkers and neuropathology by decreasing activated c-jun-N-terminal kinase, phospho-tau, total tau and attenuating the reduction of synaptophysin in the disease ( $\mathrm{Li}$ et al., 2012). There is tau protein accumulation in chronic epilepsy (Thorn et al., 2011). Metformin has recently been demonstrated to reduce the main amyloidogenic enzyme, $\beta$-secretase (Hettich et al., 2014) and thus inhibit $A \beta$ neurotoxicity.

Signal transduction by neuronal insulin receptors is strikingly sensitive to disruption by soluble $A \beta$ oligomers (Zhao et al., 2008). Inositol stereoisomers, which are upregulated by metformin (Baillargeon et al., 2004), are anti-epileptogenic (Bazan and Musto, 2009), inhibit $A \beta$ neurotoxicity and protect against the synaptic targeting by these oligomers (Pitt et al., 2013) in Alzheimer's disease.

\section{Sleep disorders, insulin resistance, bipolar disorder and epilepsy}

Wright (1993) reported a case of mania following sleep deprivation for four nights. Other workers (Tufik et al., 1978; Gessa et al., 1995; Suchecki, 2000; Armani et al., 2012) reported induction of mania in sleep models. Benedetti et al (2008) reported sensitization to repeated sleep deprivation in animal models while Holst et al (2014) reported pronounced hyperactivity in dopamine transporter (DAT) knock-out animals. Poor sleep has been noted (Kamphuis et al., 2011) to be a potential causal factor in aggression and violence. Sleep deprivation, which is associated with impaired glucose homeostasis (Naidoo et al., 2014), facilitates the onset of epileptic seizures (Fountain et al., 1998; Diaz-Negrillo, 2013). High-fat diet increases sleep fragmentation (Kotz et al., 2012) and may decrease brain GABA levels
(Valladolid-Acebes et al., 2011).

All these reports point out that repeated sleep deprivation may upregulate dopaminergic signalling, a causal factor in facets of bipolar disorder and epilepsy; and rapid eye movement (REM) sleep-deprived rats are more responsive to apomorphine (Tufik et al., 1978). Inadequate sleep, which is associated with low BDNF scores (Singh et al., 2014), has recently been recognised also as an important risk factor for insulin resistance and diabetes (Naidoo et al., 2014). The workers pointed out that even relatively short bouts of sleep deprivation reduce glucose tolerance by as much as $40 \%$ in aged rodents, though not in the absence of food. Sleep deprivation induces the unfolded protein response (UPR) in the brain, with robust induction of the chaperone protein, binding immunoglobulin protein $(\mathrm{BiP})$ (which is neuroprotective) following marked increase in the proapoptotic transcription factor, C/Enhancer binding protein homologous protein (CHOP). The UPR is a coordinated adaptive response to limit the accumulation of unfolded proteins in the endoplasmic reticulum and can be induced by perturbations in calcium signalling, glucose/energy deprivation or excessive secretory protein synthesis. The insulin sensitizer, metformin, causes lower induction/activation of various endoplasmic reticulumstress markers such as CHOP (Simon-Szabo et al., 2014). Activation of the X-box binding protein-I (XBPI), which is required for UPR and impaired in bipolar disorder, results in relief of endoplasmic reticulum stress and establishment of euglycaemia (Wang and Kaufman, 2012; Lee et al., 2011; Kakiuchi et al., 2003). Normally, XBPI helps upregulate the chaperone protein, BiP. The UPR is also upregulated in disease-states such as type 2 diabetes mellitus (upregulation of the spliced variant of XBPI (Engin et al., 2014, though its over-activation may result in apoptosis)), Alzheimer's disease and Parkinson's disease (Hoozemans et al., 2012). Reduction in oxidative stress by metformin may be beneficial in diabetes and sleep disorder control (Abdulkadir and Thanoon, 2012).

\section{5'- AMP- Activated kinase regulates circadian clock}

Glucose, lipid homeostasis and adiposity are under clock control and mice with aberrant clock function exhibit features of the metabolic syndrome (Rudic, 2009). AMPK actication restores the 24-hour pattern of clock genes, decreasing glucagon levels and increasing leptin levels (Vieira, 2014). Activation of AMPK with metformin induces casein kinase-l dependent degradation of the clock protein, Period 2 (mPer2) (Um et al., 2007). Casein kinase-I epsilon, an essential component of the core molecular clock genes, is a REM sleep candidate gene. It phosphorylates Period (Per) and cryptochrome (CRY) proteins, the negative regulators of the feedback loop of the circadian clock, thus facilitating their degradation and 
translocation and consequently regulating the circadian period (Zhou, 2012). Casein kinase-I epsilon is also a negative regulator of psychostimulants such as heroin and opioids (Bryant et al., 2009). Activated casein kinase2 and nuclear factor (erythroid-derived 2)-like 2 (Nrf2) signaling are reported (Iniaghe et al., 2015) to confer neuroprotection in murine intracerebral haemorrhage, though, casein kinase-I delta and epsilon may not play a major role in the risk of major psychiatric disorders (Matsunaga et al., 2012).

\section{Genetic influence in bipolar disorder, substance abuse, epilepsy and type 2 diabetes mellitus}

Genetic and epigenetic influence over neuropsychiatric and cardiometabolic disorders is multifactorial and variable. For example, polymorphisms within the coding regions of the serotonin 5HTR2A receptor locus have been found in some studies to be positively associated with neuropsychiatric and cardiometabolic disorders (Nichols, 2009; Sklar et al., 2008). Deficits in 5HTR2A receptor function (which includes deficits in anti-TNFalpha activity and blood pressure regulation) may underlie part of the co-morbidity of neuropsychiatric and cardiometabolic disorders. Genome-wide expression analysis has also identified chemokine (chemoattractant cytokine) signalling and toll-like receptor signalling as convergent epileptogenic pathways (Sharma, 2012). Kan et al (2012) demonstrated that there is upregulation of genes involved in chemokine signalling in epileptogenesis; and downregulation of multiple GABA system-related genes (Arion et al., 2006).

There is significant association between bipolar disorder and polymorphism in the TNF- $\alpha$ gene (Pae et al., 2004), interleukin-I cluster group (Papiol et al., 2004; 2008) and variations in the vesicular monoamine transporter I (VMATI) gene (Lohoff et al., 2006). Cyclic adenosine monophosphate response element binding protein I (CREB I) gene polymorphism is associated with cognitive dysfunction, dysfunction in selective attention and retrieval of long-term memory in major depression (BPD V) (Guo et al., 2014). Lithium and valproate, effective pharmacotherapies for bipolar disorder, increase the expression of VMATI. An expanded convergent functional genomics approach (Ogden et al., 2004) shows the dopamine-and cAMP-regulated phosphoprotein of $32 \mathrm{Kda}$ (DARPP-32) tops the list of candidate genes followed by preproenkephalin (PENK) and then tachykinin I (substance P). Clock gene D-box binding protein (DBP) is also a candidate gene for bipolar disorder (Le-Niculescu et al., 2008). DBP knock-out mice are activated by sleep disorders and increase alcohol intake following stress, similar to bipolar patients.

Monocytes of bipolar patients exhibit a coherent mutually correlating set (signature) of 19 aberrantly expressed mRNAs of inflammatory, trafficking, survival and mitogen-activated protein kinase pathway genes when compared with control. Genome-wide association studies strongly suggest that the genetic predisposition to bipolar disorder is due to a combination of many common variants (Brietzke et al., 2011) and that there are overlapping genes in both bipolar disorder and metabolic syndrome. The TSPAN gene which encodes a tetraspanin protein involved in the organisation of cellular receptors and signalling represents a susceptibility locus for both type 2 diabetes and bipolar disorder in genomewide association studies (Zeggini et al., 2008; Sklar et al., 2008). Also, BDNF val66met polymorphism is associated with both bipolar disorder (BPD) and metabolic syndrome (MS) (Fan and Sklar, 2008). Early life stress may be a mediator of the increased inflammatory activity found in bipolar disorder.

DNA methylation causes gene silencing (Bird et al., 2009). DNA methylation of certain genes has been found to mediate persistent epileptiform activity in vitro and in vivo (Machnes et al., 2013) and is implicated in drug seeking behaviours (Massart et al., 2015). There may be increased DNA methylation in bipolar disorder at specific BDNF promoters leading to decreased neural BDNF levels which may be a biomarker for the disease (Ikegame et al., 2013). Hypermethylation of BDNF promoter region is specifically found in bipolar disorder II with lithium and valproate showing significant reduction of hypermethylation (D'Addario et al., 2012; Dell'Osso et al., 2014). Also, DNA methylation profiling implicates several genes in type 2 diabetes. Top association was for a cytosine-phosphate-guanine $(\mathrm{CpG})$ site in the TXNIP gene (Carless et al., 2013); known to modulate glucose metabolism and insulin sensitivity. It likely plays a role in type 2 diabetes and contributing to the therapeutic action of metformin. In the same vein, obesity caused by highfat diet increases DNA methylation at the leptin promoter in rat adipocytes (Kalliman and Parrizas, 2011). Prenatal poor nutrition or high-fat diet, exposure to tobacco smoke or ethanol, glucocorticoids and methyl donors may influence adult lipid metabolism by DNA methylation (Napoli et al., 2011; Yajnik, 2010). The expression of endothelial nitric oxide synthase (eNOS) is influenced by DNA methylation (Chan et al., 2004) and aberrant methylation of the asymmetric dimethylarginine degrading enzyme dimethylarginine dimethylaminohydrolase (DDAH) induced by homocysteine (Zhang et al., 2007). Sufficient level of hydrogen sulphide is able to inhibit mitochondrial transcription factor A (TFAM) promoter methylation and maintain mitochondrial DNA copy number ( $\mathrm{Li}$ and Yang, 2015).Moreover, class I HDAC inhibition blocks cocaineinduced plasticity through targeted changes in histone methylation (Kennedy et al., 2013) and opposes the effects of sirtuin I (HDAC 3) (Renthal et al., 2009).

Upregulation of the non-coding microRNAs $29 \mathrm{~b}$ and microRNA 132 and downregulation microRNAs 134 and $34 a$ may be beneficial in cardiometabolic and 
neuropsychiatric disorders (Zhu et al., 2013; Zheng et al., 2013; Hu et al., 2012; Jimenez-Mateo et al., 2012; Zhou et al., 2009; Rong et al., 2011). Cocaine decreases microRNA-124 and upregulates microRNA-212 and CREB-microRNA-212-X-linked transcriptional repressor methyl CpG binding protein 2 (MeCP2)-BDNF signalling is responsible for cocaine tolerance and escalating intake (Robison and Nestler, 2007; Im et al., 2010). Striatal MeCP2 signaling is pro-addictive.

Impaired feedback regulation of XBPI transcription factor may be a genetic risk factor for bipolar disorder (Kakiuchi et al., 2003). XBPI, upregulated by valproate (Kim et al., 2009) and by metformin (Kim et al., 2014), is neuroprotective and prevents the accumulation of free calcium $\left(\mathrm{Ca}^{2+}\right)$ in the cytosol, a process that downregulates amyloid-beta neurotoxicity (Casas-Tinto et al., 2011). Also, Glu 640 Arg single nucleotide polymorphism of ATP P2X7 receptor is a potential susceptibility gene for bipolar disorder and major depression (Skaper et al., 2009).

\section{Biomarkers for Bipolar Disorder and Epilepsy}

Protein biomarkers for depression by multi analyte profiling of case-control collections (Domenici et al., 2010) show insulin as topping the list, followed by matrix metallo-proteinase-9 (MMPs), alpha-2 macroglogulin and tissue inhibitors of metallo-proteinase (TIMP). Insulin tops the list probably because metabolic syndrome is associated with bipolar disorder in $31 \%$ of cases (Vuksan-Cusa et al., 2010). Central insulin signalling may increase the surface expression of the $\mathrm{GABA}_{A}$ receptor, facilitating neuroprotection (Mielke et al., 2006) and antiepileptogenesis. MMP-9 has a key role in the CNS though its overexpression may be epileptogenic (Yin et al., 2011) and polymorphism in the MMP-9 gene as well as inflammation may be a mediating factor amongst cardiovascular disorders, cancer, bipolar disorders and epilepsy (Rybakowski, 2009; Rybakowski et al., 2013; Yin et al., 2011; Kim et al., 2013; Vezzani and Friedman, 2014; Wilczynski et al., 2008). This may explain the comorbidity between some somatic and neuropsychiatric illnesses. MMP-9 is able to process several proteins crucial for synaptogenesis, synaptic plasticity and longterm potentiation. MMP-9 is able to modulate cytokines and growth factors such as tumor necrosis factor-alpha and BDNF by processing the pro-forms into the active proteins. TIMP binds to MMP-9 and regulates its activity, able to prevent MMP-9-dependent late long-term potentiation important for epileptogenesis.

Biological markers help in prevention and early intervention at the prodromal stage of affective disorders. C-reactive protein may be a biomarker of de-novo depression risk in bipolar disorder (Walker et al., 2014) and also of metabolic syndrome (Vuksan-Cusa et al., 2010). Other biomarkers are tumor necrosis factor-alpha, interleukin-6 and interleukin-10. Increases in interferongamma (IFN-gamma) are associated with dysregulation of the tryptophan metabolite pathway via 2, 3dioxygenase activation. BDNF and glycogen synthase kinase are also useful biomarkers. Individuals who exhibit allele-specific DNA demethylation in functional glucocorticoid response element of FK506 binding protein 5 (FKBP5) are prone to developing persistent cortisol dysregulation. This association is found to be associated with trauma in early life (Walker et al 2014). Others include alterations in markers for lipid peroxidation, for example, 8-isoprostaglandin F (2 alpha), oxidative damage to DNA (8-hydroxy-2-deoxyguanosine) and RNA (8-hydroxyguanosine).

\section{Defective mitochondrial biogenesis is a hall-mark of the metabolic or insulin resistance syndrome, Drug Addiction, Epilepsy and neurodegenerative diseases}

Metformin, glucagon-like peptide-I (GLP-I), cannabinoid CB2 agonists, artemisinin, carvedilol and valproate are drugs that increase eNOS to upregulate mitochondrial biogenesis (Figure 1) and activate anti-oxidant systems which may be anti-diabetogenic and antiepileptogenic. Mitochondrial dysfunction as a result of defective endothelial nitric oxide signalling (Sartori and Scherrer, 1999 ) is a hall-mark of the high cardiovascular risk in the metabolic syndrome (Nisoli et al., 2007; 2005; 2003; Patel et al., 2000; Jobgen et al., 2006; Joseph et al., 2012); epilepsy (Waldbaum and Patel, 2010; Martinc et al., 2012); drug addiction (Dietrich et al., 2005; Chudy et al., 2014; Cunha-Oliveira et al., 2013) where there is decrease in mitochondrial DNA copy number (Feng et al.,2013; Lee et al., 2009); Alzheimer's disease (Moreira et al., 2010; Aulston et al., 2013); decreased threshold to MPTP - induced seizures (Chen et al., 2011) and bipolar disorder (Young, 2007; Kato, 2007; Kato and Kato, 2000).

\section{Role of endothelial nitric oxide in mitochondrial function}

Endothelial nitric oxide through boosting anti-oxidant mechanisms and decreasing brain excitability may occupy a central place in cardiometabolic and neuropsychiatric disorders (Chen et al., 2013; Patel et al., 2000; Murashima et al., 2000; Ferraro and Sardo, 2004; Wang et al., 2014, 2015; Oriaifo et al., 2015). It decreases lipid peroxidation while upregulating glutathione production and serotonin release. Endothelial nitric oxide signalling to PGC-I alpha (Figure 1) vis-a-vis reactive oxygen species/ matrix-metalloproteinases /glycogen synthase kinase-3 $\beta$ may have opposing roles in the aetiopathogenesis of excitotoxicity, pancreatic beta-cell exhaustion and neurodegeneration (Dietrich et 
IRS I-2 (IRS I-2 downregulated by chronic insulin stimul ation (Qi et al, 2013) while IRS 2 is prefere ntially upregulated

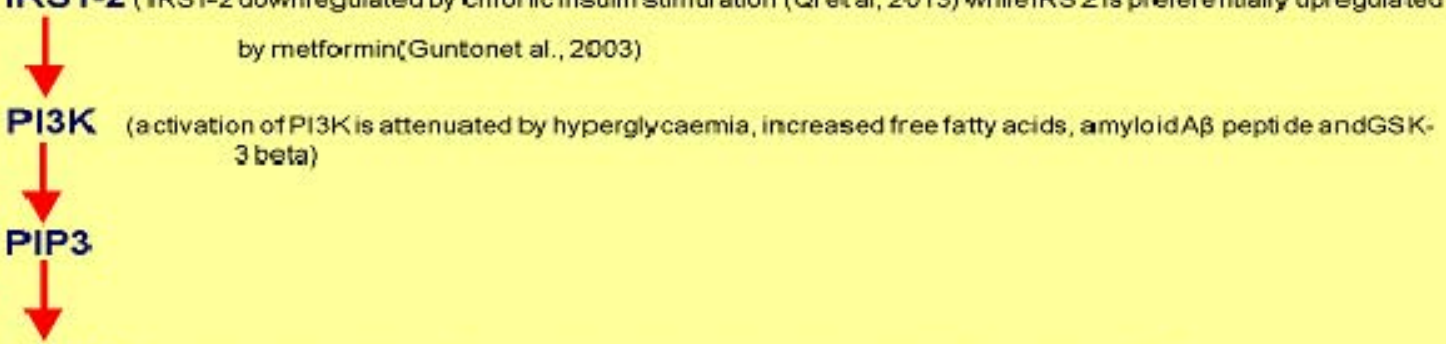

AMPK (ampk is activated by metformin, artesunate and cannabinoid CB2 agonists and CBI antagonists such as

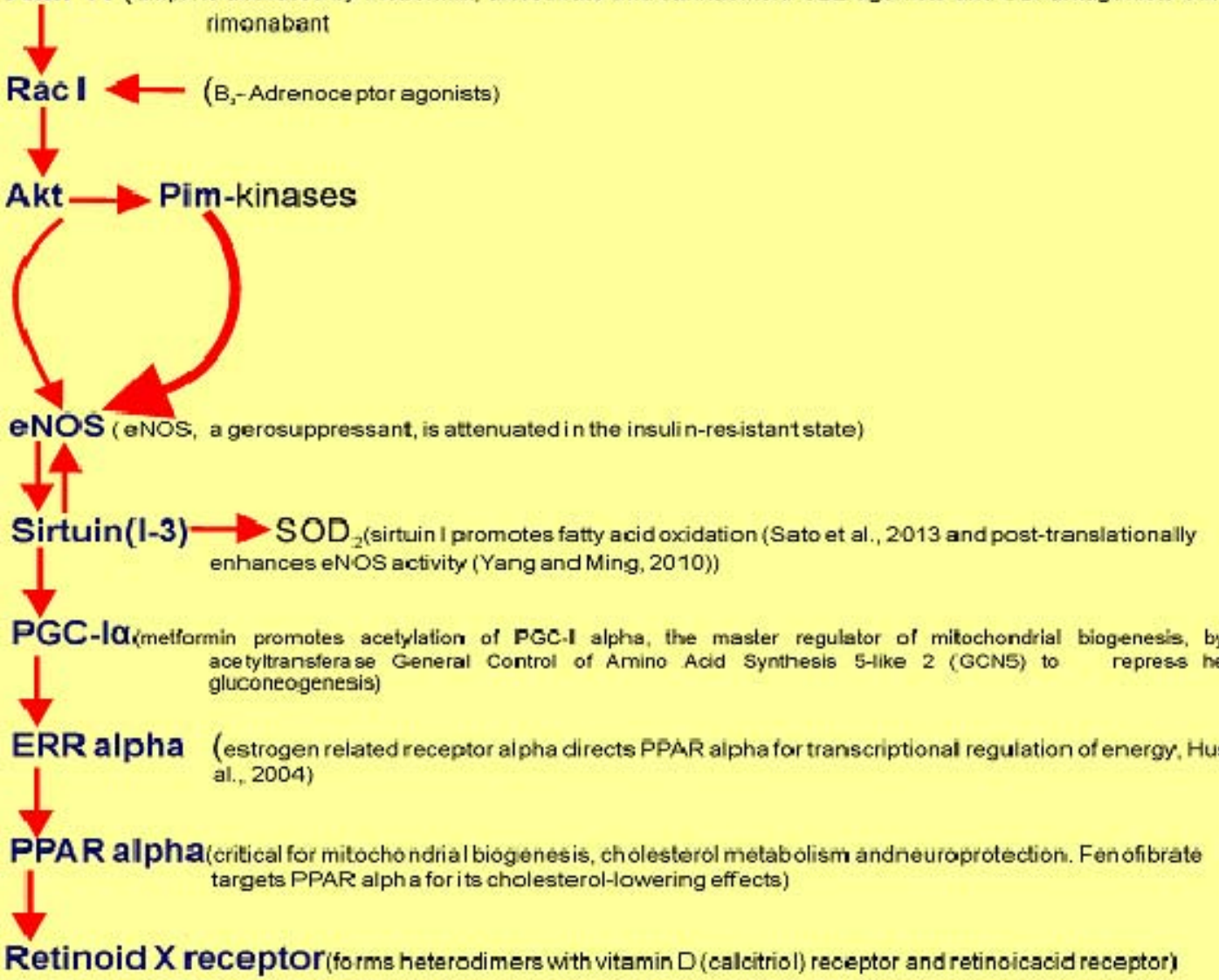

Figure1: Metformin, GLP-1 artesunate and cannabinoild CB2 receptor agonists upregulateAkt-eNOS signaling to PPAR alpha to enhance mitochondrial biogenesis and lipid oxidation

Figure1: Metformin, GLP-1, artesunante and cannabinolds increase PPAR alpha singnaling important for mitochonodrial function and lipid oxidation, thereby attenuating the effect of ROS/MMPS/GSK-3 beta signaling which poses rick for atherosclerosis, coronary artery disease, stroke and seizure susceptibility. GLP-1: glucagon-like peptide; IRS: insulin receptor substrate; P13K: phosphoinositide 3-kinase; PIP3: phosphatidylinositol 3,4,5-triphosphate; AMPK:5' adenosine monophosphate activated protein kinase; Racl; GTPase; AKT: protein kinase: pro-viral insertion site for moloney leukaemia virus; Enos: endotheliaintric oxide synthase; Sirtuinl; NAD-dependent deacetylase silent information regulator; PGC-1 alpha: peroxisome proliferator activated receptor gamma- coativator I apha;ERR alpha: estrogen related receptor alpha; PPAR alpha: peroxisome proliferator activated

al., 2005; Ceriello et al., 2004; Hink et al., 2001; O'Sullivan et al., 2014; Cerqueira et al., 2011). While metformin upregulated endothelial nitric oxide synthase (eNOS) mRNA (Kim et al., 2007), methamphetamine had no effect on eNOS mRNA (Friend et al., 2013) which may be at the basis of methamphetamine-induced neurotoxicity. There is deregulation of ceramide production in mitochondrial dysfunction (Novgorodov and Gudz, 2011) and inhibition of sphingomyelinases represent a novel action of nitric oxide (Barsacchi et al., 2007) which might be relevant in anti-apoptosis (Stafstrom, 2003), insulin resistance (Hansen et al., 
2014), status epilepticus (Mikati et al., 2003; Schauwecke, 2012) and bipolar disorder (Schwarz et al., 2008).

\section{Garlic may potentiate the effects of metformin}

Increased hydrogen sulphide consumption by hyperglycaemic cells may lead to dampening of Aktmediated cardioprotection (Szabo, 2012; King et al., 2014). While increased generation of hydrogen sulphide $\left(\mathrm{H}_{2} \mathrm{~S}\right)$ by garlic and metformin may enhance mitochondrial function and rescue eNOS from peroxynitrite-induced uncoupling (Benavides et al., 2013; Wilinski et al., 2013; Guo et al., 2012; Gu et al., 2012). Garlic and metformin may help prevent AD (Wang et al., 2011) and depression (Chen et al., 2013) partly through $\mathrm{H}_{2} \mathrm{~S}$ which upregulates nitric oxide production (Wilinski et al., 2011). Studies (Kamat et al., 2015; 2013) have shown that hydrogen sulphide attenuates homocysteine-induced mitochondrial toxicity and neurodegeneration mediated through NMDA receptors, implicating a possible preventive action of metformin and garlic.

\section{AMPK Activators Enhance Mitochondrial Function}

Metformin, adenosine, adiponectin, ghrelin, adenine nucleotides, valproate, artesunate and cannabinoid CB2 receptor agonists/CB1 inverse agonists activate AMPK (Graham Hardie: www.lifesci.dundee.ac.uk; Towler and Hardie, 2007) and increase proteins involved in enhancing mitochondrial function (Figure 1). These proteins exhibit a redox control of MMPs (Nelson and Melendez, 2004) and limiting ROS accumulation and the inflammatory state (Wang et al., 2015; Besse-Patin and Estall, 2014; Sitarc et al., 2014; Tedescoet al., 2008). A normally functioning mitochondrion helps to attenuate the effects of nutrient overload and hyperglycaemia (Aulston et al., 2013) on negatively impacting on insulin receptor substrate signalling to phosphatidylinositol 3, 4, 5triphosphate (PIP3) (Figure 1).

Metformin increases extracellular ATP levels (Piwkowska et al., 2013) which may inhibit GSK-3 beta (Sutherland et al., 1993) and allosterically potentiates $G_{A B A} R$-gated chloride channels to regulate neuronal excitability (Liu and Wang, 2014). A major effect of extracellular ATP is attenuation of recurrent epileptiform discharges through adenosine receptor $\mathrm{Al}$ activation (Klaft et al., 2012) and the endothelial nitric oxide upregulation. The (ATP) P2X7 receptor-pannexin I complex decreases seizure susceptibility (Kim and Kang, 2011).

Metformin, cannabinoid CB2 agonists, valproate upregulate genes important for mitochondrial biogenesis (such as the PGC-I alpha gene) including genes for lipid oxidation, glycolysis and stress response (Oriaifo, 2001; Martin-Montalvo et al., 2013, Tedesco et al., 2008, 2010;
Sitarc et al., 2014; Cowell et al., 2009; Zheng et al., 2013). The transcriptional co-activatior, PGC-I alpha, is a recognised master regulator of mitochondrial biogenesis and oxidative metabolism (Handschin and Mootha, 2005); and metformin and cannabinoid CB2 agonists may in concert increase its interaction with estrogen-related receptor-alpha (ERRa) (Huss et al., 2004; Priestley et al., 2015; Sun et al., 2007) to direct PPAR alpha for transcriptional regulation of energy. PGC-I alpha gene polymorphism may be associated with alcohol consumption (Frances et al., 2008) and its expression decreases in Alzheimer's disease (Qin et al., 2009). The PGC-I alpha 4 (PGC-la4)-regulated hormone, meteorinlike, promotes browning of white adipose tissue by inducing interleukin 4/13 and activating M2 macrophages (Rao et al., 2014; Qiu et al., 2014).

PPAR alpha agonists attenuate epileptogenesis, major depression, Alzheimer's disease and drug addiction

Metformin via PPAR-alpha-dependent but AMPKindependent mechanisms upregulate the GLP-I receptor axis (Maida et al., 2011) and PPAR alpha agonists such as the cannabinoids have been reported to suppress nicotine reward effects and relapse (Mascia et al., 2012) and Alzheimer's disease (Tremblay-Mercier, 2012). The ketogenic diet and fenofibrate are reported to exert anticonvulsive effects via PPAR-alpha (Porta et al., 2008). PPAR agonists attenuate hyperdopaminergic signalling maintained by cholinergic nicotinic receptors in the ventral tegmental area (VTA)(Melis et al., 2011; 2013), and increase adiponectin levels critically useful against major depression (Tsuchida et al., 2005; Leo et al; 2006; Liu et al., 2012).

Metformin, GLP-I, artesunate, valproate and cannabinoid CB2 receptor agonists/CBI inverse agonists upregulate AMPK activation

The serine/threonine kinase, 5'-adenosine monophosphate activated protein kinase (AMPK), the key energy sensor with the ability to metabolically adapt to external cues, is activated upon an increase in AMP/ATP ratio. AMPK acts as an important mediator of the beneficial effects of calorie restriction and metformin (Towler and Hardie, 2007), GLP-I agonists (Ben-Shlomo et al., 2011), artesunate (Wang et al., 2015; Tan et al., 2014), valproate (Avery and Bumpus, 2013) and cannabinoid CB2 agonists (Tedesco et al., 2010). AMPK exerts dual regulatory effects on the PI3K pathway, enhancing PIP3Akt-eNOS signalling while inhibiting mTOR/S6K signalling which has negative effect on insulin signalling (Tao et al., 2010). Rimonabant, an antagonist and inverse agonist of cannabinoid $\mathrm{CBI}$ receptors, enhances mitochondrial biogenesis (Tedesco et al., 2008). 
Type 2 diabetes mellitus, drug addiction, bipolar disorder and epilepsy underpinnings: $\mathrm{mTOR}$ and role of ampk activators

Epidemiological data demonstrate that primary psychiatric disorders are more frequent in people who develop epilepsy before the onset of the seizure disorder than among controls (Kanner et al., 2014). This may support the notion that there may be neurological underpinnings of metabolic syndrome, drug addiction, bipolar disorder and epilepsy (Amann and Grunze, 2005; Kenny, 2011). Common mechanisms at the level of ion channels might include the anti-kindling and the calciumantagonist and potassium outward current modulating properties of antiepileptic drugs (Mazza et al., 2007; Ghasemi et al., 2010) and AMPK activators such as valproate and metformin (Kim et al., 2013; Zhao et al., 2014). This report by Zhao et al (2014) supports the preliminary observation in our laboratory that chronic administrations of metformin (200 mg/kg daily) and artesunate are protective against pentylenetetrazoleinduced seizures. Seizure threshold in diabetic mice is lower than in control mice (Ghasemi et al., 2010). The gerosuppressants metformin, calorie restriction and GLPI agonists (via hydrogen sulphide (Selley et al., 2014)) might suppress hyperactive and aberrant mTOR signalling (Shaw, 2009; Potter et al., 2010, O'Callaghan and Roopra, 2014; Dogan et al., 2011; Lee et al., 2012) responsible for the epileptogenic late-long term potentiation (L-LTP), which plays a role in progression of seizures to intractable epilepsy, via reduction in ROS production. mTOR partly mediates insulin resistance (Xin-Long et al., 2011), upregulates proteins such as AMPARs responsible for drug addiction/relapse (Dayas et al., 2012; Neasta et al., 2010) and is a biomarker and central pathway to disorders such as obesity, epilepsy and aging (Perl, 2015). AMPK activators via attenuating microglial activation (Matsushita et al., 2013) and other inhibitors of Mtor such as I-cysteine (Lee et al., 2012) may prevent drug tolerance and reinstatement. The AMPK pathway which is activated by metformin, cannabinoids and valproate may also protect the brain from seizure-induced cell death by upregulating the $\mathrm{Bcl}_{2}$ modifying facor (Bmf) which prevents neuronal death in status epilepticus (Moran et al., 2013).

Metformin, GLP-I agonists and the other AMPK activators such as valproate, valsartan and the cannabinoid CB2 agonists may also downregulate Tolllike receptors and the High-Mobility Group Box-I protein (HMGBI) (Kovacs, 2012; Ha et al., 2014; Avery and Bumpus, 2013; Maroso et al., 2010; Gan et al., 2013); antagonise the cytokine, interleukin-I (Maroso et al., 201l; Vezzani et al., 2011; Roger et al., 2010; Suh et al., 2010); decrease advanced glycation end-products which is also associated with epilepsy, diabetes and drugs of abuse (lori et al., 2013; Treweek et al., 2009) and upregulate BDNF (Whitfield et al., 2011; Hashimoto et al., 2002;
Bovolenta et al., 2010) needed for attenuation of seizure progression and effects of microglia activation in diabetes and reward-related neuronal circuits. Additionally, via an AMPK-dependent mechanism, they may suppress matrix metalloproteinase-9 (MMP-9) which is upregulated in epilepsy (Wilczynski et al., 2008; Morizane et al., 2011; Esfahanian et al., 2012; Yin et al., 2011; Wang et al., 2011) and type 2 diabetes mellitus (Das and Maiti, 2013) and may be a potential new target in epilepsy treatment. It is known that metformin indirectly downregulates GSK3 beta (Neary and Kang, 2006; Ortega et al., 2010) crucial for mossy fibre sprouting in epileptogenesis (Lee et al., 2012) and also involved in bipolar disorder, diabetes and drug addiction. Via AMPK-independent mechanisms in upregulating adenosine signalling and PPAR-alpha, metformin is also in good stead to attenuate epileptiform discharges similar to the ketogenic diet (Maida et al., 2011; Todora et al., 2000; Masino et al., 2009; Masino and Geiger, 2009; Diaz-Negrillo, 2013; Roopra A: www.sciencedaily.com/2008) and calorie restriction (Greene et al., 2001). The ketogenic diet as already mentioned may also be helpful for treatment of bipolar disorder II (Phelps et al., 2013) underlining a relationship between epilepsy and bipolar disorder. Importantly, metformin corrects the circadian desynchrony caused by a high-fat diet (Vieira, 2014; Lee and Kim, 2013).

\section{Inflammatory cytokines are elevated in obesity, type 2 diabetes mellitus, epilepsy, drud addiction and bipolar disorder}

Inflammation contributes to the pathogenesis of bloodbrain-barrier (BBB) dysfunction and pharmacoresistant epilepsy (Kim et al., 2012; Takata et al., 2013)and is also important in the aetiopathogenesis of drug addiction, type 2 diabetes mellitus and bipolar disorder. Cocaine, alcohol and other drugs of abuse activate NF-kappaß (Kenny, 2011) which maintains cocaine reward (Russo et al., 2009). They also may affect the inhibitory neurotransmission mediated by G-protein gated inwardly rectifying potassium channel (GIRK) (de Velasco et al., 2015) important in bipolar disorder (Farhy-Tselnicker, 2014) and epileptogenesis (Mazarati et al., 2006). Activity of $\mathrm{mTORCl}$ is induced by low levels of ROS, as is the case in cocaine addiction (Dietrich et al., 2005), while mild and high levels may inhibit its activity ( $\mathrm{Li}$ et al., 2010). Activation of microglia by drugs of addiction, which can be dampened by AMPK activators such as metformin,results in a pro-inflammatory dominance of the innate immune system which is then critically synergised on the neurocircuits of reward and dependence (Kovacs, 2012; Matsushita et al., 2013). These activated microglia elaborate TLR-4 and IL-I beta during the addictive process.Thus, interleukin-I receptor/toll-like receptor signalling is critically important in the metabolic 
syndrome, bipolar disorder, epilepsy, drug addiction and neurodegeneration.Upregulation of TLR4/NF-kappaB signalling is associated with fetal programming of babies born to obese mothers (Yan et al., 2009; Tong et al., 2009). The endogenous injury sensor, human mobility group box-I (HMGBI), a trigger of inflammatory cascades is implicated in epileptogenesis (Engel, 2011) and seizure- or epileptogenic injury-induced toll-like receptor 4 (TLR4)/HMGBI interactions. These interactions activate nuclear factor-kappa $\beta$ to release pro-inflammatory cytokines alsoinvolved, for example, in ictogenesis and can be targeted to reduce seizures (Kim et al., 2012; Maroso et al., 2010; Gan et al., 2013).

C-reactive protein, tumor necrosis factor-alpha, interleukin-6 levels are elevated in type 2 diabetes, epilepsy and bipolar disorder (Brietzke et al., 2011; Maroso et al., 2010). Prolonged activation of cytokines may lead to diminished neurotrophic support, decreased neurogenesis, increased glutamatergic activation (Najjar et al., 2013; Vezzani et al., 2011; Kovacs, 2012), oxidative stress, induction of apoptosis in astrocytes and oligodendrocytes. Tumor necrosis factor- $\alpha$ - nuclear factor-kappa $\beta$ signalling may be deleterious and may be important in causation of both bipolar disorder and type 2 diabetes mellitus (Moller, 2000; Shulman, 2000; Barrientos et al., 2003; Tilleux and Hermans, 2007; Prossin et al., 2013). Tumor necrosis factor-alpha, the receptors of which are upregulated in major depressive disorder downregulates BDNF (Brietzke et al., 2011) and may increase dopaminergic activity important for manic phase of bipolar disorder (De Laurentis et al., 2002). Interleukin-I $\beta$ which is upregulated by cocaine (Winick-Ng et al., 2012) is capable of inducing cyclooxygenase-2 gene expression and prostaglandin E2 synthesis in islet $\beta$-cells (Tran et al., 1999). Prostaglandin E2 is a known inhibitor of glucose-induced insulin secretion.

\section{Cytokine signaling important in aetiopathogenesis of epilepsy, bipolar disorder, type 2 diabetes mellitus and exaggerated dopaminergic signaling is attenuated by metformin and ampk activators}

Metformin attenuates the cytokine expression of proinflammatory and adhesion molecule genes by upregulating the anti-oxidant heat- shock protein-32 or heme oxygenase-I (HO-I) (Liu et al., 2011) and inhibiting NF-kappa $\beta$ via AMPK activation (Hattori et al., 2006). The induction of HO-I expression mediates the antioxidant and anti-apoptotic effect of AMPK (Liu et al., 2011). Induction of HO-I, which is upregulated by activation of $\mathrm{PI}$ IK/Akt/GSK-3 signaling, in brain is important for neuroprotection and neuroplasticity (Kitagishi et al., 2012). Elevated levels of TNF-alpha, which induces NFkappa B (Theiss et al., 2009), may induce insulin resistance (Moller, 2001), bipolar disorder (Tilleux and Herman,
2007) and epilepsy (Vezzani et al., 2011) via increases in excitatory synaptic strength and decreases in inhibitory synaptic strength (Stellwagen et al., 2005).Protein tyrosine phosphatase (PTP I $\beta$ ) acts like a physiological negative regulator of insulin signalling and is upregulated by TNF- $\alpha$ (Lorenzo et al., 2008). Furthermore, adipose tissue secretes adipokines, such as TNF- $\alpha$ and leptin, which can downregulate peroxisome proliferatoractivated receptor gamma-coactivator- I- $\alpha$ (PGC-I $\alpha)$, the inducible transcription co-activator important for mitochondrial biogenesis, anti-epileptogenesis and fatty acid oxidation.

TNF-alpha and interleukin-I $\beta$ upregulate SERT (Nichols, 2009; Zhu et al., 2006), decrease BDNF levels (Brietzke et al., 2011) and may increase dopaminergic activity important for epileptogenesis (Stellwagen et al., 2005) and manic phase of bipolar disorder (De Laurentis et al., 2002). Metformin dose-dependently inhibits TNFalpha and interleukin-I beta-induced NF-kappaß reporter gene expression (Hattori et al., 2006); while allicin from garlic may decrease interleukin-I beta mRNA levels (Lang et al., 2004). Interleukin-I beta is important in the mechanisms of type 2 DM (Dinarello et al., 2010), epilepsy (Vezzani and Baram, 2007), bipolar disorder (Papiol et al., 2008; Soderlund et al., 2011) and substance addiction (Cearley et al., 2011; Zhang et al., 2015) and may be targeted as a common front for prevention. Chronic metformin may decrease prostaglandin E2 (PGE2) receptor signalling, thereby decreasing steroidogenesis (Xu et al., 2014) as well as decreasing hyperdopaminergic signalling (Kitaoka et al., 2007) via arachidonic acid (Piomelli et al., 1991). Pathological behaviours, such as epilepsy, hypersexuality, hyperlocomotion and aggression, may be mediated by dopamine D3/2 receptors (Kelly et al., 2012), signalling through GSK-3 beta (Li and Gao, 2011). C-reactive protein levels, which are elevated in pilocarpine-induced status epilepticus (Holtman et al., 2013), and may be a biomarker of de-novo depression risk in bipolar disorder (Walker et al., 2014), is lowered by metformin (Oriaifo et al., 2014) which also decreases $\mathrm{COX}_{2}$ levels (Luchetti et al., 2008) that may be upregulated by NF-kappa B (Crofford et al., 1997) and important for epileptogenesis (Loscher et al., 2010). Metformin and other AMPK activators such as valproate may acutely and chronically suppress TLR 4 signaling (Soraya et al., 2014) and high-mobility group box-I (HMGBI) (Tsoyi et al., 2011) important for genesis of proinflammatory cascades, insulin resistance, bipolar disorder and epileptogenesis showing a convergence of mechanisms amongst these disorders.

Oxidative stress in bipolar disorder, drug addiction, epilepsy and type 2 diabetes mellitus

Oxidative stress also represents an overlapping factor 
relevant to the pathogenesis of bipolar disorder, insulin resistance and drug addiction (Kemp and Fan, 2012; Mclntyre et al., 2009; Najjar et al., 2013; Dietrich et al., 2005). Oxidative stress and cocaine administration generate reactive oxygen species (ROS) that can activate Jun kinase, p38 mitogen activated protein kinase and increase I kappa ßkinase (IKK) to induce insulin resistance (Qatanani and Lazar, 2007), modulate dopaminergic signalling and alter mitochondria and nuclear gene expression (Chudy et al., 2014). IKK specifically phosphorylates the protein that inhibits NFkappa $\beta$, IK $\beta \alpha$, resulting in its dissociation from NFkappa $\beta$ and, thereby allowing NF-kappa $\beta$ to migrate to the nucleus to generate the transcription of proinflammatory and adhesion molecules. Cocaine, GSK-3 $\beta$, oxidative stress and high glucose may activate NFkappa $\beta$ to induce matrix metalloproteinase-9 (Kenny, 2011; Zhong and Kowluru, 2013; Zhong et al., 2014) which is pro-apoptotic and may increase sensitivity to pentylenetetrazole-induced seizures (Wilczynski et al., 2008). Metformin attenuates the cytokine expression of pro-inflammatory and adhesion molecule genes by inhibiting NF-kappa $\beta$ via AMPK activation (Hattori et al., 2006). Reactive oxygen species may damage DNA and pancreatic $\beta$-cells (Robertson et al., 2004). Tumor necrosis factor-alpha stimulates $\mathrm{N}$-methyl-D-aspartate (NMDA) receptor activity in mouse cortical neurons resulting in early signal regulated kinase (ERK)dependent death (Jara et al., 2006) and could also induce prostaglandin E2 and glutamate release through TNF- $\alpha-C O X 2$ dependent mechanism (Weaver-Mikaere et al., 2013). Interleukin-I $\beta$ and interleukin- 6 may cause NMDA-dependent neurodegeneration (Viviani et al., 2003; Orellana et al., 2005) and NMDA receptor antagonists and NOS inhibitors may be useful for opioid tolerance and withdrawal (Herman et al., 1996).

\section{Bipolar disorder, Type 2 Diabetes Mellitus, drug addiction and Adipokines}

Low levels of BDNF and NGF, also recognised as adipokines, are found in mood disorders, epilepsy, obesity, drug addiction and type 2 diabetes mellitus (Whitefield et al., 2011; McGinty et al., 2010; Singh et al., 2014; Chaldakov et al., 2014; Yanev et al., 2013). Polyunsaturated fatty acids, levels of which may be low in the metabolic syndrome, such as docosahexaenoic and exogenous unesterified arachidonic acid are now known to regulate adult hippocampal neurogenesis via G-protein coupled receptor-40 (GPCR40). Brain - type fatty acid binding protein (FABP7) binds particularly docosahexaenioc acid involved in adult neurogenesis (Tonchev, 2007). High-fat diet reduces brain docosahexaenoic acid, BDNF, CREB, $\rho$-synapsin, neuropeptide $Y$ and calcium-calmodulin dependent protein kinase II (CaMKII) (Sharma et al., 2014).
Adiponectin levels are low in mood disorders patients and increases risk for type 2 diabetes mellitus (Taylor and MacQueen, 2010) with high resistin, leptin (leptin resistance) and cortisol (Yumuru et al., 2012; Zeman et al., 2009). Resistin, which inactivates glucose transporter 4 (GLUT 4), and interleukin-6 impairs insulin signalling by down-regulation of insulin receptor substrate (IRS) and upregulation of the suppressor of cytokine signalling, (SOCS-3) which is a negative regulator of insulin signalling (Qatanani and Lazar, 2007). Mice lacking resistin have improved glucose homeostasis. Retinolbinding protein 4 (RBP 4), which also increases insulin resistance, is produced by adipose tissue.

\section{Dysregulated HPA Axis in Bipolar Disorder, Substance Use Disorder and Type 2 Diabetes Mellitus}

There is elevated cortisol or glucocorticoid resistance in obesity, type 2 diabetes mellitus and mood disorders due to dysregulation of the hypothalamic-pituitary-adrenal axis (Qi and Rodrigues, 2007; Taylor and MacQueen, 2010; Zeman et al., 2009); with abnormal dexamethasone suppression tests (Rush et al., 1996). The biguanide, metformin, reduces the expression of corticotropin-releasing hormone (Dafopoulous et al., 2013) which plays a key role in the neurobiology of addiction (Zorilla et al., 2014). CRF is genetically upregulated in alcohol-preferring rats (Zhou et al., 2013) and its antagonist CP 154,526 may be effective against cocaine craving (Przgalinski et al., 2005). Stress causes activation of the hypothalamic-pituitary-adrenal (HPA) axis with corresponding increase in cortisol secretion and stimulates $\mathrm{CRH}$ synthesis via activation of NF-kappaB (Thomson, 2013)and at excessive concentrations, cortisol can suppress BDNF production (Nessler et al., 2002; Klimpton, 2012; Issa et al., 2010). Acute cortisol treatment increase systemic glycerol and non-esterified fatty acid in plasma while chronically promoting net central fat deposition (Samra et al., 1998). In fact, both metabolic syndrome and major depression (hypercortisolaemic depression) as seen in in bipolar disorder share a specific endocrine syndrome that promotes insulin resistance and the accumulation of visceral fat, a marker of increased cardiovascular morbidity and mortality (Weber-Hammer et al., 2002).

Cortisol is also produced by adipose tissue. Adipose tissue contains $11 \beta$-hydroxysteroid dehydrogenase I (II $\beta$ HSD I) which converts the inactive metabolite, cortisone, to cortisol which is known to oppose the antigluconeogenic effects of insulin (Qatanani and Lazar, 2007; Wang, 2005) and may induce hypertension through mineralocorticoid receptor activation.

Foetal growth restriction may be associated with increased risk of adult cardiometabolic and neuropsychiatric disorders. Maternal malnutrition (lowprotein diet and stress/glucocorticoid exposure may 
cause persisting abnormalities (programming) in adult offsprings. Low amino acids, intrauterine growth restriction cause deficiency of placental II- $\beta$ hydroxysteroid dehydrogenase 2 which inactivates cortisol and decreases mineralocorticoid receptor activation and may lead to fetal programming and increased risk of neuropsychiatric disorders (Cottrell et al., 2012; O'Donnel et al., 2011; Shang et al., 2012; Holmes et al., 2015) through NF-kappaB (Tong et al., 2009).

\section{The brain arachidonic acid cascade in bipolar disorder, drug relapse and type 2 diabetes mellitus}

Hyperdopaminergic signalling (via upregulation of GSK-3 (Li et al., 2009)) and an upregulated brain arachidonic acid cascade may contribute to bipolar disorder (Ramadan et al., 2011; Bazinet, 2009) as well as to food and drug addiction (Zhuang et al., 2001; Baik, 2013). The endocannabinoid-arachidonic acid pathway may be an important part in the neural machinery underlying relapse which is the resumption of drug taking following a period of abstinence (Yamamoto et al., 2005). Lithium and valproate attenuated brain dopaminergic D2, D3 and D4 receptor signalling involving arachidonic acid when given chronically (Ramadan et al., 2011). Chronic lithium and valproate decrease arachidonic acid turn-over and downregulate brain cyclooxygenase 2 (COX 2) and prostaglandin $\mathrm{E} 2$ ), thereby decreasing the phospholipase A2- arachidonic acid dependent metabolites and reducing excitotoxicity / neuro-inflammation-induced upregulation of the markers (Kim et al., 2011; Bosetti et al., 2002. Antidepressants upregulate enzymes of the arachidonic acid cascade to different extents thereby causing manic switches, for example, imipramine and fluoxetine (Bazinet, 2009). Also, the products of COX2 and lipooxygenase (LOX) have been implicated in cytokine-mediated damage to $\beta$-cells (Persaud et al., 2007 ) but the secretion of insulin through arachidonic acid does not require it metabolism through COX2 and 5112- LOX pathways. Selective inhibitors of COX2 and LOX would have a dual protective role in diabetes - a) minimise $\beta$-cell dysfunction, while b) maintain insulin secretion through enhancing endogenous arachidonic acid levels (Persaud et al., 2007). The cyclooxygenase inhibitor, diclofenac, is also useful as anti-relapse measure (Anggadiredja et al., 2004). These results may explain why the combination of metformin and nonsteroidal anti-inflammatory drugs is more effective than metformin alone on NGF and BDNF production (Hristova, 2011) while metformin also downregulates the steroidogenic acute regulatory protein (STAR) mRNA expression stimulated by prostaglandin E2 (Xu et al., 2014). Inhibitors of COX2 activity such as metformin may significantly decrease PGE2 production.
There is participation of prostaglandin E2 in dopamine D2 receptor-dependent potentiation of arachidonic acid release (Di Marzo and Piomelli, 1992) and this may be a basis for D1 D2 receptor synergism (Piomelli et al.,1991). Results suggest that prostaglandin E2 is formed in response to dopamine receptor stimulation in the striatum and amplifies both D1 and D2 receptor signalling via prostaglandin receptor EP1. EPI -deficient mice exhibit significant suppression of hyperlocomotion induced by cocaine. Prostaglandin EP1 agonists may augment dopaminergic activity only in the striatum, thus possibly circumventing psychotic symptoms associated with the use of levodopa (Kitaoka et al., 2007).

\section{Immune Activation in Bipolar Disorder and Metabolic Syndrome}

The monocyte-T-cell theory of mood disorders considers activation of the immune response system as the driving force behind mood disorders. IL-4, IL-I beta, TNF-alpha may be stongly associated with bipolar disorder (Barbosa et al., 2014). Increased inflammatory cytokines prior to treatment may predict non-response (Becking et al., 2013). Tumor necrosis factor-alpha is associated with both metabolic syndrome and bipolar disorder (Prossin et al., 2013) who pointed out the possible utility of TNF-a antagonists in the treatment of mood disorders. High levels of cytokines (Walker et al., 2014) not only underlie non-response but also predict the onset of manic symptoms and C-reactive protein levels are elevated in unipolar depressed men who develop manic symptoms. Activated microglia in the kynurenine pathway during drug addiction and diabetes trigger an alternate route of trptophan metabolism that increase production of the toxic quinolic acid and ultimately reduce overall serotonin availability (Kovacs, 2012; Watkins et al., 2014); while TNF-alpha may induce mitochondrial dysfunction (Najjar et al., 2013). AMP-activated protein kinase signalling increases neurotrophic factors, decreases inducible nitric oxide synthase and oxidative stress to protect oligodendrocytes that restore CNS functions in an experimental autoimmune encephalomyelitis model (Paintlia et al., 2013).

\section{Cholinergic Mechanisms in Diabetesand Bipolar Disorder}

There may be decreased activities of cholinesterase in the brain during diabetes with increased accumulation of acetylcholine, due to insulin and lipid peroxidation, which may lead to cholinergic -induced hyper-activity, convulsions and epilepsy (Ashokkumar et al., 2006). Hyperinsulinaemia may decrease brain acetylcholinesterase, $\mathrm{Na}^{+}-\mathrm{K}^{+}$-ATPase and $\mathrm{Mg}^{2+}$-ATPase (Chen et al., 2009). Cholinergic excess has been 
implicated as a mechanism for the causation of depressive disorder (Renshaw et al., 1997) though Craft and Watson (2004) had found decreased brain acetylcholine levels in insulin resistance. Valproate treatment normalises mania-like behavioural deficits by enhancing $\mathrm{M}_{1}$-receptor-ERK pathway signalling (Chiu et al., 2013). Administration of N-benzoyl-D-phenylalanine and metformin attenuates brain acetylcholinesterase dysfunction in neonatal streptozotocin-diabetic rats.

Recently, (Mulherin, 2011), metformin was found to increase glucagon-like peptide-I (GLP-I), which may decrease alcohol craving (Shirazi et al., 2013), by a stimulant action on the parasympathetic $\mathrm{M}_{3}$-cholinergic receptors and on gastrin releasing peptide.

There is upregulation of hippocampal $\alpha 7$ acetylcholine receptor levels in patients with bipolar disorder but not in those with schizophrenia or major depressive disorder (Thomsen et al., 2011; Varela et al., 2013) but this could be an adaptive mechanism. Acetylcholine has been associated recently with upreregulation of the nutrient sensor, AMPK, and with mammaliam target of rapamycin (mTOR) inhibition. Metformin could increase acetylcholine release by AMPK activation (Dong et al., 2010), and increase also nicotinic acetylcholine receptors and GABA (A) (Zhao et al., 2013). Alpha 7 nicotinic acetylcholine receptor-selective agonists reduce weight gain and metabolic changes in mouse models of diabetes supporting the cholinergic anti-inflammatory pathway that act on $\alpha 7$ receptors expressed on macrophages and immune cells making its agonists to be helpful in diabetes mellitus. Elevated levels of butyrylcholinesterase and acetylcholinesterase may predict the development of type 2 DM and Alzheimer's disease (Rao et al., 2007).

The pathology in Alzheimer's disease is apoptosis of cholinergic neurons in basal fore-brain with decreased cholinesterase activity in other brain areas and anticholinesterases may be used as adjunct medication because they reduce rate of degradation of acetylcholine, have off-target effects such as increasing growth factors, for example, growth hormone and insulin-like growth factor-I. They also decrease glutamate excitotoxicity and increase phosphatidyl-inositol-3-kinase/protein kinase B (Akt) signalling to promote neuronal survival (de la Monte, 2012).

\section{Noradrenergic mechanisms in insulin resistance, substance use disorder and mania}

There is reduction in neuronal reuptake of noradrenaline and lower levels of monoamine oxidase $A\left(M_{A} O_{A}\right)$ in type 2 diabetes mellitus resulting in increased central sympathetic outflow (Straznicky et al., 2012) in tandem with decrease in ethanol-induced sleep in transgenic mice lacking $\mathrm{MAO}_{\mathrm{A}}$ (Popova et al., 2000). Cerebro-spinal fluid norepinephrine metabolite (3-methoxy-4-hydroxyphenylglycol (MHPG) is elevated in mania patients compared to the dopamine metabolite, homovanillic acid (HVA) or the serotonin metabolite, 5-hydroxyindoleacetic acid (HIAA) implying an excessive, abnormal noradrenergic activity in mania (Swan et al., 1983). Higher urinary catecholamine concentration in adulthood predicts higher levels of drug use (Brody et al., 2014). Levels of MHPG are decreased by lithium (Ostrow et al., 1984). Normally, there is activation of the norepinephrine transporter by insulin (Apparsundaram (2001).

\section{Dopaminergic activity in bipolar disorder, drug addiction, epilepsy and diabetes}

Dysfunctional processing of reward-based feeding through the dopaminergic system is a potential contributor to the obesity epidemic and likely contributes to the co-morbidity of the metabolic syndrome and mental health diseases including drug addiction (Nousen et al., 2013; Volkowet al., 2009; Zhuang et al., 2001; Graham et al., 2013) and epilepsy (Chen, 2006). Drugs of abuse and food cause substantial modifications to the mesolimbic dopaminergic system (Baik, 2013). Dopamine $D_{3} R$ through cross-talk with dopamine $D_{l} R$ is involved in induction and expression of behavioural sensitization to levodopa (Sokoloff et al., 2001) and dopamine $D_{3} R$ antagonists are reported to be beneficial for drug addiction (Le Fall et al., 2014). Dopaminergic $\left(D_{2} R\right)$ stimulation activates glycogen synthase kinase-3 $\beta$ (GSK3ß) (Beaulieu et al., 2011) while serotonergic activity contributes to the inhibitory control of GSK3 $\beta$ (Beaulieu, 2012; www.pharmatutor.org).Indirect activation of the dopamine $\mathrm{DI}$ receptor by cocaine increases nitric oxide production and this contributes to its behavioural effects (Winick-Ng et al., 2012). The dopamine hypothesis of bipolar disorder implicates dopamine dysregulation syndrome and suggests increased dopaminergic drive in mania and the converse in depression. Bipolar disorder may be a cyclical process, where increased dopaminergic transmission is responsible for the manic features and receptor down-regulation may correspond to the depression phase (Berk et al., 2007). Pronounced hyperactivity, caffeine hypersensitivity and reduced sleep are typically observed in dopamine transporter (DAT) knock-out animals (Holst et al., 2014) and sleepdeprivation may induce supersensitivity of dopaminergic receptors in the rat brain (Tufik et al., 1978; Palma et al., 2009; De Laurentis et al., 2002; Troncone et al., 1998). Prostaglandin E2 may amplify DI and D2 receptor signalling (Kitaoka et al., 2007; Di Marzo and Piomelli, 1992). There is increased $D_{2} R$ availability in obese subjects (Dunn et al., 2012) and insulin sensitivity is negatively associated with $D_{2} R$ availability. Sustained expression of PGC-la in the rat nigrostriatal system selectively impairs dopaminergic function (Ciron et al., 2010) and this and PPAR a (Melis et al., 2011; 2013) may synergistically serve to antagonise the essential role 
of SIRTI (HDAC 3)-FOXO3a signalling in the nucleus accumbens in cocaine and morphine addiction (Ferguson et al., 2013; Ferguson et al., 2015). Cocaine increases expression of SIRTI which probably increases NF-kappa $\beta$ to maintain the addiction state (Russo et al., 2009) and resveratrol-induced activation of SIRTI enhances the motivational properties of cocaine (Kenny, 2011). Chronic valproate (Ramadan et al., 2011) and metformin (Xu et al., 2014; Hristova, 2011) may block D2-like receptor-mediated brain signalling via arachidonic acid. Cannabinoid CB2 agonists modulate midbrain dopamine neuronal activity and dopamine-related behaviour in mice (Zhang et al., 2014; Oriaifo et al., 2015).

The immature dentate gyrus may be an endophenotype of bipolar disorder and epilepsy (Hagihara et al., 2013), mediated partly by hyperdopaminergic signalling which dysregulates GSK-3 signalling, and metformin may upregulate neurogenesis in the dentate gyrus after dematuration by high-fat diet (Yoo et al., 2011).

\section{Serotonergic mechanisms in bipolar disorder and cardiometabolic risk}

Drugs with agonist effect at serotonin 5-HTIA receptors such as lithium and ziprasidone including cannabinoids are useful for management of bipolar disorder (Nemeroff et al., 2005; Muraki, 2001; Bambico et al., 2014; Ashton et al., 2005). The hypothesis of dysregulation of the serotonergic system in bipolar disorder is supported by the decrease in 5-HTIA mRNA levels in subjects with major depressive disorder and decrease in 5-HT2A mRNA in subjects with bipolar disorder (Lopez-Figueroa et al., 2004). There is also decrease in 5-HT2A mRNA in the hippocampal formation in subjects with bipolar disorderplus significant reductions in major serotonin metabolite, 5-HIAA, in frontal and parietal cortex in bipolar patients. Also, mechanisms that increase the expression of BDNF may decrease the serotonin transporter (SERT) and increase serotonergic signalling (Deltheil et al., 2008). This may be a mechanism to explain the effects of the BDNF-mimetic agents such as lithium, valproate, metformin and calorie-restriction (Araya et al., 2008) in upregulation of serotonergic signalling.

Modulation of the serotonergic system might be implied in epileptogenesis in temporal lobe epilepsy (Schenkel et al., 2011). Metformin may increase serotonergic neurotransmission by its inhibition of the serotonin transporter, SERT, (Han et al., 2013) and activation of BDNF release (Yanev et al., 2013; Yoo et al., 2011; Hristova, 2011) which which in turn inhibits SERT (Deltheil et al., 2008). Metformin may antagonise TNF-alpha upregulation of SERT (Nichols, 2009). It has been reported that metformin elevates the activity of tyrosine kinase receptors and may amplify BDNF signalling (Hong et al., 2009), the cortical levels of which are low in epilepsy(Chaldakov et al., 2014) and drug addiction (Whitfield et al., 2011). Metformin's activation of insulin release (Gunton et al., 2003; Holland et al., 2004) enhances central serotonergic neurotransmission (Horacek et al., 1999), partly, due to the observation that insulin increases the movement of tryptophan through the blood-brain-barrier. Conversely, stimulation of 5-HT neurotransmission by metformin and cannabinoid CB2 agonists enhance the release of and sensitivity to insulin (Paulmann et al., 2009; Pazos et al., 2013; Goodnick et al., 1995) and mitochondrial biogenesis (Rasbach et al., 2010). Serotonergic agonists attenuate the actions of GSK-3 beta and enhance Akt opposite to drugs such as amphetamine and levodopoa which activate GSK-3 beta and inhibit Akt (Beaulieu, 2012).

The calorie restriction-mimetics, metformin (Onken and Driscoll, 2010) and cannabinoids (Oriaifo et al., 2015), may increase serotonin turn-over in the brain (Bambico et al., 2014; Schweiger et al., 1989). This enhances neural plasticity by effects on the serotonin transporter in a manner similar to the serotonin agonists, the selective serotonin reuptake inhibitors (Riddle et al., 2013)

Metformin also prevents decreases in synaptophysin levels (Li et al., 2012). GSK-3 inhibitors (Horike et al., 2008), such as metformin and valproate, result in accumulation of synapsin- I which is a protein involved in synaptic vesicle docking at growth cone-like areas (Manji et al., 2003). The calorie-mimetic, metformin, (MartinMontalvo et al., 2013) may shift expression patterns of mice towards those on calorie restriction and increase BDNF levels (Arayaet al., 2008) necessary for prevention of pancreatic exhaustion (Yamanaka et al., 2008) and upregulation of synaptogenesis (El-Sayed et al., 2014).

\section{Inositol and neuropsychiatric illnesses}

Inositol has been shown to have antidepressant properties (Einat et al., 2001) and myo-inositol treatment prevents $\mathrm{GABA}_{\mathrm{A}}$ receptor subunit alpha-4 and alpha-2 degradation (Solomonia et al., 2013) and halts reduction of calcium-dependent calmodulin protein kinase II (CaMKII) (Solomonia et al., 2010). Inositol lipid signalling is important in synaptic activity, neuronal plasticity and anti-epileptogenesis (Bazan and Musto, 2009).The coupling between insulin action and the release of $\mathrm{D}$ chiro-inositol-containing inositolphosphoglycan (DCI-IPG) mediator is selectively impaired in obese women with polycystic ovary syndrome (PCOS) which may contribute to the insulin resistance and symptoms of bipolar disorder in these women (Agarwal et al., 2011; Mclntyre et al.,2003; Baillargeon et al., 2010) that may be responsive to valproate and metformin. Metformin therapy increases insulin-stimulated release of D-chiro-inositol-containing inositol phosphoglycan mediators in women with 
polycystic ovary syndrome (Baillargeon et al., 2004) which may have genetic overlap with bipolar disorder and corrects the D-chiro-inositol/myo-inositol imbalance.

Role guanine nucleotide (GTP)-binding proteins (GProteins) in bipolar disorder and metabolic syndrome

New evidence suggests abnormalities in the interaction between the neurotransmitter systems and G-proteins in bipolar disorder and diabetes. Considerable evidence exists demonstrating a link between inhibitory guanine nucleotide binding-proteins (G-proteins) and G-proteincoupled receptor (GPCR) signalling in insulin-responsive tissues and the pathogenesis of obesity, type 2 diabetes mellitus and beta-cell dysfunction (Kimple et al., 2014). The insulin sensitizer, metformin, is able to disrupt crosstalk between G-protein coupled receptors and insulin receptor signalling systems (Kisfalvi et al., 2009). Also, enhanced receptor to G-protein coupling leads to an increase in the active state of the G-proteins with attendant exaggerated trans-membrane signalling (Friedman et al., 2002), an effect which is abrogated by lithium (Avissar and Schreiber, 1989; Risby et al., 1991) and this may explain the antimanic and antidepressant effects of lithium. For example, $\alpha_{2 A}$-adrenoceptor (which binds to inhibitory G-proteins) sensitivity is increased in the frontal cortex of suicide victims with mood disorders (Gonzalez-Maeso et al., 2002).

\section{GABAergic mechanisms in bipolar disorder and Alzheimer's disease}

There is reduced number of somatostatin- and parvalbumin- positive cells (a marker of mature fastspiking interneurons), GABAergic gene expression, NPY mRNAs in regions that participate in mood regulation, namely the anterior cingulate cortex, hippocampus, entorhinal and dorsolateral prefrontal cortex, all suggesting that bipolar disorder and schizophrenia might be associated with decreased levels of gamma-aminobutyric acid (GABA) neurotransmission (Kuromitsu et al., 2001; Mellios et al., 2009; Wang et al., 2011; Gandal et al., 2012), though epigenetic mechanisms expressed in basal ganglia GABAergic neurons differentiate schizophrenia from bipolar disorder (Veldic et al., 2007). This may be the cause of the disrupted synchronisation and integration of cortico-hippocampal circuits. GABAergic dysfunction may be attenuated by the master regulator of mitochondrial biogenesis, PGC-I alpha (Lucas et al., 2010) which rescues paralbumin deficiency. Additionally, the epileptogenic focus has been demonstrated to have biochemical defects in metabolism of acetylcholine, glutamic acid, GABA and potassium. There may also be enhanced NMDA conductance (Bazan et al., 2002). The onset of ictus is heralded by exhaustion of pre-synaptic release of GABA and unopposed increased glutamatergic responses (Zhang et al., 2012). The enhancement of GABAergic neuron numbers, neurite outgrowth and phenotypic expression via increases in the neuronal differentiation of neural stem cell may contribute to the therapeutic effects of valproate in the treatment of bipolar disorder (Laeng et al., 2004). Cannabinoids may regulate GABAergic signalling in a CBI R-independent manner (Golovko et al., 2015) while metformin may enhance GABA-B receptor activation of inwardly-rectifying potassium channels and inhibit calcium channels to attenuate seizures (Kuramoto et al., 2007).

There is also reduction in neuronal calbindin immunereactivity in diabetes (Yi, 2013) and Alzheimer's diaease (Kook et al., 2014). Calbindin buffers free calcium $\left(\mathrm{Ca}^{2+}\right)$ and prevents neuronal apoptosis. Removal of calbindin from amyloid precursor protein/presenelin in transgenic mice aggravates Alzheimer's disease (AD) pathogenesis, suggesting that calbindin has a critical role in $A D$ pathogenesis.

\section{Glycogen Synthase Kinase-3 beta: role in insulin resistance, Seizure Activity, drug addiction and bipolar disoder}

Metformin is a glucagon-like peptide-I (GLP-I) enhancer and sensitizer (Kim et al., 2014; Mulherin, 2011; Cho and Kieffer, 2011) acting via cholinergic $M_{3}$ receptors and PPAR-a. GLP-I which activates eNOS (Ding and Zhang, 2012) is neuroprotective (Darsalia et al., 2012; Shirazi et al., 2013), shows promise for treatment of bipolar disorder and Alzheimer's disease (Mclntyre et al., 2013; Holscher, 2010), psychosis (Dixit et al., 2013) and addiction disorders (Shirazi et al., 2013; Engel and Jerlhag, 2014; Skibicka, 2013). It has been linked to modification of glycogen synthase kinase-3 (GSK-3) (Gao et al., 2011) whose overexpression or overactivation induces a series of changes which are hallmarks of Alzheimer's disease, bipolar disorder, epileptogenesis, type 2 diabetes mellitus (Sutherland, 2011; Li et al., 2002; Lee et al., 2012; Nikoulina et al., 2000) and substance addiction (Xu et al., 2011; Parkitna et al., 2006; Li et al., 2013).

\section{Metformin upregulates adenosine triphosphate}

Adenosine triphosphate (ATP) may be required for inactivation of GSK-3 beta by phosphorylation (Sutherland et al., 1993) and metformin upregulates ATP levels by switching on ATP-producing catabolic pathways (Zhang et al., 2006). Metformin, via AMPK activation of protein kinase $B$ (Akt), also inactivates GSK-3 beta (Horike et al., 2008) and activates cyclic adenosine monophosphate response element binding protein 
(CREB) (Sag et al., 2008). Adenosine monophosphateactivated protein kinase (AMPK) activators, such as metformin, activate Akt which is accompanied by increased inhibitory phosphorylation of GSK-3 beta and activation of CREB (Sag et al., 2008). Another way by which metformin, which increases extracellular ATP concentration (Piwkowska et al., 2013), could also indirectly inhibit GSK-3 beta is through upregulation of the G-protein coupled purinergic (ATP) P2 receptor (Neary and Kang, 2006) and P2X7 receptor (Ortega et al., 2010).

\section{Brain-derived neurotrophic factor, which is upregulated by metformin, also inhibits GSK-3 beta by inhibitory phosphorylation (Mai et al., 2002).}

The activities of TLRs are regulated by glycogen synthase kinase-3 (GSK3) (Martin et al., 2005; Wang et al., 2011) and GSK-3 beta expression is increased in type 2 diabetes mellitus (Nikoulina et al., 2000). It may be crucial for epileptogenesis (Lee et al., 2012). In hyperinsulinaemia, oxidative stress, high glucose and GSK-3 beta may activate nuclear factor-kappa $\beta$ to induce matrix metalloproteinase-9 (Zhong and Kowluru, 2013; Zhong et al., 2014) which increases excitability to leptazol-induced seizures (Wilczynski et al., 2008). Nonspecific inhibitors of glycogen synthase kinase such as metformin and cannabinoids may suppress the production of interleukin-I beta, interleukin-6, interleukin12 and tumor necrosis factor whilst enhancing production of interleukin-10. Epilepsy-related lafora disease is caused by defective mutation in laforin which inactivates GSK3 at Ser9 from the N-terminus (Cho, 2011).

There is also evidence for antimanic efficacy of glycogen synthase kinase-3 beta (GSK-3 beta) inhibitors in animal models of mania (Kalinicher and Dawson, 2011). Valproate, carbamazepine and ziprasidone produce selective inhibition of rearing hyperactivity in mice. Valproate and lithium inhibit GSK-3 beta directly or indirectly (Kim et al., 2005; Huang et al., 2014; Prickarets et al., 2006) via stimulation of protein kinase B (Akt-I). Glycogen synthase kinase-3 beta regulates endoplasmic reticulum (ER) stress-induced expression of the apoptotic protein, $\mathrm{CHOP}$, in neuronal cells and its inhibitors reduce the expression of CHOP (Meares et al., 2012).

Valproate, by inhibiting GSK-3 beta, increases the expression of chaperones that assist in the folding of proteins including glucose regulated protein 78 or binding immunoglobulin protein (GRP 78/BiP), GRP 94, protein disulphide isomerase (PDI) and calreticulin as well as the cytosolic chaperone heat shock protein 70 (HSP70) (Kim et al., 2005; Huang et al., 2014), thereby protecting cells from ER stress-induced lipid accumulation and lethal damage induced by unfolded/misfolded proteins.
Hyperglutamatergic excitotoxicity in bipolar disorder, substance addiction, epilepsy and diabetes mellitus

Hyperglutamatergic excitotoxic-mediated increases in intracellular calcium and lipid messengers such as arachidonic acid (AA) and platelet-activating factor may lead to neuronal death and reactive gliosis, resulting in the formation of a glial scar which becomes the epicentre of an epileptogenic hyperexcitable focus (Bazan et al., 2002). Dysregulation of NMDA and CREB signalling is also important in drug addiction ( $\mathrm{Li}$ et al., 2013; Pandey et al., 2004), bipolar disorder (Chen et al., 2014) and epilepsy where seizures induce increases in intracellular calcium (Raza et al., 2001). BDNF suppressed cocaine prime-induced increase in extracellular glutamate levels in the nucleus accumbens (McGinty et al., 2010). The specificity protein transcription factor $\left(\mathrm{SP}_{4}\right)$, which regulates mitochondrial key glutamatergic receptor subunit genes (Johar et al., 2013), is reduced by NMDA receptor signalling (Saia et al., 2014; Pinacho et al., 2011) and may be normalised by lithium and valproate (Arinze et al., 2013), while its degradation is promoted by store-operated calcium entry which could be a consequence of mitochondrial dysfunction (Lalonde et al., 2014; Kato, 2008). SP 1 modulates the expression of metformin transporters, such as the organic cationic transporters, and genetic variants in this specificity protein I have been found associated with metformin response (treatment $\mathrm{HbAlc}$ ), with homozygous carriers having $24 \%$ reduction in apparent clearance (Goswami et al., 2014). Also, the endoplasic reticulum (ER) stress response protein, X-box binding protein I (XBPI), which is neuroprotective, prevents the accumulation of free calcium $\left(\mathrm{Ca}^{2+}\right)$ in the cytosol (Casas-Tinto et al., 2011).

Tumor necrosis factor-alpha, interleukin- $\beta$ and interleukin-6 mechanisms increase glutamate release (Weaver-Mikaere et al., 2013; Viviani et al., 2003; Orellana et al., 2005). Metformin prevents mitochondrial permeability transition induced by calcium (Guigas et al., 2004) and antagonises PKC- and calcium-induced detrusor overactivity in a model of obesity-associated with insulin resistance in mice (Leina et al., 2012). AMPK activation by metformin and valproate also protects against glutamate-induced cell death (Kim et al., 2013; Culmsec et al., 2001; Hashimoto et al., 2002). AMPK activation dampens the excitatory effect of NMDA via potentiation of potassium-ATP (K-ATP) current (Shen et al., 2014; Kirpichnikov et al., 2002)and opposes the inhibitory effect on $\mathrm{K}^{+}(\mathrm{Kv})$ channels by GSK-dependent phosphorylation (Wildburger and Laezza, 2012). Mild mitochondrial uncoupling induced-protection against neuronal excitotoxicity requires AMPK activity (Weisova et al., 2014) which decreases with aging, contributing to mitochondrial dysfunction (Khatri et al., 2013). CREB which regulates GLUT3 is reduced in AD because 
overactivation of calpain in neuropsychiatric diseases/ cardiometabolic diseases by calcium proteolyses CREB (Khatri et al., 2013). High -fat diets induce changes in hippocampal glutamate metabolism and neurotransmission (Valladolia-Acebes et al., 2012) who showed that glial glutamate carriers were upregulated while glutamate-degrading enzymes, glutamine synthase and GABA-decarboxylase, were downregulated.Glutamatergic pre-ictal discharges are at the transition to seizure in human epilepsy (Huberfeld et al., 2011).

\section{Role of oxidants in drug addiction and neural dysfunction}

Mitochondrial calcium is modulated by reactive oxygen and nitrogen species and sustained $\mathrm{Ca}^{2+}$ increase generates reactive oxygen species (ROS) and cell death (Manzl, 1992). Additionally, a hyperactive mammalian target of rapamycin (mTOR) signalling and drugs of abuse increase generation of ROS (Potter et al., 2010; Dietrich et al., 2005) and mTOR inhibitors block cocaineinduced locomotion sensitization (Wu et al., 2011; Dayas et al., 2012). AMPK activation suppresses ER stress by inhibiting $\mathrm{NAD}(\mathrm{P}) \mathrm{H}$ oxidase-derived ROS, a well-known stress initiator (Dong et al., 2010). Cannabidiol may target mitochondria to regulate intracellular $\mathrm{Ca}^{2+}$ levels (Ryan et al., 2009) and suppress epileptogenesis in a cannabinoid $\mathrm{CB}_{1}$-receptor independent manner (Jones et al., 2010). Oxidants such as superoxide, hydroxyl radicals and lipid hydroperoxides (ROS) are now to stimulate signal transduction such as $\mathrm{Ca}^{2+}$ signalling and phosphorylate kinases such as the oxidative stress response kinase (Geng et al., 2009). The O subclass of the forkhead family of transcription factors, particularly FOXO $3 a$, protects from oxidative stress by upregulating antioxidants such as catalase and manganese superoxide dismutase (MnSOD) (Nicolli and Partridge, 2012). MnSOD is important in maintaining intracellular ROS and redox balance and modulates the activation of several redox-sensitive transcriptional factors such as NF-kappa $\beta$ (Zhang, H (Sfrbm.org). ROS production by mitochondria leads to further DNA damage and decrease in mitochondrial function, impairing mitochondrial function in $A D$, for example. There is a link between ROS-induced DNA damage and neurodegeneration (Kamatet al., 2013).

\section{Sterol Regulatory Element Binding Protein- I c in Mania, Seizures and Diabetes Mellitus}

All antidepressants activate sterol regulatory element binding protein- I c (SREBP-Ic), which induce lipogenic genes, to different extents. Especially antidepressants such as imipramine and fluoxetine, which induce manic switch responsible for bipolar disorder IV, activate SREBP-I c. In this regard, there is functional similarity between antipsychotics and antidepressants (Raeder et al., 2006). Mood stabilisers such as lithim and valproate are known to downregulate SREBP-I c (Raeder et al., 2006). Polymorphisms in SREBPI and SREBP2, two antipsy- chotic activated transcription factors controlling cellular lipogenesis, are associated with schizophrenia (Le Hellard et al., 2008) and with type 2 diabetes mellitus (Liu et al., 2008). SREBP activation is an essential step in NMDAR-mediated excitotoxic neuronal death (Taghibiglou et al., 2009) and DNA microarray data show that stearoylCOA desaturase-I, a SREBPla target gene, is upregulated in human temporal lobe epilepsy (Arion et al., 2006).. Also, uric acid promotes lipogenesis through overexpression of acetyl-CoA carboxylase-I and fatty acid synthase via activation of SREBP-I $C$ and this is antagonised by metformin (a known blocker of SREBP-I c) (Choi et al., 2014). AMPK-activated protein kinase is required for metformin inhibition of SREBP-I c mRNA and nuclear SREBP-I c protein (Yang et al., 2009). The hepatic expression of SREBP-I $c$ is activated by insulin (Foretz et al., 1999) and this may contribute to insulinassociated weight gain.

The Na, K-ATPase hypothesis for bipolar disorder, epilepsy and alcohol abuse: hyperglycaemia-induced activation of the endogenous digitalis system

The decline in $\mathrm{Na}$, K-ATPase pump activity with age is paralled by age-related increase in intracellular sodium with concomitant increase in neuronal excitability. Epilepsy and manic symptoms are related to decrease in $\mathrm{Na}$, K-ATPase pump activity (Martinc et al., 2012; Parisi et al., 2008; El-Mallakh et al., 1993) which might decrease GABA activity.Reinforcing effects of ethanol as well as its voluntary consumption may be affected by the digitalis system (Bagrov et al., 2002). Insulin deficiency leads to hyperglycaemia, oxidative stress and the pathological activation of the endogenous digitalis system and renin-angiotensin system (Rosta Klara , 2009). Diabetes is accompanied by $\mathrm{Na}$, K-ATPase (NKA) dysfunction. Activity of NKA is lower in diabetic animals (44\% lower), while metformin increases the amount of NKA isoform in the plasma membrane fraction (Rosta Klara, 2009). Activation of AMP-activated protein kinase stimulates $\mathrm{Na}$, K-ATPase activity in skeletal muscle cells (Benziane et al., 2012) and this may be beneficial in epileptogenesis prevention.

\section{Autophagy enhancers may be protective in bipolar disorder, epilepsy and type 2 diabetes mellitus}

Insulin resistance, which increases the insulin-like growth factor (IGF) - insulin receptor (IR) crosstalk, impairs memory and is a risk factor for the deposition of $A \beta$ proteins implicated in Alzheimer's disease (AD). Reduced insulin signalling is a hall-mark of $A D$ (Nicolli and Partridge, 2012). Inhibition of the mammalian target of 
rapamycin (mTOR) signalling and its downstream target, S6KI coupled with suppression of the IGF - IR signalling (Sarfstein et al., 2013), by metformin increases insulin sensitivity, induces autophagy (Perez-Revuelta et al., 2014; Renna et al., 2010) and may be anti-epileptogenic (Loscher et al., 2010).

Induction of autophagy helps neurons clear abnormal protein aggregates, enhances cellular tolerance to various stresses and enhances survival. Autophagy is a cellular catabolic pathway by which long-lived proteins and damaged organelles are targeted for degradation by autophagosomes (Gammoh et al., 2012; Heras-Sandovul et al., 2014). Metformin activation of the survival PI3K/Akt pathway inhibits mTOR activity, thereby inducing autophagy. Valproic acid also inhibits mTOR signalling and induces autophagy (Renna et al., 2010). (Also, metformin activation of AMPK or liver kinase $B$ results in mTOR signalling inhibition (Perez-Revuelta et al.,2014). Activation of protein phosphatase $2 \mathrm{~A}$ activity lowers tau phosphorylation both in vitro and in vivo and leads to increased dephosphorylation of protein phosphatase 2Adependent tau epitopes. This mechanism also decreases the ratio of phosphor-Ser 129 alpha-synuclein to total alpha-synuclein in the brain of mice, processes beneficial in AD and Parkinson's disease (Perez-Revuelta et al., 2014; Kickstein et al., 2010); and also in diabetes which may reflect an early stage of amyloid pathology (Alexander et al., 2011).

Furthermore, glucagon induces Class II histone deacetylase which activates FOXO deactylation and nuclear translocation. Inhibition of class II histone deacetylase by metformin-dependent activation of AMPK results in inhibition of FOXO target genes and lowering of blood glucose (Mihaylova et al., 2011). Valproic acid also inhibits histone deacetylase (Phiel et al., 2001). Histone deacetylase inhibition potentiates the ability of mTOR inhibitors to induce autophagy (Dong et al., 2013), for example, pointing to a possible metformin + valproate synergism.

\section{Role for adenosine, adenine nucleotides in epilepsy, bipolar disorder, diabetes mellitus and alcohol addiction}

Drugs that upregulate adenosine and adenosine kinase inhibitors are important for anti-epileptogenesis (Boison, 2008) with the caveat that adenosine may contribute to alcohol-induced ataxia. Adenosine, which is important for the efficacy of the ketogenic diet, is upregulated by metformin (Paiva et al., 2009; Vignozzi et al., 2014; Masino et al., 2009) which increases the levels of adenosine monophosphate (AMP) that can be converted to adenosine, and also inhibits adenosine monophosphate deaminase (AMPD) for its inhibition of glucose transport and blood glucose lowering effect (Ouyang et al., 2011). There is raised serum adenosine deaminase level in non-obese type 2 diabetes mellitus (Khemka et al., 2013) who pointed out that interaction between adenosine deaminase and dipeptidyl peptidase4 (DPP-4) can lead to T-cell proliferation and increased cytokine release. This seems to be holding fort compared to other proposals for the glucose-lowering effect of metformin.

There is upregulation $\mathrm{A} 2 \mathrm{~A}$ adenosine receptors in platelets from bipolar disorder patients under treatment with typical antipsychotics which are most commonly used for bipolar disorders (Trincavelli et al., 2012), and here, there is antagonistic interactions between adenosine A2A receptors and dopamine D2 receptors (Martini et al., 2008; Masino et al., 2009). Pre-synaptic activity-dependent release of adenosine, through activation of adenosine A2A receptors, facilitates BDNF model of synaptic transmission in hippocampal slices (Diogenes et al., 2004). There is also antagonistic interactions between adenosine $\mathrm{Al}$ receptors and dopamine DI receptors (Popoli et al., 1996). Adenosine is known to tonically inhibit neuronal excitability (Masino et al., 2009), attenuate hyperdopaminergic signalling (Shen et al., 2014; Movsessian, 2005) and promote sleep by increasing slow-wave sleep and increasing latency to enter paradoxical or rapid-eye-movement (REM) sleep (Masino and Geiger, 2009; Kotagal and Yardi, 2008; Diaz-Negrillo, 2013). Adenosine augmentation ameliorates psychotic and cognitive endophenotypes of schizophrenia (Shen et al., 2014); and adjuvant purinergic modulators have been found helpful in bipolar disorder (Hirota and Kishi, 2013) where reduced adenosinergic activity may be related to initiation of manic behaviour (Machado-Vieira et al., 2002).

At low concemtrations of NMDA, ATP P2X7 receptor agonists such as BzATP, exhibit additive effects with both NMDA and BDNF to prevent cell-death in cerebellar granule cells induced by PI3K inhibitors (Ortega et al., 2010; Bhave et al., 1999). Extracellular adenosine through conversion to adenosine monophosphate (AMP) (Ouyang et al., 2011) activates AMPK, a process linked to $\mathrm{LKBI}$, and mediated by nucleoside transporters (Goncalves et al., 2010). Calcium-calmodulin dependent protein kinase II (CaMKK II) is the kinase involved in ATP (nucleotide)-mediated AMPK activation (Goncalves et al., 2010) who noted that metformin may induce AMPK activation not dependent on AMP/ATP ratio. ATP P2X7 receptor, inhibited by alcohol (Xiong et al.,2005) but rescued by ivermectinn (Norenberg et al., 2012), activates AMPK to inhibit mTOR (Bian et al., 2013) important for autophagy induction and it may also be coupled to GSK-3 inhibition and neuroprotection in cerebellar granule cells (Leonet al., 2006; Ortega et al., 2009). P2XRs and serotonergic signaling have important roles in modulating the activity of dopaminergic neurons important for controlling ethanol intake (Abbracchio et al., 2009). 
In the synaptic $\mathrm{P} 2 \mathrm{X} 7$ receptor regenerative loop hypothesis for depression and bipolar disorder (Bennet, 2007), ATP/P2X7 pathway triggers the T-cell attack on the pancreas and may also lead to bipolar disorder, when, instead of ATP/glutamate synergising with TNFalpha to post-synaptically increase alpha-amino 3hydroxy-5-methyl-4-propionic acid (AMPA) receptors, Toll-like receptors (TLR) activated by infections release interleukin-I beta which decrease alpha-amino-3-hydroxy5-methyl-4-isoxazole propionic acid (AMPA) receptors, thereby, decreasing synaptic efficacy. This may be due to the observation that ATP acts as a competitive antagonist of NMDA receptors at low glutamate concentrations and a positive allosteric modulator at high glutamate concentrations engendered by infections (Ortinau et al., 2003; Kloda et al., 2004).

The P2X7 receptor is graduating to be seen as a key point of communication between the nervous, immune and cardiovascular diseases (Skaper et al., 2009) whilst the P2YI receptor may be central in autocrine stimulation of human beta cells (Tengholm, 2014). Overactivation or overexpression of P2X7 receptors, however, (Skaper and Giusti, 2009) may promote TNF-alpha-induced apoptosis via activation of caspase-3 and interleukin-I beta release. Interleukin-I beta is a key mediator of neurodegeneration and type 2 diabetes mellitus and P2X7 receptor knockout mice have antidepressant phenotype (Tran et al., 1999; Skaper et al., 2009).

\section{Vasopressin V I (b) contributes to epilepsy, mood disorders andcardiometabolic disease: the role of AMPK}

BDNF (Choe et al., 2014); metformin (Bhalla et al., 1996) and valproate (Coiro and Chiodera, 1989) antagonise arginine vasopressin-induced responses in contributing to both mood disorders (Dempster et al., 2007) and seizures (Gulec and Novan, 2002) as well as to drug addiction (Zhou et al., 2012; Zhou et al., 2008); and the transition from compensated left ventricular hypertrophy to the decompensated heart (cardiac hypertrophy) (Beauloye et al., 2011; Chalterie, 2005). These reports show arginine vasopressin to be one of the factors linking cardiometabolic and neuropsychiatric disorders.

\section{Neurotrophins, cellular plasticity and resilience}

The family of receptors known as tyrosine kinase kinase receptors (Trks) mediate neurotrophic factor signalling. Nerve growth factor (NGF) binds to TrkA and brainderived neurotrophic factor (BDNF) binds to TrkB

(Saarelainen et al., 2003). Phosphatidylinositol-3kinase $(\mathrm{PI}-3 \mathrm{~K})$ is then activated; also, there is activation of mitogen-activated protein (MAP) kinase. MAP kinase cascade activation can inhibit apoptosis by inducing the phosphorylation of Bcl-2 associated agonist of cell death (Bad) (a major pro-apoptotic protein) and increasing the expression of Bcl-2 (a major antiapoptotic protein)(Manji et al., 2003). The increased Bcl-2 expression involves cyclic adenosine monophosphate response -element binding protein (CREB). Bcl-2 is neuroprotective and exerts neurotrophic effects (Manji et al., 2003). The presence of TrkB, the high-affinity receptor for BDNF, in hippocampal neural progenitor cells is required for the neurogenic and behavioural actions of antidepressant treatments (Banasr and Duman, 2009). BDNFcontrols dopamine $D_{3} R$ expression (Guillin et al., 2001). It normalises cocaine-induced disruption of glutamatergic transmission in the nucleus accumbens and the suppressive effect of BDNF in the prefrontal cortex on cocaine-seeking is Trk receptor dependent (Whitfield et al., 2011).

Recently, studies in adipobiology (Chaldakov et al., 2010) and neuroadipocrinology (Chaldakov et al., 2014) has revealed that the neurotrophic factors NGF and BDNF (important for the process of activity-dependent synaptic plasticity, dendritic spine density and cytoskeletal dynamics), are also produced by adipose tissue (Yanev et al., 2013) and that NGF-BDNF/TrKA, B dysfunction may synergistically lead to cardiometabolic and neuropsychiatric diseases. NGF is related to an enhanced upregulation of the purinergic $\mathrm{P} 2 \mathrm{X} 3$ receptor (Liu et al., 2011) and NMDA antagonists such as ketamine and AMPA agonists increase synthesis of BDNF.

BDNF-producing haematopoietic cells, which can control appetite and energy homeostasis by migrating to the brain (Urabe et al., 2013) may represent useful tools to treat neuropsychiatric and cardiometabolic disorders such as obesity and the metabolic syndrome (Azoulay et al., 2008).

\section{Calorie restriction potentiates the effect of metformin, cannabinoids and valproate and inhibits drug relapse behaviour.}

Calorie restriction increases seizure threshold (Greene et al., 2001). The calorie-memetics, metformin, cannabinoids and artesunate, stand to potentiate the effect of calorie-restriction (CR) in the management of epilepsy and AD where the activity of FOXO3a is reduced (Wang et al., 2015; Oriaifo, 2001; Penner et al., 2012; Kim et al., 2014; Qin et al., 2008). Calorie-restriction with weight loss inhibits drug relapse behaviour (Guccione et al., 2013). It also increases insulin sensitivity by activating FOXO3a, a key regulator of insulin and IGF-I signalling. Independently, CR prevents amyloid-beta (Abeta) neuropathology in mouse models of Alzheimer's disease, results in elevation of alpha-secretase activity and induces sirtuin I (SIRT I) activation (Qin et al., 2006a, 2006b). 


\section{Homocysteine is implicated in the mechanisms of cardiometabolic and neuropsychiatric illnesses}

Calorie restriction attenuates the adverse CNS changes due to homocysteine (Willette et al., 2012). Homocysteine upregulates NF-kappa B signalling (AuYeung et al., 2006) important in drug relapse and for the rewarding effects of cocaine. It is also important in the mecanisms of type 2 diabetes mellitus (Ebesunun and Obajobi, 2010), epilepsy (Eldeen et al., 2012), bipolar disorder (Osher et al., 2004), stroke (Ma et al., 2015) and Alzheimer's disease (Morris, 2003).

\section{CONCLUSION}

Evidence reviewed substantiate that there is considerable overlap in the aetiopathogenic mechanisms of the metabolic syndrome, bipolar disorder, substance use disorder and epilepsy. This consideration may signal a common front, such as using the NF-kappa B and interleukin- I beta antagonists, in tackling these considers.

\section{REFERENCES}

Abbracchio MP, Bumstock G, Verkhratsky A, Zimmermnn H (2009). Purinergic signalling in the nervous system: an overview. Treds. Neurosci. 32(1): 19-29

Abdulkadir AA, Thanoon IA (2012). Comparative effects of glibenclamide and metformin on C-reactive protein and oxidant/antioxidant status in patients with type 2 DM. Sultan Qaboos Uni. Med. J. 121: 55-61

Abdulla MH, Sattar MA, Johns EJ (2011). The relation between fructose-induced metabolic syndrome and altered renal haemodynamic and excretory function in the rat. Intern. J. Nephrol. 2011 Article ID: 934659 dx.doi. org/10.4061/2011/934659

Agarwal SM, Behere RV, Venkatasubramanian G, Rao NP, Verambally S, Gangadhar BN (2011). A case of successful treatment of comorbid obesity and PCOS with add-on metformin in bipolar disorder. Prim. Car. Comp. CNS. Disord. 15(5): doi:10.4088/pcc.III0II64

Akiskal HS, Pinto O, Lara DR (2014). "Bipolarity" in the setting of dementia: bipolar type VI? www.medscape.com

Alajbegovic A, Metelko Z, alajbegovic S, Kantardzic D, Bratic M, Suljic E (2002). Correlation between early and late epileptic seizures and diabetes mellitus during and after stroke. Diabetol. Croat. 31-33

Alberti KG, Zimmet P, Shaw J (2005). The metabolic syndrome-a new world definition. Lanc. 366(9491): 1059-1062

Alexander G, Hanna A, Serna V, Younkin L, Younkin S, Janus C (2011). Increased aggression in males in transgenic Tg2576 mouse model of Alzheimer's disease. Behav. Br. Res. 216(1): 77-83

Algreeshah FS, Cavazos JE, Benbadis SR, Blum AS (2013). Psychiatric disorders associated with epilepsy.emedicine.medscape.com

Alldredge BK, Lowenstein DH, Simon RP (1989). Seizures associated with recreational drug use. Neurol. 39(8): 1037-9

Amann B, Grunze H (2005). Neurochemical underpinnings in bipolar disorder and epilepsy. Epileps. 46(4): 26-30

Ambati S (2013). Garlic derivatives: role in obesity and related disorders. OA Biotechnol. 2(1):1

Anggadiredja K, Nakamichi M, Hiranita T, Tanaka H, Shoyama Y, Watanabe $S$ (2004). Endocannabinoid system modulates relapse to methamphetamine seeking: possible mediation by the arachidonic acid cascade. Neuropsychopharmacol. 79: 1470-1476

Apprarsundaram S, Sung U, Price R, Blakely RD (2001). Trafficking- dependent and independent pathways of neurotransmitter transporter regulation differentially involving P38 mitogen-activated protein kinase revealed in studies of insulin modulation of norepinephrine transporter in SK-N-SH cells. JPET. 299: 666-677

Araya AV, Orellana X, Espinoza J (2008). Evaluation of the effects of calorie restriction on serum BDNF in over-weight and obese subjects: preliminary evidences. Endocrin. 33(3): 300-304

Arinze I, Kawai $Y$ (2013). SP family of transcription factors is involved in valproic acid-induced expression of $\mathrm{Gai}_{2}$. J. Biol. Chem. 278: 17788-17791

Arion D, Sabatina M, Unger T, Pastor J, Alonso-Nanclares L, Ballesteros-Yanez I (2006). Correlation of transcriptome profile with electrical activity in temporal lobe epilepsy. Neurobiol. Dis. 22(2): 374-67

Armani F, Andersen ML, Andreatini R, Frussa-Filho R, Tufik S, Galduroz JC (2012). Successful combined therapy with tamoxifen and lithium in a paradoxical sleep deprivation-induced mania model. CNS Neurosci. Therapeut. 18:119-25

Arnold SE, Lucki I, Brookshire BR, Carlson GC, Browne CA, Kazi H (2014). High fat diet produces brain insulin resistance, synaptodendritic abnormalities and altered behaviour in mice. Neurobiol. Dis. 67: 79-87

Ashokkumar N, Pari L, Ramakumar KM (2006). N-benzoyl-Dphenylalanine attenuates brain acetylcholinesterase dysfunction in neonatal streptozotocin-diabetic rats. Bas. Clin. Pharmacol. Toxic. 99: $246-250$

Ashton CH, Moore PB, Gallagher P, Young AH (2005). Cannabinoids in bipolar affective disorder: a review and discussion of their therapeutic potential. J. Psychopharmacol. 19(3): 293-300

Aulston BD, Odero GL, Aboud Z, Glazner GW (2013). Alzheimer's disease and diabetes. doi: 10.5772-54913 cdn.intechopen. com

Au-Yeung KK, Yip JC, Siow YL (2010). Folic acid inhibits homocysteineinduced superoxide anion production and NF-kappa B activation in macrophages. Can. J. Physiol. Pharmacol. 84(1): 141-147

Avery LB, Bumpus NN (2013). Valproic acid as a novel activator of AMPK and decreases liver mass, hepatic fat accumulation and serum glucose in obese mice. (Valproic acid and metabolites activate AMPK). Mol. Pharmacol. doi: 10.1124/mol.113.089755

Avissar S, Schreider G (1989). Muscarinic receptor subclassification and G-proteins: significance for lithium action in affective disorders and for the treatment of the extrapyramidal side-effects of neuroleptics. Biol. Psychiatr. 29(2): 113-130

Awosan KJ, Ibrahim MTO, Arisegi SA, Ejimadu SP, Erhiano EE, Aderahman AT (2013). Prevalence of metabolic syndrome and its components among civil servants in a metropolitan city in Northern Nigeria. Glob. Adv. Res. J. Med. Med. Sci. 2(11): 238-246

Azoulay D, Urshansky N, Karni A (2008). Low and dysregulated BDNF secretion from immune cells of MS patients is related to reduced neuroprotection. J. Neuroimmunol. 195: 186-193

Bagrov AY, Fedorova OV, Kashkin VA, Patkina NA, Zvartan ET, Bagrov YY (2002). Endogenous digitalis-like ligands of the sodium pumps: possible involvement in mood control and ethanol addiction. Eur. Neuropsychopharmacol. 12(1): 1-12

Baik JH (2013). Dopamine signalling in reward-related behaviours. Front. Neur. Circuits. 7: 152 doi:10.3389/fncir.2013.00152

Baillargeon J-P, luorno MJ, Apridonidze T, Nestler JE (2010). Uncoupling between insulin and release of a D-chiro-inositolcontaining inositol phosphoglycan mediator of insulin action in obese women with polycystic ovary syndrome. Metab. Syndr. Relat. Disord. 8(2): 127-136

Baillargeon JP, luorno MJ, Jakubowicz DJ, Apridonidze T, He V, Nestler JE (2004). Metformin therapy increases insulin-stimulated release of D-chiro-inositol- containing inositol phosphoglycan mediators in women with PCOS. J. Endocrinol. Metab. 89: 242-249

Baker DA, McFarland K, Lake RW, Shen H, Toda S, Kalivas PW (2003). N-acetyl cysteine-induced blockade of cocaine-induced reinstatement. ANYAS.US. 1003: 349-51

Balamurugan K, Sharan S, Klarman K, Zhang Y, Coppola V, Summers G (2012). FBXW7 alpha attenuates inflammatory signalling by downregulating C/EBP delta and its target gene TLR 4. Nat. Commun. 4 Art Number 1662 doi: 10.1038/ncomms.2677 
Bambico FR, Katz N, Debonnel G, Gobbi G (2014). Cannabinoids elicit anti-depressant-like behaviours and activate serotonergic neurons through the medial prefrontal cortex. J. Neurosci. 27(43): 1170011711

Banasr M, Duman R (2009). Keeping 'Trk' of antidepressant actions. Neuron 59(3): 349-351

Barbosa IG, Bauer ME, Machado-Vieira R, Teixeira AC (2014). Cytokines in bipolar disorder: paving the way for neuroprogression. Neur. Plast. 2014: Art. ID: 360481

Barrientos RM, Sprunger DB, Campeau S (2003). BDNF mRNA downregulation produced by social isolation is blocked by intrahippocampal interleukin-I receptor antagonist. Neurosci. 12(4): 847-853

Barsacchi R, Perrota C, Sestili P, Cantoni O, Moncada S, Clementi E (2007). Cyclic GMP-dependent inhibition of acid sphingomyelinase by nitric oxide: an early step in protection against apoptosis. Cell Death Differ. 9(11): 1248-55

Barskova VG, Eliseev MS, Kudaeva FM, Aleksandros EN, Volkov AV, Nasonova VA (2009). Effect of metformin on the clinical course of gout and insulin resistance. Klinich. Med. (Russian) 87(7): 41-6

Barskova VG, Eliseev MS, Nasonov EL, Volkov AV, Tsapina TN, Zilov AV (2005). Use of metformin in patients with gout and insulin resistance (pilot 6-month results). Terapevt. Arkhiv 77(12): 44-9

Bautista DM, Movahed P, Hinman A, Arelsson O, Hogestatt ED (2005). Pungent products from garlic activate the sensory ion channel TRPAI. PNAS. USA. 102(34): 12248-12252

Bazan NG, Musto AE (2009). Inositol lipid signalling in synaptic activity, neuronal plasticity and epileptogenesis. Encyclop. Bas. Epilep. Res. 1: 1160-1166

Bazan NG, Tu B, Rodriguez de Turco EB (2002). What synaptic lipid signalling tells us about seizure-induced damage and epileptogenesis. Prog. Br. Res. 135: 75-85

Bazinet RP (2009). Is the brain arachidonic acid cascade a common target of drugs used to manage bipolar disorder? Biochem. Soc. Trans. 37(5): 1104-1109

Beaulieu J-M (2012). A role for Akt and GSK-3 as integrators of dopamine and serotonin neurotransmission in mental health. J. Psychiatr. Neurol. 37(1): 7-16

Beaulieu J-M, Del'Guidice T, Sotnikova TD, Lemasson M, Gainetdinov RR (2011). Beyond cAMP: The regulation of Akt and GSK3 by dopamine receptors. Front. Mol. Neurosci. 4 doi: 10.3389/fnmol.2011.00038

Beauloye C, Bertrand L, Horman S, Hue L (2011). AMPK activation, a preventive therapeutic target in the transition from cardiac injury to heart failure. Cardiovasc. Res. 90(2): 224-233

Becking K, Boschloo L, Vogelzangs N, Haarman BCM, Riemersma-van der Lek R, Penninx BWJH (2013). The association between immune activation and manic symptoms in patients with depressive disorders. Transl. Psychiatr. 3, e314 doi: 10.1038/tp.2013.82

Benavides GA, Squadrito G, Mills RW, Patel HO, Isbell TS, Patel RP (2007). Hydrogen sulphide mediates the vasoactivity of garlic. PNAS. USA. 104(46): 17977-17982

Benedetti F, Fresi F, Maccioni P, Smeraldi E (2008). Sensitization to repeated sleep deprivation in a mice model of mania. Behav. $\mathrm{Br}$. Res. 187: 221-227

Bennett MR (2007). Synaptic P2X7 receptor regenerative loop hypothesis for depression. Austr. New Zeal. J. Psych. 41(7): 563567

Ben-Shlomo S, Zvibee I, Shnell M, Shlomai A, Chepurko E, Halpern Z (2011). GLP-I reduces hepatic lipogenesis via AMPK. J. Hepatol. 54: $1214-1223$

Benziane B, Bjornholm M, Pirkmaje S, Austin RL, Kotova O, Viollet B (2012). Activation of AMPK stimulates $\mathrm{Na}$, K-ATPase activity in skeletal muscle cells. J.Biol. Chem. 287(3): 23451-23463

Berk M (2012). Pathways to new drug discovery in neuropsychiatry. BMC med. 10: 151 doi: 10.1186/1741-7015-10-151

Berk M, Dodd S, Kaauer-Sant'anna M, Malhi GS, Bourin M, Kapczinski F, Norman T (2007). Dopamine dysregulation syndrome: implications for a dopamine hypothesis of bipolar disorder. Acta Psychiatri. Scand. Suppl. 434: 41-9.
Besse-Patin A, Estall JL (2014). An intimate relationship between ROS and insulin signalling: implications for anti-oxidant treatment of fatty liver disease. Int. J. Cell. Biol. Article 11S: 51953

Bhalla RC, Toth KF, Tan E, Bhatty RA, Mathias E, Sharmar RV (1996). Vascular effects of metformin. Possible mechanisms for its antihypertensive action in the SHR. Am. J. Hypertens. 9(6): 570576

Bhave SV, Ghoda L, Hoffman PL (1999). BDNF mediates the antiapoptotic effect of NMDA in cerebellar granule neurons: signal transduction cascades and site of ethanol action. J. Neurosci. 19(9): 3277-86

Bi P, Shan T, Liu W, Yue F, Yang X, Liang X-R (2014). Inhibition of Notch signalling promotes browning of white adipose tissue and ameliorates obesity. Nat. Med. 20: 911-918

Bian S, Sun X, Bai A, Zhang C, Li L, Enjyoji K, Junger WG (2013). P2X7 integrates PI3K/AKT and AMPK-PRAS40-mTOR signalling pathways to mediate tumor cell death. PLoS One doi: 10.1371/journal.pone. 0060184

Bird A, Skene P, Illingworth R, Guy T (2009). I.I Epigenetics: DNA methylation and far beyond. IL I.I-I The role of MeCP2 in the brain. FEBS Journal 276(1): Symposium I: Functional genomics, proteomics and bioinformatics

Boison D (2008). The adenosine kinase hypothesis of epileptogenesis. Prog. Neurobiol. 84(3): 249-262

Bosetti F, Rintale J, Seemann R, Rosenberger TA, Contreras MA, Rapoport SI (2002). Chronic lithium downregulates COX2 activity and PGE2 concentration inrat brain. Mol. Psychiatr. 7(8): 845-450

Bovolenta R, Zucchini S, Paradiso B, Rodi D, Merigo F, Mora GN (2010). Hippocampal fibroblast growth factor-2 (FGF-2) and BDNF overexpression attenuates epileptogenesis-associated neuroinflammation and reduces spontaneous recurrent seizures. J. Neuroinflamm. 7:81

Brady KT, Lydiard RB (1992). Bipolar affective disorder and substance abuse. J. Clin. Psychopharmacol. 12(1): 17S-22S

Brietzke E, Kapczinski F, Grassi-Oliveira R, Grande I, Vieta E, Mclntyre RS (2011). Insulin dysfunction and allostatic load in bipolar disorder. Exp. Rev. Neurotherapeut. 11(7): 1017-1028

Brietzke E, Stabellini R, Grass-Oliveira R (2011). Cytokines in bipolar disorder: recent finding, deleterious effects but promise for future therapeutics. Cent. Nerv. Sys. Spect. 16: epub Ahead of Print

Brody GH, Yu T, MacKillop J, Miller GE, Chen E, Obasi EM (2014). Catecholamine levels and delay discounting forecast drug use among African-Americans youths. Addiction. 109(7): 1112-1118

Bryant CD, Graham ME, Distler MG, Munov MB, Li D, Vezine P (2009). A role for casein kinase-I epsilon in the locomotor stimulant response to methamphetamine. Psychopharmacol. 203(4): 703-707

Calkin CV, Gardiner DM, Ransom T, Alda M (2013). The relationship between bipolar disorder and type 2 diabetes : more than just comorbid disorders. Ann. Med. 45(2): 171-181

Carless MA, Kulkarni H, Mahaney MC, Goring HHH, Almasy L, Comuzzie AG (2013). DNA methylation profiling implicates several genes in type 2 diabetes. Am. Soc. Hum. Genet. 2013 Meeting www.ashg.org Abstract 425F

Casas-Tinto S, Zhang Y, Sanchez-Garcia J, Gomez-Velaquez M, Rincon-Limas DE, Fernandez-Funez P (2011). The ER stress XBPIs prevents amyloid-beta neurotoxicity, Hum. Mol. Gen. 20(11): 2144-2150

Cearley CN, Blindheim K, Song BA, Krueger JM, Churchill L (2011). Acute cocaine increases interleukin-l beta mRNA and immunoreactive cells in the cortex and nucleus accumbens. Neurochemical Res. 36(4): 686-692

Ceriello A, Motz E (2004). Is oxidative stress the pathogenic mechanisms underlying insulin resistance, diabetes and cardiovascular disease? The common soil hypothesis revisited. Antioxid. Thromb.Vasc.Biol. 24: 816-824

Cerqueira FM, Laurindo FRM, Kowaitowski AJ (2011). Mild mitochondrial uncoupling and CR increase fasting eNOS, Akt and mitochondrial biogenesis. PLoS One 6(3): e18433doi: 10.1371/journal pone. 0018433

Chaldakov GN, Fiore M, Ranci G, Beltowski J, Tuncel N, Aloe L (2014). 
An integrated view: Neuroadipocrinology of diabesity. Serbian J. Expt. Clin. Res. 15(2): 115-159

Chaldakov GN, Fiore M, Tonchev AB, Aloe L (2010). Neuroadipology: a novel component of neuroendocrinology. Cell Biol. Intern. 34: 10511053

Chaldakov GN, Tonchev AB, Aloe L (2009). NGF and BDNF: from nerves to adipose tissue, from neurokines to metabokines. Riv. di Psychiatr. 44(2): 79-87

Chaldakov GN, Tonchev AB, Aloe L (2014). NGF and BDNF: from nerves to adipose tissue, from neurokines to metabokines. II Pens. Scient. Edit. (Review) 17: 38-49

Chalterie $E$ (2005). Neurohumoral activation in congestive heart failure and the role of vasopressin. Am. J. Cardiol. 95(9A): 8B-13B

Chan Y, Fish JE, D'Abreo C, Marsden PA (2004). The cell-specific expression of ENOS: a role for DNA methylation. J. Biol. Chem. 279: 35087-35103

Chen CC, Wang HJ, Shin HC, Sheen LY, Chang CT, Chen RH (2001). Comparison of the metabolic effects of metformin and troglitazone on fructose-induced insulin resistance in male Sprague-Dawley rats. J. Formos Med. Ass. 100(3): 176-180

Chen HM, DeLong CJ, Barne M, Rajapakse I, Herrion TJ, McInnis MG (2014). Transcripts involved in calcium signalling and telencephalic neuronal fate are altered in induced pluripotent stem cells from bipolar disorder patients. Transl. Psychiatr. 4: e375 doi: 10.1038/tp.2014.12

Chen M,Yi B, Qin Q, You X, Sun J (2013). Abstract 16025 Phosphorylation of eNOS at ser 633 by a novel protein kinase Pim-I. Circulation. 128: A16025 American Heart Association: Core 7: Vasc. Dis. Biol. Clin. Sci.

Chen S-C (2006). Epilepsy and migraine: the dopamine hypothesis. Med. Hypoth. 66(3): 466-472

Chen S-D, Yang D-I, Lin T-K, Shaw F-Z, Liou C-W, Chuang Y-C (2011). Roles of oxidative stress, apoptosis, PGC-I alpha and mitochondrial biogenesis in cerebral ischaemia. Int J. Mol. Sci. 12: 7199-7215

Chen WL, Xie B, Zhang C, Xu KL, Niu YY, Yang XQ (2013). Antidepressant-like and anxiolytic-like effects of hydrogen sulphide in behaviour models of depression and anxiety. Behav. Pharmacol. 24(7): 500-507.

Chen Y, Zhou K, Wang R, Liu Y, Kwak Y, Ma T (2009). Antidiabetic drug metformin, (Glucophage $R$ ), increases biogenesis of Alzheimer's amyloid peptides via upregulating BACEI transcription. PNAS. US. 106(10): 3907-3912

Chikere EK, Mayowa MO (2011). Prevalence and perceived health effect of alcohol use among male undergraduate students in Owerri, South-East Nigeria: a descriptive cross-sectional study. BMC Pub. Health. 11:118 doi:10.1180/1471-2488-11-118

Chiu C-T, Wang Z, Hunsberger JG, Chuang D-M (2013). Therapeutic potential of mood stabilisers, lithium and valproic acid: beyond bipolar disorder. Pharmacol. Rev. 65(1): 105-142

Cho C-H (2011). Frontier of epilepsy research-mTOR signalling pathway. Expt. Mol. Med. 43(5): 231-274

Cho YM, Kieffer T (2011). New aspects of an old drug: metformin as a GLP-I enhancer and sensitizer. Diabetol. 54(2): 219-222

Choe K, Han S, Gaub P, Shell B, Knapp B, Barker P, Brown C, Voisin D, Cunningham J, Bourquel C (2014). BDNF causes chloride gradient collapse in supraoptic neurons inducing vasopressin mediated blood pressure increase. FASEB. J. 28(1): Supplement LB847

Choi Y-J, Shin H-J, Choi HS, Park J-W, Jo I, Oh E-S (2014). Uric acid induces fat accumulation via generation of endoplasmic reticulum stress and SREBP-I c activation in hepatocytes. Lab. Investig. doi: 10.1038/labinvest. 2014.98

Chudy AS, Frankowska M, Filip M (2014). Mitoepigenetics and drug addiction. Pharmacol. Therapeut. 144(2) doi:10.1016/j.pharmther2014.06.002

Ciron C, Lengacher S, Dusonchet J, Aebischer P, Schneider BL (2010). Sustained expression of PGC-I alpha in the rat nigrostriatal system selectively impairs dopaminergic function. Hum.Mol. Genet. 21(8): 1861-1876

Coiro V, Chiodera P (1989). Inhibition by sodium valproate of the arginine vasopressin and ACTH responses to angiotensin-II in normal men. Br. Res. 491(1): 169-72
Cole AR, Astell A, Green C, Sutherland C (2007). Molecular connexions between dementia and diabetes. Neurosci. Biobehav. Rev. 31(7) 1046-1063

Cottrell EC, Holmes MC, Livingstone DE, Kenyon CJ, Secki JR (2012). Reconciling the nutritional and glucocorticoid hypothesis of foetal programming. FASEB J. 26(5): 1866-1874

Cowell RM, Talati P, Blake KR, Meador-Woodruff JH, Russel JM (2009). Identification of novel targets for PGC-I alpha and histone deacetylase inhibitors in neuroblastoma cells. Biochim. Biophys. Res. Commun. 379(2): 578-682

Craft S, Watson GS (2004). Insulin and neurodegenerative diseases: shared and specific mechanisms. Lanc. Neurol. 3: 169-178

Crofford LJ, Tan B, McCarthy CJ, Hla T (1997). Involvement of the NFkappa $B$ in the regulation of COX-2 expression by IL-I beta in rheumatoid synoviocytes. Arthritis Rheum. 40(2): 226-236

Culmsec C, Monnig J, Kenap BE, Mattson MP (2001). AMP-acticated protein kinase is highly expressed in neurons in the developing rat brain and promotes neuronal survival following glucose deprivation. J. Mol. Neurosci. 17(1): 45-98

Cunha-Oliveira T, Silva L, Silva AM, Moreno AJ, Oliveira CR, Santos MS (2013). Mitochondrial complex I dysfunction induced by cocaine and cocaine plus morphine in brain and liver mitochondria. Toxicol. Lett. 219(3): 298-306

Czepielewski L, Filho LD, Brietzke E, Grassi Oliveira R (2013). Bipolar disorder and metabolic syndrome: a systematic review. J. Rev. Bras. Psiq. 35(1): 88-93

D'Addario C, Dell'Osso B, Palazzo MC, Benatri B, Lietti L, Cattaneo E (2012). Selective DNA methylation of BDNF promoter in bipolar disorder: differences among patients with bipolar disorder I and II. Neuropsychopharmacol. 37(7): 1647-55

D'Mello D, Narang S, Agredano G (2010). The prevalence and clinical consequences of concurrent hypertension in patients with bipolar disorder. American Psychiatric Association Meeting, New Orleans, Los Angeles Abstract NR4-17

Dafopoulos K, Vackoussis T, Chalvatzas N, Messi C, Kalantaridou SN (2013). Metformin reduces expression of corticotropin-releasing hormone and urocortin in the endometrium of healthy women. Fert. Steril. doi: 10.1016/j.fertnsterl.2013.07.1983

Dai Y, Mehta JL, Chen M (2013). Glucagon-like peptide-I receptor agonist liraglutide inhibits endothelin-I in endothelial cell by repressing NF-kappa B. Cardiovasc. Drugs Therap. 27(5): 371-380

Darsalia V, Mansouni S, Ortsater H, Olverling A, Nazadze M, Kappe C (2012). GLIP-I receptor activation reduces brain damage following stroke in type 2 DM. Clin. Sci. (London). 122(10): 473-483

Das S, Maiti A (2013). Matrix metalloproteinases in subjects with type 2 DM: Pattern of MMP-2 and MMP-9 profile in type 2 DM patients. Am. Intern. J. Res. Form. Appl. Nat. Sci. 3(1): 57-69

Dayas CV, Smith DU, Dunkley PR (2012). An emerging role for mTOR in 'pathological' protein translation: relevance to cocaine addiction. Front. Pharmacol. Doi: 10.3389/fphar.2012.00013

De la Monte S (2012). Brain insulin resistance and deficiency as therapeutic targets in Alzheimer's disease. Curr. Alzh. Res. 9(1): 36-66

De Laurentis A, Pisera D, Caruso C, Candolfi M, Mohn C, Rettori V (2002). Lipopolysaccharide- and tumor necrosis factor-alphainduced changes in prolactin secretion and dopaminergic activity in the hypothalamic-pituitary axis. Neuroimmunomod. 10(1): 30-39

De Velasco EMF, McCall N, Wickman K (2015). GIRK channel plasticity and implications for drug addiction. Int. Rev. Neurobiol. http://dx.doi.org/10.1016/bs.im.2015.05.011

DeBosch BJ, Kluth O. Fujiwara H, Schurmann H, Moley KH (2014). Early-onset metabolic syndrome in mice lacking the intestinal uric acid transporter SLC2A9. Nat. Commun. doi: 10 1038/ncomms5642

Dell'Osso B, Palazzo MC, Camuri G, D'Addario C, Benatti B, Galimberti

D (2014). Epigenetic modulation of BDNF gene: differences in DNA methylation between unipolar and bipolar patients. J. Affect. Disord. 166C: $330-333$

Deltheil T, Guiard B, Cerdan I, David DT, Tanaka KF, Reperant C (2008). Behavioral and serotonergic consequences of decreasing or increasing hippocampal BDNF protein levels in mice. Neuropharmacol. 55(6): 1006-1014 
Dempster EL, Burcescu I, Wigg K, Kiss E, Baji I, Gadaros J (2007). Evidence of an association between the vasopressin $\mathrm{Vlb}$ receptor gene (AVPR IB) and childhood-onset mood disorders. Arch. Gen. Psych. 64(10): 1189-1195

Dhar I, Dhar A, Wu L, Desail LM (2013). Increased methylglyoxal formation with upregulation of renin angiotensin system in fructosefed Sprague-Dawley rats. PLoS One. doi. 10.1371/journal.pone-. 0074212

Di Marzo V, Piomelli D (1992). Participation of prostaglandin E2 in dopamine D2 receptor-dependent potentiation of arachidonic acid release. J. Neurochem. 59(1): 379-82

Diaz-Negrillo A (2013). Influence of sleep deprivation on ictal and interictal epileptiform activity. Epilep. Res. Develop. 2013: 49 dx.doi.org/10.1155/2013/492524-

Dietrich JB, Mangeol A, Revel M-O, Burgun C, Zwiller J (2005). Acute or repeated cocaine administration generates ROS and induces anti-oxidant enzyme activity in dopaminergic brain structures. Neuropharmacol. 48(7): 965-975

Dinarello CA, Donath MY, Mandrup-Poulsen T (2010). Role of IL-I beta in type 2 diabetes mellitus. Curr. Opin. Endocrinol. Diabet. 17(4): 314-321

Ding L, Zhang J (2012). Glucagon-like peptide-I activates eNOS in human umbilical vein endothelial cells. Acta Pharmacol. Sin. 33(1): $75-81$

Diogenes MJ, Fernandes CC, Sebastio AM, Ribeiro O (2004). Activation of adenosine A2A receptor facilitates BDNF modulation of synaptic transmission in hippocampal slices. J. Neurosci. 24: 29052913

Dixit TS, Sharma AN, Lucot JB, Elased KM (2013). Anti-psychotic-like effect of GLP-I agonist liraglutide but not DPP-IV inhibitor sitagliptin in mouse model for psychosis. Psychol. Behav. 114-115(2013): 3841

Dogan S, Johannsen AC, Grande JP, Cleary MP (2011). Effects of intermittent and chronic calorie restriction on mTOR and IGF-I signalling pathway in mammary fat pad tissues and mammary tumors. Nutr. Can. 63(3): 389-401

Domenici E, Willie DR, Tozzi F, Prokopenko I, Miller S, Mckeown $A(2010)$. Plasma protein biomarkers for depression and schizophrenia by multi analyte profiling of case-control collections. Doi: 10.137/journal.pone.0009166

Dong LH, Cheng S, Zheng Z, Wang C, Shen Y, Xang Z (2013). Histone deacetylase inhibitor potentiated the ability of mTOR inhibitor to induce autophagic cell death in Burkitt leukaemia/lymphoma. J. Haematol. 6: 53 doi: 10.1186/1756-8722-6-53

Dong Y, Zhang M, Wang S, Liang S, Zhao Z, Liu C (2010). Activation of AMP-activated protein kinase inhibits oxidised LDL-triggered endoplasmic reticulum stress in vivo. Diabet. 59(6): 1386-1396

Dunn JP, Kessler RM, Feurer ID, Volkow ND, Patterson BW, Ansari MS (2012). Relationship of dopamine type 2 receptor binding potential with fasting neuroendocrine hormones and insulin sensitivity in human obesity. Diabet. Car. 35(5): 1105- 1111

Ebesunun MA, Obajobi EO (2010). Elevated plasma homocysteine in type 2 DM: a risk factor for cardiovascular diseases. Pan. Afr. Med. J. 12: 18 PMC: 3428168

Einat $\mathrm{H}$, Clenet $\mathrm{F}$, Shaldubina A, Belmaker RH, Bourin M (2001). The antidepressant activity of inositol in the forced swim test involves 5HT (2) receptors. Behav. Br. Res. 118: 77-83

Ekpeyong SN (2012). Drug abuse in Nigerian schools: a study of selected secondary institutions in Bayelsa State, South-South, Nigeria. Int. J. Scientif. Res. Edu. 5(3): 220-28

El Mallakh RS, Barrett JL, Jed Wyatt R (1993). The Na, K-ATPase hypothesis for bipolar disorder: implications for normal development. J. Child Adolesc. Psychopharmacol. 3(1): 37-52

El - Atat FA, Stas SN, Mcfarlane SI, Sowers JR (2004). The

relationship between hyperinsulinaemia, hypertension and progressive renal disease. J. Am. Soc. Nephrol. 15: 2816-2827

Elder ON, Abd-Eldayem SM, Shatla HH, Omara HA, Elgammal SS (2012). Homocysteine, folic acid and vitamin B12 levels in serum of epileptic children. Egypt. J. Med. Hum. Genet. 13(3): 275-280

Elhaik E, Zandi B (2015). Dysregulation of the NF-kappa B pathway as a potential inducer of bipolar disorder. J. Psychiatr. Res. 70: 18-22
Elliot SS, Keim NL, Stern JJ, Teff K, Havel PJ (2002). Fructose, weight gain, and the insulin resistance syndrome. Am. J. Clin. Nutr. 76(5): 911-922

El-Sayed M, Hofman-Bang J, Mikkelsen JD (2014). Effect of BDNF on Arc gene expression in primary frontal cortical neurons: comparison with NMDA and AMPA. Eur. J. Pharmacol. 660(2-3): 351-357

Emery EC, Diakogiannaki E, Gentry C, Psichas A, Habib AM, Bevan S (2015). Stimulation of GLP-I secretion downstream of the ligandgated ion channel TRPAI. Diabet. 64(4): 1202-1210

Engel J.Jr (2011). Biomarkers in epilepsy (Introduction). Biomark Epilep. 5(5): 537-44

Engel JA, Jerlhag E (2014). Role of appetite-regulating peptides in the pathophysiology of addiction: implications for pharmacotherapy. CNS Drugs. 28(10): 875-886

Engin F, Nguyen T, Yermalovich A, Hotamisligil GS (2014). Aberrant islet unfolded protein response in type 2 diabetes. Scientif. Rep. 4054: doi: 1038/srep04054

Epps SA, Tabb KD, Lin SJ, Kahn AB, Javors MA, Boss-Williams KA (2012). Seizure susceptibility and epileptogenesis in a rat model of epilepsy and depression co-morbidity.Neuropsychopharmacol. 37: 2756-2763

Esfahanian N, Shakiba Y, Nikbin B, Soraya H, Maleki-Dizaji N, GhaziKhansari M (2012). Effect of metformin on the proliferation, migration and MM-2 and -9 expression of human umbilical vein endothelial cells. Mol. Med. Rep. doi: $10.3892 / \mathrm{mmr} 2012.753$

Fan J, Sklar P (2008). Genetics of bipolar disorder: focus on BDNF val 66met polymorphism. Novartis Foundation Symposium 269: 60-72

Farhy-Tselnicker I, Tsemakhovich L, Rishal I, Kahanovitch U, Dessaue CW, Dascal V (2014). Dual regulation of G-proteins and the Gprotein-activated $\mathrm{K}^{+}$channel by lithium. PNAS. US. 111(13): 501823

Feng YM, Jia YF, Su LY, Wang D, Lv L, Xu L, Yao YG (2013). Decreased mitochondrial DNA copy number in the hippocampus and peripheral blood during opiate addiction is mediated by autophagy and can be salvaged by melatonin. Autophagy. 9(9): 1395-406

Ferdaoussi M, Abdelli S, Yang JY, Cornu M, Niederhauser G, Favre D (2008). Exendin-4 protects beta-cells from interleukin-I beta-induced apoptosis by interfering with the c-Jun $\mathrm{NH}_{2}$-terminal kinase signalling. Diabet. 57(5): 1205-15

Ferguson D, Koo JW, Feng J, Heller E, Rabkin J, Heshmati M (2013). Essential role of SIRTI signalling in the nucleus accumbens in cocaine and morphine action. J. Neurosc. 33(41): 16088-16098

Ferguson D, Shao N-Y, Heller E, Nestler EJ (2015). SIRTI-FOXO3a regulate cocaine actions in the nucleus accumbens. J. Neurosc $35(7)>3100-11$

Ferraro G, Sardo P (2004). Nitric oxide and brain excitability. In Vivo. 18: $357-366$

Fisher RS, Acevedo C, Arzimaneglou A, Bogacz A, Cross JH, Elger CE (2014). ILAE Official Report: A practical clinical definition of epilepsy. Epileps. 55(4): 475-82

Foretz M, Guichard C, Ferre P, Foufelle F (1999). Sterol regulator element binding protein- I $\mathrm{C}$ is a major mediator of insulin action on the hepatic expression of glucokinase and lipogenesis-related genes. PNAS. US. 96(22): 12737-12742

Foretz M, Hebrard S, Leclerc J, Zarrinpashnen E, Soty M, Mithieux G (2010). Metformin inhibits hepatic gluconeogenesis in mice independently of the LKBI/AMPK pathway via a decrease in hepatic energy state. J. Clin. Investig. 120: 2355-2369

Fountain NB, Kim JS. Lee SI (1998). Sleep deprivation activates epileptiform discharges independent of the activating effects of sleep. J. Clin. Neurophysiol. 15(1): 59-75

Frances F, Verdu F, Portoles Q, Castello A, Sorli JA, Guillen M (2008) PPAR-alpha L162V and PGC-I G482S gene polymorphism, but not PPAR-gamma P12A, are associated with alcohol consumption in a Spanish Mediterranean population. Clin. Chimic. Acta. 398(1-2): $72-$ 74

Fraying TM, Timpson NJ, Weedon MN, Zeggini E, Freathy RM, Lindgren CM (2007). A common variant in the FTO gene is associated with body mass index and predisposes to childhood and adult obesity. Sci. 31(5826): 889-94 
Friedman E, Wang BY (2002). Receptor-mediated activation of Gproteins is increased in post-mortem brains of bipolar affective disorder subjects. J. Neurochem. 67(3): 1145-1152

Friend DM, Son JH, Keefe KA, Fricks-Gleason AN (2013). Expression and activity of nitric oxide synthase isoforms in methamphetamineinduced striatal dopamine toxicity. JPET. 344(2): 511-521

Gammoh N, Lam D, Puente C, Gantlet I, Marks PA, Jiang X (2012). Role of autophagy in histone deacetylase inhibitor-induced apoptotic and non-apoptotic cell death. PNAS. US. 109(17): 6561-5

Gan N, Yang L, Omran A, Peng J, Wu L, He F (2013). Myeloid-related protein-8, an endogenous ligand of TLR-4, is involved in epileptogenesis of mesial temporal lobe epilepsy, via activation of the nuclear factor- $\mathrm{\beta} \beta$ pathway in astrocytes. Mol. Neurobiol. doi: 10.1007/s12035-013-8522-7

Gandal MJ, Nesbitt AM, McCundy RM, Alter MD (2012). Measuring the maturity of the fast-spiking interneurons transcriptional program in autism, schizophrenia and bipolar disorder. PLoS ONE e41215 doi: 10.1371/journal pone.0041215

Gao C, Holscher C, Liu Y, Li L (2011). GSK 3: a key target for the development of novel treatments for T2DM and AD. Rev. Neurosci. 23(1): 1-11

Geng Y, Hoke A, Delpire F (2009). The Ste20 kinases Ste20-related proline-alanine-rich kinase and oxidative-stress response kinase-I regulate $\mathrm{NKCCl}$ function in sensory neurons. J. Biol. Chem. 284: 14020-14028

Gessa GL, Pani L, Fadda P, Fratta W (1995). Sleep deprivation in the rat: an animal model of mania. Eur. J. Neuropsychopharmacol. 5: 89-93

Ghasemi M, Shafaroodi H, Karimollah AR, Gholipour T, Nezanni BG, Ebrahimi F (2010). ATP-sensitive potassium channels contribute to the time-dependent alteration in the PTZ-induced seizure threshold in diabetic mice. Seiz. (Eur. J. Epilep.) 19(1): 53-56

Golovko T, Min R, Lozovaya N, Falconer C, Yatsenko N, Tsintsadze T (2015). Control of inhibition by the direct action of cannabinoids on GABA $_{A}$ receptors. Cereb. Cortex. 25(9): 2440-2455

Gomes FA, Magalhaes PV, Kunz M, de Silveira LE, Weyne F, Andrezza AC (2010). Insulin resistance and metabolic syndrome in outpatients with bipolar disorder. Rev. Clin. Psychi. 37(2): dx.doi.org/ $105590 / 50101$

Goncalves da Silva C, Jarzyna R, Specht A, Kaczmarek E (2010). Extracellular nucleotides and adenosine independently activate AMP-activated protein kinase in endothelial cells. Involvement of P2 receptors and adenosine transporters. Circ. Res. 98(5): e39-e47

Gonzalez-Maeso J, Rodriguez-Puertas R, Meaner JJ, Garcia-Sevilla J, Guimon J (2002). Neurotransmitter receptor-mediated activation of G-proteins in brain of suicide victims with mood disorders: selective supersensitivity of $\alpha_{2 A}$-adrenoceptors. Mol. Psychiatr. 7(7): 755-707

Goodnick PJ, Henry JA, Buki VMH (1995). Treatment of depression in patients with diabetes mellitus. J. Clin. Psychiatr. 56: 128-136

Goswami S, Yee SW, Stocker S, Mosley JD, Castro R, Mefford JA (2014). Genetic variants in transcription factors are associated with the pharmacokinetics and pharmacodynamics of metformin. Clin. Pharmacol. Therapeut. 96(3): 370-374

Graham DL, Errege IC, Galli A, Stanwood GD (2013). GLP-I analog attenuates cocaine reward. Mol. Psychiatri. 18(9): 961-962

Granic I, Dolga A, Nijholt IM, van Dijk G, Eisel ULM (2009). Inflammation and NF-kappa B in Alzheimer's disease and Diabetes. J. Alzh. Dis. 16(4): 803-821

Gray J, Yeo GSH, Cox JJ, Morton J, Adlam A-L R, Keogh JM (2006). Hyperphagia, severe obesity, impaired cognitive function, and hyperactivity associated with functional loss of one copy of the BDNF gene. Diabet. 55(12): 3366-337

Greene AE, Todrova MT, McGowan R, Seyfried TN (2001). Calorie restriction inhibits seizure susceptibility in epileptic EL mice by reducing blood glucose. Epilepsia 42(11): 1371-8

Greenwood TA, Akiskal HA, Akiskal KK, Kelsoe JR (2012). Genomewide association study of temperament in bipoloar disorder reveals significant association to three novel loci. Biol. Psychiatr. 72(4): 303310

Grover S, Malhotra N, Chakrabarti S (2012). Metabolic syndrome in bipolar patients,. Indian J. Psychol. Med. 34(2): 110-118
Gu Q, Wang B, Zhang Z-F, Ma Y-P, Liu J-D, Wang X-Z (2012). Contribution of hydrogen sulphide and nitric oxide to exerciseinduced attenuation of aortic remodelling and improvement of endothelial function in SHR. Mol. Cell. Biochem. 375(1) doi: 10.1007/s11010-012-1542-1

Guccione L, Djouma E, Penman J, Paolini AG (2013). Calorie restriction inhibits relapse behaviour and preference for alcohol within a twobottle paradigm in the alcohol preferring (iP) rat. Physiol. Behav. 110-111: $34-41$

Guigas B, Detaille D, Leverve X (2004). Metformin inhibits mitochondrial permeability transition and cell death: a pharmacological in vitro study. Biochem. J. 382(pt3): 877-884

Guillin O, Diaz J, Carroll P, Griffon N, Schwartz J-C, Sokoloff P (2001). BDNF controls dopamine $D_{3}$ receptor expression and triggers behavioural sensitization. Nat. 411: 66-89

Gulec G, Novan B (2002). Arginine vasopressin in the pathogenesis of febrile convulsion and temporal lobe epilepsy. Neuroreport. 13(16): 2045-8

Gunton JE, Delhanty PJ, Takahashi S, Baxter RC (2003). Metformin rapidly increases insulin receptor activation in human liver and signals preferentially through insulin receptor substrate 2 . J. Endocrinol. Metab. 88(3): 1323-32

Guo J, Liu Z, Dai H, Zhu Z, Wang H, Yang C (2014). Preliminary investigation of the influence of CREBI gene polymorphism on cognitive dysfunction in Chinese patients with major depression. Intern. J. Neurosci.124(1): 22-9

Guo T, Marmol P, Moliner A, Bjornholm M, Zhang C, Shokat KM, Ibanez CF (2014). Adipocyte ALK7 links nutrient overload to catecholamine resistance in obesity. elife 3: e03245 dx.doi.org/10.7554 eLife. 03245

Guo W, Kan J-T, Cheng C-Y, Chen J-F, Shen Y-Q, Xu J (2012). Hydrogen sulphide as an endogenous modulator in mitochondria and mitochondrial dysfunction. Oxid. Med. Cell. Longev. 2012: 878052 http://dx.doi.org/10.1155/2012/878052

Gupta A, Bisht B, Sanker DC (2011). Peripheral insulin-sensitizer drug metformin ameliorates neuronal insulin resistance and Alzheimer'slike changes. Neuropharmacol. 60(6): 910-20

Ha YM, Park EJ, Kang YJ, Park SW, Kim HJ, Chang KC (2014). Valsartan independent of ATI receptor inhibits tissue factor, TLR-2 and -4 expression by upregulation of Egr-I through activation of AMPK in diabetic conditions. J. Cell. Mol. Med. doi: 10.111/jcemm 12354

Hagihara H, Takao K, Walton NM, Matsumoto M, Miyakawa T (2013). Immature dentate gyrus: an endophenotype of neuropsychiatric disorders. Neur. Plast. 2013: 318596 doi: 10.1155/2013/318596

Hajek T, Calkin C, Blagdon R, Slaney C, Uher R, Alda M (2014). Insulin resistance, diabetes mellitus, and brain structure in bipolar disorders. Neuropsychopharmacol. doi: 10.1038/npp.2014.148

Hamed SA, Nabeshima T (2005). The high atherosclerotic risk among epileptics. The atheroprotective role of multivitamins. J. Pharmacologic. Sci. 98(4): 340-353

Han TK, Everett RS, Thakker DR (2013). Interplay between metformin and serotonin transport in the gastro-intestinal tract: a novel mechanism for the intestinal absorption and adverse effects of metformin. Retrieved from pharmacy.unc.edu

Handschin C, Mootha V (2005). Estrogen-related receptor alpha (ERR a): a novel target in type 2 diabetes. Drug Discovery Today: Therapeut. Strateg. 2(2): 151-156

Hansen ME, Tippetta TS, Anderson MC, Holub ZE, Moulton ER, Swensen AC (2014). Insulin increases ceramide synthesis in skeletal muscle. J. Diabet. Res. 2014: 765-784.

Hashimoto R, Taki N, Shimazu K, Christ L, Lu B, Chuang DM (2002). Lithium induces BDNF and activates TrkB in rodent cortical neurons: an essential step for neuroprotection against glutamate excitotoxicity. Neuropharmacol. 43: 1173-1179

Hattori Y, Suzuki K, Hattori S, Kasai K (2006). Metformin inhibits

cytokine-induced NF-kappa $\beta$ activation via AMPK activation in vascular endothelial cells. Hypertens. 47: 1183-118

Hebert SS (2009). Putative role of microRNA-regulated pathways in comorbid neurological and cardiovascular disorders. Cardiovasc. Psychiatr. Neurol. 2009: 849519 dx.doi.org/10.1155/2009/849519 
Heras-Sandovul D, Perez-Ropas J, Hernandez-Danvan J, Pedraza Chavem J (2014). The role of PI3K/AKT/mTOR pathway in the modulation of autophagy and the clearance of protein aggregates in neurodegeneration. Cell. Signal. doi: 10.1016/jcellsig.2014.08.019

Herman BH, Vocci F, Bridge P (1996). The effects of NMDA receptor antagonists and NOS inhibitors on opioid tolerance and withdrawal: medication development issues for opiate addiction. Neuropsychopharmacol. 14(4): 269-93

Hettich MM, Mathias F, Ryan DP, Griesche N, Schroder S, Dorn S (2014). The anti-diabetic drug metformin reduces BACEI protein level by interfering with the MIDI complex. PLoS One 9(7): e102420 doi: 10.1371 /journal pone. 0102420

Hink U, Li H, Mollinar H, Oelz M, Mathias E, Hartmann M (2001). Mechanisms underlying endothelial dysfunction in DM. Circ. 88: e14-e22

Hirota T, Kishi T (2013). Adenosine hypothesis in schizophrenia and bipolar disorder: a systematic review and meta-analysis of randomised controlled trial of adjuvant purinergic modulators. Schiz. Res. 149(1-3): 88-95

Holland W, Mouison T, Chang Y, Wiernsperger N, Stith BJ (2004). Metformin (Glucophage) inhibits tyrosine phosphatase activity to stimulate the insulin receptor tyrosine kinase. Biochem. Pharmacol. 67(11): 2081-2091

Holmes MC, Wyrwoll C, Seckl J (2015). Fetal prpgramming of adult behaviour by stress and glucocorticoids. Psychoneuroendocrinol. 61: 9

Holscher C (2010). Incretin analogues that have been developed to treat type 2 diabetes hold promise as a novel treatment strategy for AD. Recent Pat. CNS. Drug Discover. 5(2): 109-17

Holst SC, Bersagliere A, Bachmann V, Berger W, Acherman P, Landolt H-P (2014). Dopaminergic role in regulating neurophysiological markers of sleep homeostasis in humans. J. Neurosci. 34(2): 566573

Holtman L, van Vliet EA, Aronica E, Wouters D, Wadman WJ, Gorter JA (2013). Blood plasma inflammatory markers during epileptogenesis in post-status epilepticus rat model for temporal lobe epilepsy. Epileps. 54(4): 589-595

Hong SG, Jang G, Oh HJ, Koo, OJ, Park JE, Park HJ, Kang SK, Lee BC (2009). The effects of BDNF and metformin on in vitro developmental competence of bovine oocytes. Zygote. 17(3): 187193

Hoozemans JJ, van Haastert ES, Niiholt DA, Rozemuller AJ, Scheper W (2012). Activation of the unfolded protein response is an early event in Alzheimer's and Parkinson's disease. J. Neurodeg. Dis. 10(1-4): $212-5$

Horacek J, Kuzmiakova M, Hoschi C, Andel M, Bahbonh R (1999). The relationship between central serotonergic activity and insulin sensitivity in healthy volunteers. Psychoneuroendocrinol. 24(8): 785797

Horike $N$, Sakoda $H$, Kushiyama $A$, Ono $H$, Fujishiro $M$, Kamato $H$ (2008). AMPK activation increases phosphorylation of glycogen synthase kinase- 3 beta and thereby reduces cAMP-response element transcriptional activity and phosphoenolpyruvate carboxykinase $\mathrm{C}$ gene expression in the liver. J. Biol. Chem. 283(49): 33902-10

Hristova MG (2011). Metabolic syndrome and neurotropins: effects of metformin and non-steroidal anti-inflammatory drug treatment. Euras. J. Med. 43: 141-145

Hu K, Xie YY, Zhang C, Ouyang DS, Long HY, Sun DN, Long LL (2012). MicroRNA expression profile of the hippocampus in a rat model of temporal lobe epilepsy and miRNA 34a-targeted neuroprotection against hippocampal neurone cell apoptosis poststatus epilepticus. BMC Neurosci. 13: 115 doi: 10.1186/1471-220213-115

Huang CW, Tsai JJ, Ou HY, Wang ST, Cheng JT, Wu SN (2008). Diabetic hyperglycaemia is associated with the severity of epileptic seizures in adults. Epilep. Res. 79(1): 71-77

Huang S, Zhu M, Wu W, Rashid A, Liang Y, Hou C, Ning S, Luo X (2014). Valproate pretreatment protects pancreatic beta-cells from palmitate-induced ER stress and apoptosis by inhibiting glycogen synthase kinase-3 beta. J. Biomed. Sci. 21(1): 38-42
Huberfeld G, de la Prida LM, Pallud J, Cohen I, Le van Guyen M, Adam C (2011). Glutamatergic pre-ictal discharges emerge at the transition to seizure in human epilepsy. Nat. Neurosci. 14: 627-634

Huss JM, Torra JP, Staeis B, Giguere V, Kelly DP (2004). Estrogenrelated receptor alpha directs PPAR alpha signalling in the transcriptional control of energy. Mol. Cell. Biol. 24(20): 9079-91

Idris J, Miller D, Page SR (2004). Familial hyperinsulinaemia associated with epilepsy and mental retardation-a syndrome of familial insulin resistance. Diabet. Med. 21(6): 628-31

Ikegame T, Bundo M, Murata Y, Kassai K, Iwamoto K (2013). DNA methylation of the BDNF gene and its relevance to psychiatric disorders. J. Hum. Gen. 58(7): 434-438

Im HI, Hollander JA, Bali P, Kenny PJ (2010). MeCP2 controls BDNF expression and cocaine intake through homeostatic interactions with miR-212. Nat. Neurosc. 13: 1120-1127

Iniaghe LO, Krafft PR, Klebe DW, Omogbai EKI, Zhang JH, Tang J (2015). Dimethyl fumarate comfers neuroprotection by casein kinase-2 phosphorylation of Nrf2 in murine intracerebral haemorrhage. 82: 349-358

Iori V, Maroso M, Rizzi M (2013). A receptor for advanced glycation end-products is upregulated in temporal lobe epilepsy and contributes to experimental seizures. Neurobiol. Dis. 58: 102-114

Isoda K, Young IL, Zirlik A, MacFarlane A, Tsuboi N, Gerdes N (2006). Metformin inhibits proinflammatory response and NF-kappa B in human vascular wall cells. Arterioscer. Thromb. Vasc. Biol. 26(3) 611-617

Issa G, Wilson C, Terry AV Jr, Pilla A (2010). An inverse relationship between cortisol and BDNF levels in schizophrenia: data from human post-mortem and animal studies. Neurobiol. Dis. 39(3): 327333

Jara JH, Singh BB, Fioden AM, Combs CK (2006). TNF-alpha stimulates NMDA receptor activity in mouse cortical neurons resulting in ERK-dependent death. J. Neurochem. 100(5): 14071420

Jia L, Vianni CR, Fukuda M, Berglund EO, Liu C, Tao C (2014) Hepatocyte toll-like receptor 4 regulates obesity-induced inflammation and insulin resistance. Nat. Commun. 5 Art Number 3878 doi. $10.1038 /$ ncomms.4878

Jimene-Mateo EM, Engel T, Merino-Serrais P, McKiernan RC, Tanaka K, Mouri G (2012). Silencing microRNA-134 produces neuroprotection and prolonged seizure-suppressive effects. Nat Med. doi: 10.1038/nm.2834

Jin Q, Cheng J, Liu Y, Wu J, Wang X, Wei S, Zhou X, Qin Z, Jia J, Zhen $X$ (2014). Improvement of functional recovery by chronic metformin treatment is associated with enhanced alternative activation of microglia/macrophages and increased angiogenesis and neurogenesis following experimental stroke. Br. Behav. Imm. 40: 131-142

Jobgen WS, Fried SK, Fu WS, Meininger CJ, Wu G (2006). Regulatory role of the arginine-nitric oxide pathway in metabolism of energy substrates. J.Nutr. Biochem. 17(9): 571-88

Johar K, Priya A, Dhar S, Liu Q, Wang-Riley MTT (2013). Neuronspecific specificity protein biogenomically regulates the transcription of all mitochondrial- and nucleus-encoded cytochrome $C$ oxidase subunit genes in neurons. J. Neurochem. 127(4): 490-508

Jones NA, Hill AJ, Smith I, Bevan SA, Williams CM, Whalley BJ (2010). Cannabidiol displays antiepileptiform and antiseizure properties in vitro and in vivo. JPET. 332(2): 569-577

Joseph A-M, Joanisse DR, Baillot RG, Hood DA (2012). Mitochondrial dysregulation in the pathogenesis of diabetes: potential for mitochondrial-mediated intervention. Expt. Diabet. Res. 2012 Art ID 642038 doi.org/1055/2012/642038

Kakiuchi C, Iwamoto K, Ishiwata M, Bundo M, Kasahara T, Kusumi I(2003). Impaired feedback regulation of XBPI as a genetic risk factor for bipolar disorder. Nat. Gen. 35(2): 171-175

Kaliman P, Parrizas M (2011). Obesity and systemic inflammation: insights into epigenetic mechanisms: role of the adipocyte in

development of type 2 diabetes. Dr. C. Croniger cdn.intechopen.com ISBN: 978-953-307-598-3. 
Kalinicher M, Dawson LA (2011). Evidence for antimanic efficacy of GSK3 inhibitors in a strain-specific model of mania. Intern. J. Neuropsychopharmacol. 14(8): 1051-1067

Kamat PK, Kalani A, Givvimani S, Sathnur P, Tyagi SC, Tyagi N (2013). Hydrogen sulphide attenuates neurodegeneration and neurovascular dysfunction induced by intracerebral administered homocysteine. Neurosci. 252 doi: 10.1016/jneuroscience.2013.07.053

Kamat PK, Kalani A, Tyagi C, Tyagi N (2015). Hydrogen sulphide epigenetically attenuates homocysteine-induced mitochondrial toxicity mediated through NMDA receptor in mouse brain endothelial cells. J. Cell Physiol. 230(2): 378-394

Kamphuis J, Meerlo P, Koolhaas JM, Lancel M (2011). Poor sleep as a causal factor in aggression and violence. Sleep Med. 13(4): 327334

Kan AA, van der Hel S, Kolk SM, Bos IWM, Verlinde SAW, van Nieuwenhuizen $O$ (2012). Prolonged increase in rat hippocampal chemokine signalling after status epilepticus. J. Neuroimmunol. 245(1-2): 15-22

Kanner AM, Mazarati A, Koepp M (2014). Biomarkers of epileptogenesis: Psychiatric co-morbidities (?) Neurotherapeut. 11(2): 358-372

Kato T (2007). Mitochondrial dysfunction as the molecular basis of bipolar disorder: therapeutic implication. CNS Drugs. 21(1): 1-11

Kato T (2008). Role of mitochondrial DNA in calcium signalling abnormality in bipolar disorder. Cell Calc. 44(1): 92-102

Kato T, Kato N (2000). Mitochondrial dysfunction in bipolar disorder. Bipolar Disord. 2(3): 180-190

Kelly BJ, Duker AP, Chiu P (2012). Dopamine agonists and pathological behaviours. Parkinson's Dis. 2012: 603631 dx. doi.org/1055/2012/ 603631

Kemp DE, Fan J (2012). Cardiometabolic health in bipolar disorder. Ann. Psychiatr. 42(50: 179-183

Kennedy PJ, Feng J, Robison AJ, Maze I, Badimon A, Mouzon E (2013). Class I histone deacetylase inhibition blocks cocaineinduced plasticity through targeted changes in histone methylation. Nat. Neurosc. 16(4): 434-440

Kenny RJ (2011). Common cellular and molecular mechanisms in obesity ad drug addiction. Nat. Rev. 12: 638-651

Kesebir S, Yayleci ET, Suner O, Gultekin BK (2014). Uric acid levels may be a biological marker for the differentiation of unipolar and bipolar disorder: the role of affective temperament. J. Affect. Disord. 165: 131-134

Khatri N, Man H-Y (2013). Synaptic activity and bioenergy homeostasis: implications in brain trauma and neurodegenerative diseases. Front. Neurosci. doi: 10.3389/fneur.2013.00199

Khemka VK, Bagchi D, Ghosh A, Sen O, Bir A, Chakrabarti S (2013). Raised serum adenosine deaminase levels in non-obese type 2 diabetes mellitus. Scient. World J. doi.org/10.1155/2013/404320 Art ID: 404320

Khitan Z, Kim DH (2013). Fructose: a key factor in the development of metabolic syndrome and hypertension. J. Nutr. Metab. 2013: Art ID: 682673 dx.doi.org/10.1155/2013/682673

Kickstein E, Krauss S, Thornhill P, Rutschow D, Zeller R, Sharkey J (2010). Biguanide metformin acts on tau phosphosylation via mTOR/protein phosphatase 2A (PP2A) signalling. PNAS. US. doi: 10.1073/pnas.0912793107

Kiechi S, Wittman J, Giaccari A, Knoflach M, Willeit P, Bozec A (2013). Blockade of receptor of NF-kappa B (RANKL) signalling improves hepatic insulin resistance and prevents development of diabetes mellitus. Nat. Med. 19: 358-363

Kim AJ, Shi Y, Austin RC, Werstuck GH (2005): Valproate protects cells from ER stress-induced lipid accumulation and apoptosis by inhibiting glycogen synthase kinase-3. J. Cell Sci. 118: 89-99

Kim B, Kim CY, Lee MJ, Yoo YH (2009). Preliminary evidence on the association between XBPI-116CG polymorphism and response to prophylactic treatment with valproate in bipolar disorders. Psychiatr. Res. 168(3): 209-211

Kim H-G, Wang J-H, Chae H-S, Chin Y-W, Choi H-J, Kim H (2014). Screening of herbal medicines for synergistic effects of metformin and herbal extracts combination in RAW 264.7 cells. J. Kor. Med. Obes. Res. 14: 13-23
Kim HW, Rapoport SI, Rao JS (2011). Altered arachidonic acid cascade enzymes in post-mortem brain from bipolar disorder patients. Mol. Psychiatr. 16(4): 419-428

Kim J, Park Y-K, Jang Y, Kwon YH (2011). AMPK activation inhibits apoptosis and tau hyperphosphorylation mediated by palmitate in SH-SY5Y cells. Brain Res. 14(8): 42-51

Kim JC, Kang T-C (2011). P2X7 receptor-pannexin I complex decreases muscarinic acetylcholine receptor-mediated seizure susceptibility in mice. J. Clin. Investig. 121(5): 2037-2047

Kim J-Y, Lee J, Song M-K, Han T, Ryu J-C (2013). Valproic acid inhibits cell size and cell proliferation by AMPK-mediated mTOR signalling pathway in JEG-3 cells. BioChip J. 7(3): 267-277

Kim MH, Jee JH, Park S, Lee MS, Kim KW, Lee MK (2014). Metformin enhances glucagon-like peptide-I via cooperation between insulin and Wnt signalling. J. Endocrinol. 220(2): 117-128

Kim S-J, Lee J-H, Chung H-S, Song J-H, Ha J, Bae H (2013). Neuroprotective effects of AMP-activated protein kinse on scopolamine-induced memory impairement. Kor. J. Physiol. Pharmacol. 17(4): 231-338

Kim SY, Buckwalter M, Soneq H, Vezzani A, Kaufer Y (2012). Bloodbrain barrier dysfunction-induced inflammatory signalling in brain pathology and epileptogenesis. Epileps. 53(6): 37-44

Kim Y-K, Na K-S, Hwang J-A, Yoon H-K, Lee H-J, Hahn S-W (2013). High insulin-like growth factor-I in patients with bipolar I disorder: a trait marker. J. Affect. Disord. 151(2): 738-743

Kim YS, Choi MY, Lee DH, Jeon BT, Roh GS, Kim KH, Kang SS (2014). Decreased interaction between FOXO3a and Akt correlates with seizure-induced neuronal death. Epilep. Res. 108(3): 367-378

Kim Y-W, Park S-Y, Kim K-Y, Huh J-Y, Jeon W-S, Yoon C-J (2007). Metformin restores the penile expression of nitric oxide synthase in high-fat-fed obese rats. J. Androl. 28(4): 555-560

Kimple ME, Neuman JC, Linnemann AK, Cassey PK (2014). Inhibitory G-proteins and their receptors: emerging therapeutic targets for obesity and diabetes. Expt. Mol. Med. 46. E102 doi: 10.1038/emm.2014.40

King AL, Polhemus DJ, Bhushan S, Osuka H, Kondo K, Nicholson CK (2014). Hydrogen sulphide cytoprotective signalling is endothelial nitric oxide synthase-nitric oxide dependent. PNAS.USA. 111(8): 3182-3187

Kings $H$, Rewers $M$ (1991). Diabetes in adults is now a third world problem. The WHO Ad Hoc Diabetes Reporting Group. Bulletin of the World Health Organisation. 69(9): 643-648

Kirchner A, Veliskova J, Velisek L (2006). Differential effects of low glucose concentration on sezures and epileptiform activity invivo and in vitro. Eur. J. Neurosci. 33(6): 1512-22

Kirpichnikov D, Mcfarlane SI, Sowers JR (2002). Metformin: an update. Ann. Intern. Med. 137: 25-33

Kisfalvia K, Eibi G, Sinnett-Smith J, Rozengurt E (2009). Metformin disrupts crosstalk between G-protein coupled receptor and insulin receptor signalling systems and inhibits pancreatic cancer growth. Can. Res. 69(16): 6539-6545

Kitagishi Y, Kobayashi M, Kikuta K, Matsuda S (2012). Role of $\mathrm{PI} 3 \mathrm{~K} / \mathrm{Akt} / \mathrm{GSK} 3 / \mathrm{mTOR}$ pathway in cell signalling of mental illnesses. Depress. Res. Treat. 2012: 752563

Kitaoka S, Furuyashiki T, Nishi A, Shuto T, Koyasu S, Matsuoka T, Miyasaka M (2007). Prostaglandin E2 acts on EPI receptor and amplifies both dopamine $\mathrm{DI}$ and D2 receptor signalling in the striatum. J. Neurosci. 27(47): 12900-12907

Klaft Z-J, Schultz SB, Maslarova A, Gabriel S, Heinemann U, Gerevich $Z$ (2012). Extracellular ATP differentially affects epileptiform activity via purinergic $\mathrm{P} 2 \mathrm{X} 7$ and adenosine $\mathrm{Al}$ receptors in naïve and chronic epileptic rats. Epileps. 53(11): 1978-1986

Klimpton J (2012). The BDNF and influence of stress in depression. Psyhiatri. Danub. 24(1): 169-171

Kloda A, Clements JD, Lewis RJ, Adams DJ (2004). Adenosine triphosphate acts as both a competitive antagonist and a positive allosteric modulator at recombinant $\mathrm{N}$-methyl-D-aspartate receptors. Mol. Pharmacol. 63(6): 1386-1396

Kook S-Y, Jeong H, Kang M-J, Park R, Shin HJ, Han S-H (2014). Crucial role of calbindin-D-28K in the pathogenesis of Alzheimer's disease mouse model. Cell Death Differ. doi: 10.1038/cdd.2014. 2014.67 
Kotagal P, Yardi $N$ (2008). The relationship between sleep and epilepsy. Sem. Ped. Neurol. 15(2): 42-9

Kotz CM, Billington CJ, Mavanji V (2012). Weight gain induced by highfat diet increases active-period sleep and sleep fragmentation. Soc. Stud. Ingest. Behav.www.sciencedaily.com/releases/2012

Kovacs KJ (2012). Microglia and drug-induced plasticity in rewardrelated neuronal circuits. Front. Mol. Neurosci. 5: 74 doi: 103380/fnmol.2012.00074

Krause KH, Berlit P, Schmidt-Gayk H, Schellenberg B (1987). Antiepileptic drugs reduce serum uric acid. Epileps. Res. 1(5): 306307

Krishnadas R, Venkatassubramanian G, Cavanagh J, Harrison NA (2014). Inflammation and the brain, in the context of mental health illness. frontiersin.org/Research Topic/2759

Kudo T, Ishida S, Kubota H, Yagi K (2001). Manic episode in epilepsy and bipolar I disorder: a comparative analysis of 13 patients. Epileps. 42(8): 1036-1042

Kuramoto N, Wilkins ME, Fairfax BP, Revilla-Sanchez R, Terunume M, Warren N (2007). Phospho-dependent functional modulation of GABA-B receptor by the metabolic sensor AMPK. Neuron. 53(2): 233-247

Kuromitsu J, Yokoi A, Kawai T, Nagasu T, Aizawa T, Haga S (2001). Reduced NPY mRNA levels in the frontal cortex of people with schizophrenia and BPD. Brain Res. Gene Exp. Patterns. 1(1): 17-21

Laeng P, Pitts RL, Lemire AL, Drabik CE, Weiner A, Tang H (2004). The mood stabiliser valproic acid stimulates GABA neurogenesis from rat forebrain stem cells. J. Neurochem. 91(1): 238-251

Lalonde J, Saia G, Gill G (2014). Store-operated calcium entry promotes the degradation of the transcription factor SP4 in resting neurons. Sci. Sign. 7: ra51

Lang A, Lahav M, Sakhnini E, Barsack I, Fidder HH, Avidan B (2004). Allicin inhibits spontaneous and TNF-alpha-induced secretion of pro-inflammatory cytokines and chemokines from intestinal epithelial cells. J. Clin. Nutri. 23(5): 1199-1208

Le Fall B, Collo G, Rabiner EA, Boileau I, Pich EM, Sokoloff P (2014). Dopamine $D_{3}$ receptor ligands for drug addiction treatment: update on recent findings. Progr. Brain. Res. 211: 255-275

Le Hellard S, Muhleissen TW, Djurovic S, Femo J, Ounaghi Z, Mattheissen M (2008). Polymorphisms in SREBP I and SREBP 2, two antipsychotic-activated transcription factors controlling cellular lipogenesis, are associated with schizophrenia in German and Scandinavian samples. Mol. Psychiatr. doi: 10.1038/mp2008110

Lee AH, Heidtman K, Hotamisligil GS. Glimcher LH (2011). Dual and opposing roles of the UPR regulated by IREI alpha and XBPI in proinsulin processing and insulin secretion. PNAS. US. 108: 88858890

Lee C-Y, Jaw T, Tseng H-C, Chen I-C, Liou H-H (2012). Lovastatin modulates GSK-3 $\beta$ pathway and inhibits mossy fibre sprouting after pilocarpine-induced status epilepticus. PLoS ONE 7(6): e38789 doi: 10.1371/journal pone.0038789

Lee HJ, Marieppan MM, Feliers D, Cavaglieri RC, Satarenatavejan IC, Abboud HE (2012). Hydrogen sulphide inhibits glucose-induced matrix protein synthesis by activating AMPK in renal epithelial cells. J. Biol. Chem. 287(7): 4451-61

Lee JE, Park H, Ju YS, Kwak M, Kim J-I, Oh HY (2009). Higher mitochondrial DNA copy number is associated with lower prevalence of microalbuminuria. Exp. Mol. Med. 41(4): 253-258

Lee Y, Kim E-K (2013). AMPK as a key molecular link between metabolism and clockwork. Expt. Mol. Med. 45, e33: doi:10.1038/emm.2013.65

Leina LO, Sollon C. Calixton MC, Lintomen L, Monica FZ, Anhe GF (2012). Role of PKC and CaVI.E in detrusor overactivity in a model of obesity-associated with insulin resistance in mice. PLoS ONE 7(11): e48507 doi: 10.1371/journal pone.0048507

Le-Niculescu H, McFarland MJ, Ogden CA, Balaraman Y, Patel S, Tan $S$ (2008). Phenomic, convergent functional genomic, and biomarker studies in a stress-reactive genetic animal model of bipolar disorder and co-morbid alcoholism. Am. J. Med. Genet. Neuropsychiatr. Genet. 147B(2): 134-166

Leo R, Di Lorenzo G, Tesauro M, Cola C, Fortuna E, Zanasi M (2006). Decreased plasma adiponectin concentration in major depression. Neurosci. Lett. 407(3): 211-213
Leon D, Herva SC, Miras-Portugal MJ (2006): P2YI and P2X7 receptors induce cacium/calmodulin-dependent protein kinase II phosphorylation in cerebellar granule neurons. Eur. J. Neurosci. 23(1): 2999-3013

Li H, Lee J, He C, Zou M-H, Xie Z (2013). Suppression of mTORCI/STAT3/Notch I pathway by activated AMPK prevents hepatic insulin resistance induced by excess amino acids. Am. J. Physiol-Endocrinol. Metab. doi: 10.1152/ajpendo.00202.2013

Li J, Deng J, Sheng W, Zuo Z (2012). Metformin attenuates Alzheimer's disease-like neuropathology in obese, leptin-resistant mice. Pharmacol. Biochem. Behav. 101(4): 564-574

Li L (2007). Is glucagon-like peptide-I, an agent to treat diabetes, a new hope for Alzheimer's disease? Neurosci. Bull. 23: 58-65

Li M, Zhao L, Liu J, Liu A, Jia C. Ma D (2010). Multi-mechanisms are involved in ROS regulation of $\mathrm{mTORCl}$ signalling. Cell Sign. 22: $1469-1473$

Li S, Yang G (2015). Hydrogen sulphide maintains mitochondrial DNA replication via demethylation of TFAM. Nitric Oxide. 47(7): doi:10.1089/ars.2014.6186

Li X, Bijur GN, Jope RS (2002). Glycogen synthase kinase-3 beta mood stabilisers, and neuroprotection. Bipol. Disord. 4(2): 137-44

Li Y, Wang H, Xie K, Wang C, Zang Z, Yu Y (2013). Ihibition of GSK-3 beta prevents remifentanil-induced hyperalgesia via regulating the expression and function of spinal NMDA receptors in vivo and in vitro. PLoS One. 8(10): e77790

Li Y-C, Gao W-J (2011). GSK-3beta activity and hyperdopaminedependent behaviours. Neurosci. Biobehav. Rev. 35(3): 645-654

Li Y-C, Xi D, Roman J, Huang Y-Q, Gao W-J (2009). Activation of GSK3 beta is required for hyperdopamine and D2 receptor-mediated inhibition of synaptic receptor function in the rat prefrontal cortex. J. Neurosci. 29(49): 15551-15583

Licinio J (2011). Translational psychiatry: leading the transition from the cesspool of devastation to a place where the grass is really greener Trans. Psychiatr. 1(4): el

Liu J, Guo M, Zhang D, Cheng SY, Liu M, Ding J (2012). Adiponectin is critical in determining susceptibility to depressive behaviours and has anti-depressant-like activity. PNAS. US. 109(30): 12248-53

Liu J, Li JD, Lu J, Xing J, Li J (2011). Contribution of nerve growth factor to upregulation of P2X3 expression in DRG neurons of rats with femoral artery occlusion. Am. J.Physiol. Heart Circ. Physiol. 301 $\mathrm{H} 1070-\mathrm{H} 1079$

Liu J, Wang YT (2014). Allosteric modulation of $\mathrm{GABA}_{\mathrm{A}} \mathrm{R}$ receptors by extracellular ATP. Mol. Br. 7: 6 doi: 10.1186/1756-6606-7-6

Liu JX, Liu J, Li PQ, Xie XD, Guo Q, Tian LM (2008). Association of sterol regulatory element-binding protein-I c gene polymorphism with type 2 diabetes mellitus, insulin resistance and blood lipid levels in Chinese population. Diabet. Res. Clin. Pract. 82(1): 42-47

Liu X, Yang Z, Yin Y, Deng X (2014). Increased expression of Notch I in temporal lobe epilepsy: animal models and clinical evidence. Neur. Regen. Res. 9(5): 526-533

Loegering D, Lennartz M (2011). Protein kinase C and toll-like receptor signalling. Enzy. Res. 2011 Art ID $537821 \mathrm{dx}$ doi.org/10.406/2011/53784

Lohoff FW, Dahi JP, Ferraro TN, Arnold SE, Gallinat J, Sander T (2006). Variations in the vesicular monoamine transport I gene (VMATI/SLC18Al) are associated with bipolar I disorder. Neuropsychopharmacol. 31(12): 2739-2747

Lopez-Figueroa AL, Norton CS, Lopez-Figueroa MO, Armellini-Dodu D, Burke S, Akil H (2004). Serotonin 5-HTIA, 5-HTIB, and 5-HT2A receptor mRNA expression in subjects with major depression, bipolar depression and schizophrenia. Biol. Psychiatr. 55(3): 225-33

Lorenzo M, Fernandez-Veledo S, Vila-Bedonas R, Garcia-Guerre L, De Alvaro L, Nieto-Vazquez I (2008). Insulin resistance induced by TNF-alpha in myocytes and brown adipocytes. J. Anim. Sci. 86(14): E94-194

Loscher W, Brandt C, Sibley D (2010). Prevention or modification of epileptogenesis after brain insults: experimental approaches and translational research. Pharmacologic. Rev. 62(4): 668-700

Lu J, Ji J, Meng H, Wang D, Jiang B, Liu L (2013). The protective effect and underlying mechanism of metformin on neointima formation in fructose-induced insulin resistant rats. Cardiovasc Diabetol. 12: 58 doi: 10.1186/1475-2840-12-58 
Lucas EK, Markwardt SJ, Gupta S, Meado-Woodruff JH, Lin JD, Overstreet-Wadiche L (2010). Parvalbumin deficiency and GABAergic dysfunction in mice lacking PGC-I alpha. J. Neurosci. 30(21): 7227-35

Luchetti CG, Szekeres-Bartho J, Paz DA, Motto AB (2008). Dehydroepiandrosterone and metformin modulates progesteroneinduced blocking factor (PIBF), COX2 and cytokines in early pregnant mice. J. Steroid Biochem. Mol. Biol. 111(3-5): 200-207

Ma J, Chen Z, Chen S, Peng X, Liu S, Zhao D (2015). A prospective study of the associarion of plasma homocysteine level with stroke in hypertensive patients. Zhonghua Nei Ke Za Zhi. 54(4): 296-301

Maccario M, Messis CP, Vastola EF (1965). Focal seizures as a manifestation of hyperglycaemia without ketoacidosis: a report of seven cases with review of the literature. Neurol. 15: 195-206

Machado-Vieira R, Lara DR, Souza D, Kapczinski F (2002). Purinergic dysfunction in mania: an integrative model. Med. Hypoth. 58(4): 287-304

Machnes ZM, Huang TC, Chang PK, Gill R, Reist N, Dessi G (2013). DNA methylation mediates persistent epileptiform activity in vitro and in vivo. PLoS One 8(10): e76299

Mai L, Jope RS, Li X (2002). BDNF-mediated signal transduction is modulated by GSK-3 beta and mood stabilising agents. J. Neurochem. 82(1): 75-83

Maida A, Lamont BJ, Cao X, Drucker DT (2011). Metformin regulates the incretin axis via a pathway dependent on PPAR alpha in mice. Diabetol. 54(2): 339-349

Maina G, Salvi V, Vitalucci A, D'Ambrosio V, Bogetto F (2008). Prevalence and correlates of overweight in drug-naïve patients with bipolar disorder. J. Affect. Disord. 110: 149-155

Malhi GS, Adams D, Berk M (2010). The pharmacological treatment of bipolar disorder in primary care. Med. J. Australia 193(4): 24

Manev $\mathrm{H}\left(2009_{\mathrm{A}}\right)$. The heart-brain connection begets cardiovascular psychiatry and neurology. Cardiovasc. Psychiatr. Neurol. 2009: 546737 dx.doi.org/10.1155/2009/546737

Manev $\mathrm{H}\left(2009_{\mathrm{B}}\right)$. Hypotheses on mechanisms linking cardiovascular and psychiatric/neurological disorders. Cardiovasc. Psychiatr. Neurol. 2009: 197132 dx.doi.org/10.1155/2009/197132

Manji HK, Quiroz JA, Payne JL, Singh J, Lopes BP, Viegas JS, Zarate CA (2003). The underlying neurobiology of bipolar disorder. World Psychiatr. 2(3): 136-146

Manzl C, Enrich J, Ebner H, Dallinger R, Krumschnabel G (2004). Copper-induced formation of ROS causes cell death and disruption of calcium homeostasis in trout hepatocytes. Toxicol. 196(1-2) 5764

Maroso M, Balosso S, Ravizza T (2011). Interleukin-I biosynthesis inhibition reduces acute seizures and drug resistanct chronic epileptic activity in mice. Neurotherapeut. 8(2): 304-315

Maroso M, Balosso S, Ravizza T, Liu J, Aronica E, Iver AM (2010). Tolllike receptor 4 and High-Mobility Group Box-I are involved in ictogenesis and can be targeted to reduce seizures. Nat. Med. 16(4): 413-419

Martin M, Rehani K, Jope RS, Michalek SM (2005). Toll-like receptormediated cytokine production is differentially regulated by glycogen synthase kinase 3. Nat. Immunol. 6(8): 777-784

Martinc B, Grabnar I, Vovk T (2012). The role of reactive species in epileptogenesis and influence of AED therapy on oxidative stress. Curr. Neuropharmacol. 10(4): 328-343

Martini C, Tuscano D, Trincavelli ML, Cerrai E, Bianchi M, Ciappareli A (2006). Upregulation of A2A adenosine receptors in platelets from patients affected by bipolar disorders under treatment with typical antipsychotics. J. Psych. Res. 40(1): 81-88

Martin-Montalvo A, Mercken EM, Mitchell SJ, Palacios HH, Mote PL, Scheibye-Knudsen M (2013). Metformin shifts expression patterns of mice towards those on calorie restriction. Metformin improves healthspan and lifespan in mice. Nat. Commun. 4 Art Number 2192 doi: 10.1038/ncommu.2192

Martin-Moreno AM, Brera B, Spuch C, Carro E, Garcia-Garcia L,

Delgado $M$ (2012). Prolonged oral cannabinoid administration prevents neuroinflammation, lowers $\beta$-amyloid levels and improves cognitive performance in Tg APP 2576 mice. J. Neuroinflamm. 9: doi: 10.1186/1742-2094-9-8
Mascia P, Tanda G, Yasar S, Heishman SJ, Goldberg SR (2012). PPAR and drug addiction. endoCannabinoids. 24: 235-260

Masino SA, Geiger JD (2009). The ketogenic diet and epilepsy: Is adenosine the missing link? Epileps. 50(2): 332-3

Masino SA, Kawamura Jr M, Wasser CD, Pomeroy LT, Ruskin DN (2009). Adenosine, ketogenic diet and epilepsy: the emerging therapeutic relationship between metabolism and brain activity. Curr. Neuropsychopharmacol. 7(3): 257-266

Massart R, Barnea R, Dickshtein Y, Suderman M, Meir O, Hallett M (2015). Role of DNA methylation in the nucleus accumbens in incubation of cocaine craving. J. Neurosci. 35(21): 8042-8058

Mathieu-Costello O, Kong A, Geraldi TP, Cui L, Chu N, Kim D (2003). Regulation of skeletal muscle morphology in type 2 DM by troglitazone and metformin: relationship to glucose disposal. Metab. 52(5): 540-546

Matsunaga S, Ikeda M, Kishi T, Fukuo K, Aleksi S, Yoshimura R (2012). An evaluation of polymorphisms in casein kinase- I delta and epsilon genes in major psychiatric disorders. Neurosci. Lett. 529(1): 66-99

Matsushita Y, Omotuyi OI, Mukae T, Ueda H (2013). Microglia activation precedes the anti-opioid BDNF and NMDA receptor mechanisms underlying morphine analgesic tolerance. Curr. Pharmaceut. Design. 19(4) doi: 10.2174/138161281942140 105161732

Mazarati A, Lundstrom L, Sollenberg U, Shin D, Langel U, Sankar R (2006). Regulation of kindling epileptogenesis by hippocampal galanin type I and 2 receptors: the effects of subtype-selective agonists and the role of G-protein-mediated signalling. JPET. 318(2): 702-708

Mazza M, Nicola M, Della Marca G, Janiri L, Mazza S (2007). Bipolar disorder and epilepsy: a bidirectional relation? Neurobiological underpinnings, current hypotheses, and future research directions. Neuroscient. 13(4): 392-404

McEwen BS (2003). Mood disorder and allostatic load. Biol. Psychiatr. 54(3): 200-207

McGinty JF, Whitfield TW Jnr, Berglind W (2010). BDNF and cocaine addiction. Brain Res. 1314: 183-93

McIntyre RS, Danilewitz M, Liauw SS, Kemp DE, Nguyen HT, Kahn LS (2010). Bipolar disorder and metabolic syndrome: an international perspective. J. Affect. Disord. (Comparative Study Review) 126(3): 366-387

Mclntyre RS, McCann S, Kennedy SH, Mancini DA, Srinivasan J (2003). Valproate, bipolar disorder and PCOS. Bipol. Disord. 5(1): 28-35

McIntyre RS, Powell AM, Kaidanovich-Beilin O, Soczynska JK, Alsuwaidan M, Woldeyohanness H (2013). The neuroprotective effects of GLP-I: possible treatments for cognitive deficits in individuals with mood disorder. Behav. Brain Res. 237: 164-71

Mclntyre RS, Rasgon NL, Kemp DE, Nguyen HT, Law CW, Taylor VT (2009). Metabolic syndrome and MDD, co-occurrence and pathophysiological overlap. Curr. Diabet. Rep. 9(1): 51-59

Mclntyre RS, Soczynska JK, Konarski JZ, Woldeyohannes HO, Law CW, Miranda $\mathrm{H}(2007)$. Should depression syndromes be reclassified as 'metabolic syndrome II'? Ann. Clin. Psychiatr. 19940: 257-64

McKernan DP, Dennison U, Gaszner G, Cryan JF, Dinan TG (2011). Enhanced peripheral toll-like receptor responses in psychosis: further evidence of a pro-inflammatory phenotype. Transl. Psychiatr. 1.e36 doi: 10.1038/tp.2011.37

Meares GP, Mines MA, Beurei E, Eom T-Y, Song L, Zmijewska AA (2012). Glycogen synthase kinase-3 regulates ER stress-induced CHOP expression in neuronal cells. Expt. Cell Res. 317(11): 16211628

Melis M, Carla S, Fattore L, Tolu S, Yasar S, Goldberg SR (2011). PPAR alpha modulates dopamine cell activity through nicotinic receptors. Biol. Psychiatr. 68(3): 2656-2664

Melis M, Scheggi S, Carta G, Madeddu C, Lecca S, Luchicchi A (2013). PPAR alpha regulates cholinergic-deriven activity of midbrain dopamine neurons via a novel mechanism involving alpha 7 nicotinic acetylcholine receptors. J. Neurosci. 33(14): 6203-6211 
Mellios K, Huang H-S, Baker SP, Galdzicka M, Ginns E, Abraham S (2009). Molecular determinants of dysfunctional GABAergic gene expression in the prefrontal cortex of subjects with schizophrenia. Biol. Rep. 65(12): 1006-1014

Merikangas KR, Gelemter CS (1990). Comorbidity for alcoholism and depression. Psychiatr. Clin. North. America. 13(4): 613-632

Merikangas KR, Herrell R, Swendsen J, Rosslen W, Ajdacic-Gross V, Angst $J$ (2008). Specificity of bipolar spectrum conditions in the comorbidity of mood and substance abuse disorders. Arch. Gen. Psychiatr. 65(1): 47-52

Mielke JG, Taghibiglou C, Wang YT (2006). Endogenous insulin signalling protects cultured neuron from oxygen-glucose deprivation-induced cell death. Neurosci. 143(1): 165-175

Mikati MA, Abi-Habib RJ, El Sabban ME, Dbaibo GS, Kurdi RM, Kobeissi M (2003). Hippocampal programmed cell death and status epilepticus: evidence for NMDA-receptor and ceramide-mediated mechanisms. Epilepsi. 44(3): 282-291

Milhaylova MM, Vasquez DS, Ravnskjaer K, Denechaud P-D, Yu RT, Alvarez JG (2011). Class II histone deacetylases are hormoneactivated regulators of FOXO and mammalian glucose homeostasis. Cell. 145(4): 607-621

Mohan V, Seedat YK, Pradeepa R (2013). The rising burden of diabetes and hypertension in South-East Asian and African regions: Need for effective strategies for prevention and control in Primary Health Care Settings. Intern. J. Hypertens. 2013 Article ID 409083 http://dx.doi.org/10.1155/2013/409083

Moien-Afshari F, Tellez-Zenteno JF (2009). Occipital seizures induced by hyperglycaemia: a case report and review of literature. Eur. J. Epilep. 18(5): 382-385

Moller DE (2000). Potential role of TNF-alpha in the pathogenesis of insulin resistance and type 2 diabetes. Trend. Endocrinol. Metab. 11: $212-217$

Moller DE (2001). New drug targets for type 2 diabetes mellitus and the metabolic syndrome. Nat. 414: 821-827

Moran C, Sanz-Rodriguez A, Jimenez-Pacheco A, Martinez-Villareal J, McKiernan RC, Jimenez-Mateos EM (2013). Bmf upregulation through the AMPK-pathway may protect the brain from seizureinduced cell death. Cell Death Dis. 4.e606 doi 10.38/cddis.2013.136

Morizane Y, Thanos A, Takeuchi K, Murakami Y, Kayama M, Trichonas G (2011). AMP-activated kinase suppresses MM-9 expression in mouse embryonic fibroblasts. J. Biol. Chem. 286: 16030-16038

Morreira PI, Carvalho C, Zhu X, Smith MA, Pery G (2010). Mitochondrial dysfunction is a trigger of Alzheimer's disease pathophysiology. BBA-Mol. Bas. Dis. 1802(1): 2-10

Morris MS (2003). Homocysteine and Alzheimer's disease. Lanc. Neurol. 2(7): 425-428

Movsessian P (2005). Neuropharmacology of theophylline induced stuttering: the role of dopamine, adenosine and GABA. Med. Hypoth. 64(2): 290-297

Mulherin AJ (2011). Mechanisms underlying metformin-induced secretion of GLP-I from the intestinal L-cells. Post-Graduate Thesis Retrieved from www.utoronto.ca

Muraki I (2001): Behavioral and neurochemical study on the mechanisms of the anxiolytic effect of a selective serotonin reuptake inhibitor, a selective serotonin $\mathrm{I}_{\mathrm{A}}$ agonist and lithium carbonate. Hokkaido igaku zasshi (Japanese) Hokkaido J. Med. Sci. 76(2): 57 70

Murashima YL, Yoshi M, Suzuki J (2000). Role of nitric oxide in epileptogenesis of EL mice. Epileps. 41(6): S195-9

Nagai $Y$, Yonemitsu S, Erion DM, Iwasaki T, Stark R, Weisman D (2009). The role of PGC-I $\beta$ in the pathogenesis of fructose-induced insulin resistance. Cell Metab. 9(3): 252-264

Naidoo N, Davis JG, Zhu J, Yabumoto M, Singletery K, Brown M (2014). Aging and sleep deprivation induce the unfolded protein response in the pancreas: implications for metabolism. Ag. Cell. 13(1): 131-141

Najjar S, Pearlman DM, Alper K, Najjar A, Devinsky O (2013). Neuroinflammation and psychiatric illness. J. Neuroinflamm. doi: 10.1186/1742-2099-10-43

Napoli C, Infante T, Casamassimi A (2011). Maternal-fetal epigenetic interactions in the beginning of cardiovascular damage. $\mathrm{J}$. Cardiovasc. Res. http://dx.doi.org.10.1093/cvr201
Nasser MI, Shupeng L, Kim MO (2009). Maternal epileptic seizure induced by PTZ: apoptotic neurodegeneration and decreased $\mathrm{GABA}_{\mathrm{B}}$ receptor expression in prenatal rat brain. Mol. Br. 2: 20 doi: 10.1186/1756-6606-2-20

Neary JT, Kang Y (2006). P2 purinergic receptors signal to GSK-3 beta in astrocytes. J. Neurosci. Res. 84(3): 515-24

Neasta J, Hamida SB, Yowell Q, Camicella S, Ron D (2010). Role for mTOR complex I signalling in neuroadaptation underlying alcoholrelated disorders. PNAS. US. 107(46): 20093-20098

Nelson KK, Melendez JA (2004). Mitochondrial redox control of MMPs. Free Rad. Biol. Med. 37(6): 768-84

Nemeroff CB, Lieberman JA, Weider PJ, Harvey PD, Newcomer JW, Schatzberg AF (2005). From clinical research to clinical practice: a 4-year review of ziprasidone. CNS Spectr. 10(11 suppl 17): 1-20

Nessler E, Barrot SM, Eisch A, Gold E, Monteggia L (2002). Neurobiology of depression. Neuron. 34: 13-25

Nguyen T-P, Caberlotto L, Morine MJ, Priami C (2014). Network analysis of neurodegenerative diseases highlights a role of Toll-like receptor signalling. BioMed. Res. Intern. Art ID: $686505 \mathrm{dx}$. Doi.org/10.1155/2014/686505

Nichols CD (2009). Serotonin 5HTRA receptor function as a contributing factor to both neuropsychiatric and cardiometabolic diseases. Cardiovasc. Psychiatr. Neurol. 2009: 475108 doi $10.1155 / 2009 / 475108$

Nicolli T, Partridge O (2012). Ageing as a risk factor for disease. Curr Biol. 22(17): R741-R752 doi: 10.1016/jcub.2012.07.024

Nikoulina SE, Ciaraldi TP, Mudaliar S, Mohideen P, Carter I, Henry RR (2000). Potential role of GSK-3 in skeletal muscle insulin resistance of T2DM. Diabet. 49(2): 263-277

Nisoli E, Clementi E, Carruba MO, Moncada S (2007). Defective mitochondrial biogenesis: A hallmark of the high cardiovascular risk in the metabolic syndrome. Circ. Res. 100: 795-806

Nisoli E, Clementi E, Paolucci C, Cozzi V, Tonello C, Sciorati C (2003). Mitochondrial biogenesis in mammals: the role of endogenous nitric oxide. Sci. 299(5608): 896-9

Nisoli E, Tonello C, Cardile A, Cozzi V, Bracale R, Tedesco L (2005). Calorie restriction promotes mitochondrial biogenesis by inducing the expression of eNOS. Sci. 310(5746): 314-317

Norenberg W, Sobottka H, Hempel C, Plotz T, Fischer W, Schmatzing $\mathrm{G}$ (2012). Positive allosteric modulation by ivermectin of human but not murine P2X7 receptors. BJP. 167(1): 48-66

Nousen EK, Franco JG, Sullivan EL (2013). Unraveling the mechanisms responsible for the co-morbidity between metabolic syndrome and mental health disorders. Neuroendocrinol. 98(4): 254-266

Novgorodov SA, Gudz TI (2011). Ceramide and mitochondria in ischaemic brain injury. Int. J. Biochem. Mol. Biol. 2(4): 347-61

O'Callaghan F, Roopra A (2014). Metformin in tuberous sclerosis complex. Retrieved from http://neuro.wisc.edu

O'Donnell KJ, Janssen A, Freeman L, Glover V (2011). Maternal prenatal anxiety and downregulation of placental 11B-HSD2. Psychoneuroendocrinol. 37(6): 818-826

O'Sullivan S, Medina C, Ledwidge M, Radomski MW, Gilmer JF (2014). Nitric oxide-MMP-9 interactions: Biological and pharmacological significance. Biochim. Biophys. Acta (BBA)-Mol. Cell Res. 1843(3): 603-617

Ogden CA, Rich ME, Schork NJ, Paulus MP, Geyer MA, Lohr JB (2004). Candidate genes, pathways and mechanisms for bipolar (manic-depressive) and related disorders: an expanded convergent functional genomics approach. Mol. Psychiatr. 9(11): 1007-1029

Oh GS, Pae JM, Lee BS, Kim BN, Kim JM, Kim HR (2006). Hydrogen sulphide inhibits nitric oxide production and NF-kappa B via heme oxygenase- I expression in RAW 264.7 macrophages stimulated with lipopolysaccharide. Free Radic. Biol. Med. 41(1): 106-119

Oliveira J, Busson M, Etain B, Jamain S, Hamdani N, Boukouaci W (2014). Polymorphism of Toll-like receptor 4 gene in bipolar disorder. J. Affect. Disord. 152-154: 395-401

Olubunmi AO (2006). Epilepsy in Nigeria-a review of aetiology, epidemiology and management. Benin J. Post-Grad. Med. 8(1) www.ajol.info.

Omar HR, El-Khabiry E, Vaughan S (2012). Seizure as the first presentation of diabetes mellitus. Therapeut. Adv. Endocrinol. Metab. 3(5): 175-177 
Onken B, Driscoll M (2010). Metformin induces a dietary restriction-like state and the oxidation stress response to extend $\mathrm{C}$. elegans healthspan via AMPK, LKBI and SKNI. PLoS One 5(1): e8758 doi: 10.1371/journal pone.0008758

Orellana D, Quintanilla RA, Gonzalez-Billauli C, Maccioni RB (2005). Role of the JAKs-STATs pathway in the intracellular calcium changes induced by interleukin-6 in hippocampal neurons. Neurotox. Res. 8(3-4): 295-304

Oriaifo SE, Oriaifo N, Omogbai EKI (2015). Metformin and calorie restriction modulate gene-environment interaction to prevent premature senescence. IRJPP. 6(1): 8-20

Oriaifo SE, Oriaifo N, Omogbai EKI, Egbeifo J (2013). Metformin prevents progression of impaired fasting plasma glucose and CIN I cervical dysplasia: a case report and literature review. Intern. Res. J. Pharm. Pharmacol. 3(8): 112-115

Oriaifo SE, Oriaifo NI, Omogbai EKI (2014). Metformin lowers Creactive protein levels and improves the modified brief pain inventory scores in a woman with endometriosis-associated chronic pelvic pain: a case report and literature review. Intern. J. Pharmaceut. Develop. Technol. 4(2): 79-85

Oriaifo, SEO (2001). Effect of cannabis on blood cholesterol. West Afr. J.Pharmacol. Drug Res. 18(1-2): Proceedings of the XXVIIIth annual conference of the WASP, 23-27-10-2001, Uniben. Nigeria. Abstract: Page 48

Ortega F, Peres-Sen R, Delicado EG, Miras-Portugal MJ (2009). P2x7 nucleotide receptor is coupled to GSK-3 inhibition and neuroprotection in cerebellar granule cells. Neurotox. Res. 15(3): 193-204

Ortega F, Perez-Sen R, Morente V, Delicado EG, Miras-Portugal MT (2010). P2X7, NMDA and BDNF receptors converge on GSK-3 phosphorylation and cooperate to promote survival in cerebellar granule neurons. Cell. Mol. Lif. Sci. 67(10): 1723-1733

Ortinau S, Laube B, Zimmermann H (2003). ATP inhibits NMDA receptors after heterologous expression and in cultured hippocampal neurons and attenuates NMDA-mediated neurotoxicity. J. Neurosci. 23: 4996-5003

Osher Y, Sela BA, Levine J, Belmaker RH (2004). Elevated homocysteine levels in euthymic bipolar disorder patients showing functional deterioration. Bipol. Disord. 6(1): 82-6

Ostrow D, Halaris A, Dysken S, DeMet E, Harrow M, Davis J (1984). State dependence of noradrenergic activity in rapidly cycling bipolar patients. J. Clin. Psychiatr. 45(7): 306-309

Osuntokun BO, Adeuja AO, Nottidge VA, Bademosi O, Olumide A, Ige O (1987). Prevalence of the epilepsies in Nigerian Africans: A community-based study. Epileps. 28(3): 272-279

Ouyang J, Parakhia RA, Ochs RS (2011). Metformin activates AMP kinase through inhibition of AMP deaminase. J. Biol. Chem. 286: 111

Pae CU, Lee KU, Han H (2004). Tumor necrosis factor alpha geneG308 polymorphism associated with bipolar disorder in the Korean population. Psychiatr. Res. 125(1): 65-68

Paintlia AS, Paintlia MK, Mohan S, Singh AK, Singh I (2013). AMPactivated protein kinase signalling protects oligodendrocytes that restore CNS functions in an experimental autoimmune encephalomyelitis model. Am. J. Pathol. 183(2): 526-541

Paiva M, Riksen NP, Davidson SM, Hausenloy D, Monteiro P, Goncalves L (2009). Metformin prevents myocardial reperfusion injury by activating the adenosine receptor. J. Cardiovasc. Pharmacol. 53(5): 373-8

Palma BD, Hipolide DC, Tufik S (2009). Effects on prolactin secretion and binding to dopaminergic receptors in sleep-deprived lupusprone mice. Braz. J. Med. Biol. Res. 42(3): 299-304

Pandey SC, Roy A, Zhang H, Hu T (2004). Partial deletion of the cAMP response element binding protein gene promotes alcohol-drinking behaviour. J. Neurosc. 24(21): 5022-30

Papiol S, Molina V, Desco M, Rosa S, Sanz J, Palomo T (2008). Gray matter deficits in bipolar disorder are associated with genetic variability at interleukin-I beta gene (2q13). J. Gen. Br. Behav. 7(7): 796-801

Papiol S, Rosa A, Gutie'rrez B (2004). Interleukin-I cluster is associated with genetic risk for schizophrenia and bipolar disorder. J. Med. Gen. 41(3): 219-223
Parisi P, Piccioli M, Villa MP, Butoinelli C, Trenite D (2008). Hypothesis on neurophysiopathological mechanisms linking epilepsy and headache. Med. Hypoth. 70(6): 1150-1154

Parkitna JP, Obara I, Wawrzczak-Bargielo A, Makuch W, Przewlocka B, Przewlocki R (2006). Effects of GSK-3 beta and cyclin-dependent kinase inhibitors on morphine-induced analgesia and tolerance in rats. JPET. 319(2): 832-9

Patel DK, Prasad SK, Kumar R, Hemalatha S (2012). An overview on anti-diabetic plants having insulin-mimetic property. Asian Pac. J. Trop. Biomed. 2(4): 320-330

Patel RP, Levonen A-L, Crawford JH, Darley-Usmar VM (2000). Mechanisms of the pro- and anti-oxidant actions of nitric oxide in atherosclerosis. Cardiovasc. Res. 47: 465-474

Paulmann N, Grohmann M, Voigt JP, Bert B, Vowinckel J, Bader M (2009). Intracellular serotonin modulates insulin secretion from pancreatic $\beta$-cells by protein serotonylation. PLoS Biol. $7(10)$ : e1000229

Pazos MR, Mohammed N, Lafuente H, Santos M, Martinez Pinilla F, Moreno E (2013). Mechanism of cannabidiol neuroprotection in hypoxic-ischaemic newbornpigs: role of $5 \mathrm{HT}(1 \mathrm{~A})$ and $\mathrm{CB} 2$ receptors. Neuropharmacol. 71: 282-91

Peana AT, Muggironi G, Calvisi G, Enrico P, Nieddu MM, Boatto G (2010). L-cysteine reduces oral ethanol self-administration and reinstatement of ethanol-drinking behaviour in rats. Pharmacol. Biochem. Behav. 94(3): 431-437

Penner EA, Buettner H, Mittleman MA (2013). The impact of marijuana use on glucose, insulin, and insulin resistance among US adults. Am. J. Med. 126(7): 583-589

Perez-Revuelta BI, Hettich M,Ciociaro A, Rotermund C, Kahle PJ, Krauss S (2014). Metformin lower Ser-129 phosphorylated alphasynuclein levels via mTOR dependent phosphatase 2A activation. Cell Death Dis. 5(5): 10: 10.1038/cddsis.2014.175

Perl A (2015). mTOR activation is a biomarker and central pathway to disorders, cancer, obesity, and aging. ANYAS. US. doi:10.1111/nyas. 12756

Persaud S, Muller D, Belin VD, Kitson-Mylona I, Asare-Anane H, Papadimitriou A (2007). The role of arachidonic and its metabolites in insulin secretion from human islets of Langerhans. Diabet. 56(1): 197-203

Phelps JR, Siemers SV, El-Mallakh RS (2013). The ketogenic diet for type II bipolar disorder. Neurocas. 19(5): 423-5

Phillips JA (2005). Tracking down the footprints of bipolar disorder. Retrieved from www.csa.com

Pinacho R, Villalmanzo N, Lalonde J, Haro JM, Meana JJ, Gill G (2011). The transcription factor SP4 is reduced in post-mortem cerebellum of bipolar disorder subjects: control by depolarisation and lithium. Bipol. Disord. 13: 474-485

Piomelli D, Pilo C, Giros B, Sokoloff P, Martres M-P, Schwarz J-C (1991). Dopamine activation of the arachidonic acid cascade as a basis for DI/D2 receptor synergism. Nat. 353: 164-167

Pitt J, Thorner M, Brautigan D, Larner J, Klein WL (2013). Protection against the synaptic targeting and toxicity of Alzheimer's-associated $A \beta$ oligomers by insulin mimetic chiro-inositols. FASEB J. 27(1): 199-207

Piwkowska A, Rogacka D, Jankowski M, Angielski S (2013). Metformin reduces $\mathrm{NAD}(\mathrm{P}) \mathrm{H}$ oxidase activity in mouse cultured podocytes through purinergic dependent mechanism by increasing extracellular ATP concentration. Acta Biochim. Polon. 60(4): 607612

Popoli P, Ferre' S, Pezzota A, Reggio R, de Carrolis AS, Fuxe IC (1996). Stimulation of adenosine Al receptors prevents the EEG arousal due to dopamine DI receptor activation in rabbits. Eur. J. Pharmacol. 305(1): 123-126

Popova NK, Vishnivetskaya GB, Ivanova EA, Skrinskaya JA, Seif I (2000). Altered behaviour and alcohol tolerance in transgenic mice lacking $\mathrm{MAO}_{\mathrm{A}}$ : a comparison with effects of MAO inhibitor clorgyline. Pharmacol. Biochem. Behav. 67(4): 719-727

Porta N, Vallee L, Le Cointe C, Staels B, Bordet R, Auvin S (2008). Fenifibrate, a PPAR alpha agonist, exerts anti-convulsive properties. Epileps. 50(4): 943-948.

Potter WB, O'Riordan KJ, Barnett D, Osting SM, Wagoner M, Burger C, Roopra A (2010). Metabolic regulation of neuronal plasticity by 
the energy sensor, AMPK. PLoS One 5: e8996

Prickaets J, Moechars D, Crins K, Lenaerts I, van Craenendonck H, Goris I (2006). Transgenic mice overexpressing glycogen synthase kinase-3 beta: a putative model of hyperactivity and mania. J. Neurosci. 26(35): 9022-9

Priestley RS, Nickolls SH, Alexander SPH, Kendall DA (2015). A potential role for cannabinoid receptors in the therapeutic action of fenofibrate. FASEB J. 29(4): 1446- 1455

Prossin AR, Zalcman SS, Evans SJ, Mclnnis MG, Ellingrod VL (2013). A pilot study investigating tumor necrosis factor-alpha as a potential intervening variable of atypical antipsychotic-associated metabolic syndrome in bipolar disorder. Therapeut. Drug Monit. 35(2): 194202

Przegalinski E, Filip M, Frankowska M, Zaniewska M, Papla I (2005). Effect of CP154,526, a CRF receptor antagonist, on behaviour response to cocaine in rats. Neuropept. 39(5): 525-533

Qatanani M, Lazar MA (2007). Mechanisms of obesity associated insulin resistance: many choices on the menu. Gen. Develop. 2: 1443-1453

Qi D, Rodrigues B (2007). Glucocorticoids produce whole body insulin resistance with changes in cardiac metabolism. Am. J. Physiol. Endocrinol. Metab. 292(3): E654-E667

Qi Y, Xu Z, Zhu Q, Thomas C, Kumar R, Feng H (2013). Myocardial loss of IRSI and IRS2 causes heart failure and is controlled by p38 MAPK during insulin resistance. Diabet. 62(11): 3887-3900

Qin W, Chachick M, Lane M, Roth G, Bryant M, de Cabo R (2006 (a)). $\mathrm{CR}$ attenuates Alzheimer's disease type brain amyloidosis in squirrel monkeys (Saimiri sciureus). J. Alzh. Dis. 10(4): 417-22

Qin W, Haroutunian V, Katsel P, Cardozo CP, Ho L, Buxbaum JD (2009). PGC-I alpha expression decreases in the AD disease brain as a function of dementia. Arch. Neurol. 66(3): 352-361

Qin W, Yang T, Ho L, Zhao Z, Wang J, Chen L (2006 (b)). Neuronal SIRTI activation as a novel mechanism underlying the prevention of AD amyloid neuropathology by CR. J. Biol. Chem. 281(3): 2174521754

Qin W, Zhao W, Ito L, Wang J, Walsh K, Gandy S (2008). Regulation of forkhead transcription factor FOXO3a contributes to calorie restriction-induced prevention of AD-type amyloid neuropathy and spatial memory deterioration. NYAS. US. 1147: 335-347

Qiu Y, Nguyen KD, Odegaard JI, Cui X, Tian X, Locksley RM, Palmiter RD, Chawla A (2014). Eosinophils and type 2 cytokine signalling in macrophages orchestrate development of functional beige fat. Cell. 157(6) 1292-1308

Qui B, Shi X, Wong ET, Lim J, Bezzi M, Low D (2014). NUCKS is a positive transcriptional regulator of insulin signalling. Cell Rep. 7(6): 1876-1886

Raeder MB, Femo J, Glambek M, Stansberg C, Steen VM (2006). Antidepressant drugs activate SREBP and upregulate cholesterol and fatty acid biosynthesis in human glial cells. Neurosci. Lett. 395(3): 185-190

Ramadan E, Basselin M, Taha A, Chen Y, Chang L, Chen M, Rapoport $S$ (2011). Chronic valproate treatment blocks D2- like receptormediated brain signalling via arachidonic acid in rats. Neuropharmacol. 61(8): 1256-64

Rao AA, Sridhar GR, Das UN (2007). Elevated butyrylcholinesterase and acetylcholinesterase may predict the development of type $2 \mathrm{DM}$ and AD. Med. Hypoth. 69: 1272-1276

Rao RR, Long JZ, White JP, Svensson KJ, Lou J, Lokurkar I (2014). Meteorin-like is a hormone that regulates immune-adipose interaction to increase beige fat thermogenesis. Cell. 157(6): 12791291

Rasbach KA, Funk JA, Jayavelu T, Green PT, Schnellmann RG (2010). 5-Hydroxytryptamine receptor stimulation of mitochondrial biogenesis. JPET. 332(2): 632-639

Raza M, Pal S, Rafiq A, and De Lorenzo RJ (2001). Long-term alteration of calcium homeostatic mechanisms in the pilocarpine model of temporal lobe epilepsy. Br. Res. 903:1-12.

Renna M, Jimenez-Sanchez M, Sarkar S, Rubinstein DC (2010). Chemical inducers of autophagy that enhance the clearance of mutant proteins in neurodegenerative disorders. J. Biol. Chem. 285: 11061-11067
Renshaw PF, Lafer B, Babb SM (1997). Brain choline levels in depression and response to fluoxetine treatment: an in vivo proton magnetic resonance spectroscopy study. Biol. Chem. 41: 837-843

Renthal W, Kumar A, Xiao G, Wilkinso0n M, Covington HC $\left(3^{\text {rd }}\right)$, Maze I (2009). Genome-wide analysis of chromatin regulation by cocaine reveals a role for sirtuins. Neuron. 62(3): 335-348

Riddle MC, McKenna MC, Yoon YJ, Pattwell SS, Santos PM, Cassey BJ (2013). Calorie restriction enhances fear extinction learning in mice. Neuropsychopharmacol. 38(6): 930-937

Risby EDE, Hsiao JK, Manji HK, Bitran J, Moses F, Zhou DF (1991). The mechanism of action of lithium. II. Effects on adenylate cyclase activity and beta-adrenergic receptor binding in normal subjects. Arch. Gen. Psychiatr. 48(6): 513-24

Rizzo LB, Costa G, Mansur RB, Swardfager W, Belangero SI, GrassiOliveira R (2014). The theory of bipolar disorder as an illness of accelerated aging: Implications for clinical care and research. Neurosci. Behav. Rev. 42: 157-169

Robertson RP, Harmon J, Tran PO, Poitout V (2004). Beta-cell glucose toxicity, lipotoxicity, and chronic oxidative stress in type $2 \mathrm{DM}$. Diabet. 53(1): S119-24

Robison AJ, Nestler EJ (2011). Transcriptional and epigenetic mechanisms of addiction. Nat. Rev. Neurosc. 12: 623-637

Rogenold WT, Thapar RK, Marano C, Gavimeni S, Kondapavuluru PV (2002). Increased prevalence of type 2 diabetes mellitus among psychiatric inpatients with bipolar I affective and schizoaffective disorders independent of psychotropic drug use. J. Affect. Disord. 70(1): 19-26

Roger T, Lugrin J, Le Roy D, Goy G, Mombelli M, Koessler T (2010). Histone deacetylase inhibitors impair innate immune responses to Toll-like receptor agonists and to infection. Blood (bloodjournal.org) dx.doi.org/10.1182/blood-2010-05-284711

Rong $\mathrm{H}$, Liu TB, Yang KJ, Yang $\mathrm{HL}$, Wu DH, Liao $\mathrm{P}$, Hong $\mathrm{F}$, Yang $\mathrm{H}$, Wan F, Ye XY (2011). MicroRNA-134 plasma levels before and after treatment for bipolar mania. J. Psychiatr. Res. 45: 92-95

Rosta Klara (2009). The role of Na/K-ATPase in the pathomechanisms of diabetes mellitus. PH.D semmelweiss.hu/mwp./ph.d (Doctor Dissertation)

Rudic RD (2009). Time is the essence: vascular implications of the circadian clock. Circ. 120: 1714-1721

Rush AJ, Giles DE, Schlesser MA, Orsulak PJ, Parker CR Jr, Weissenburger JR (1996). The dexamethasone suppression test in patients with mood disorders. J. Clin. Investig. 57(10): 470-84

Russo S, Wilkinson MB, Mazei-Robison MS, Dietz D, Maze I, Krishnan $V$ (2009). NF-kappa B signalling regulates neuronal morphology and cocaine reward. J. Neurosci. 29(11): 3529-3537

Ryan D, Drysdale AJ, Lafourcade C, Pertwee RG, Platt B (2009). Cannabidiol targets mitochondria to regulate intracellular $\mathrm{Ca}^{2+}$ levels. J. Neurosci. 29(7): 2053-2063

Rybakowski JK (2009). Matrix metalloproteinase-9 (MMP9)-a mediating enzyme in cardiovascular disease, cancer, and neuropsychiatric disorders. Cardiovasc. Psychiatr. Neurol. 2009: 904836 dx.doi.org/10.1155/2009/904836

Rybakowski JK, Remlinger-Molenda A, Czech-Kucharska A, Wojcicka M, Michalak M, Losy J (2013). Increased serum MMP-9 levels in young patients during bipolar depression. J. Affect. Disord. 146(2): 286-289

Saarelainen T, Hendolin P, Lucas G, Kaponen G, Sairanen M, McDonald E (2003). Activation of the TrkB neurotrophin receptor is induced by antidepressant drugs and is required for antidepressantinduced behavioural effects. J. Neurosci. 23: 349-357

Sag D, Carling D, Stout RD, Suttles J (2008). AMPK promotes macrophage polarisation to an anti-inflammatory functional phenotype. J. Immunol. 181(12): 8633-8641

Saia G, Lalonde J, Sun X, Ramos B, Gill G (2014). Phosphorylation of the transcription fsctor SP4 is reduced by NMDA receptor signalling. J. Neurochem. 129: 743-752

Sakurai H, Adachi Y (2005). The pharmacology of the insulinomimetic effect of zinc complexes. Biometab. 18(4): 319-323

Salvadore G, Viale Cl, Luckenbaugh DA, Zanatto VC, Portela LV, Souza DO (2010). Increased uric acid levels in drug-naïve subjects with bipolar disorder during a first manic episode. Prog. 
Neuropsychopharmacol. Biol. Psychiatr. 34(6): 819-821

Samra JS, Clark ML, Humphreys SM, MacDonald IA, Bannister PA, Frayn KN (1998). Effects of physiological hypercortisolaemia on the regulation of lipolysis in subcutaneous adipose tissue. J. Clin. Endocrinol. 83(2): 626-31

Samuel T, Liu Z-L, Wang A, Beddors SA, Geisler JG, Kahn M, Zhang KM, Monia MP, Bhanot S, Shulman GI (2007). Inhibition of protein kinase $C \varepsilon$ prevent hepatic insulin resistanse in non-alcoholic fatty liver disease. J. Clin. Invest. 117(3): 739-745

Sarfstein R, Friedman Y, Attias-Geva Z, Fishman A, Bruchim I, Werner $H$ (2013). Metformin downregulates the insulin/IGF-I signalling payhway, and inhibits uterine serous carcinoma (USC) cells proliferation and migration in P53-dependent or independent manner. PLoS One 8(4): e6157 doi: 10.1371/journal.pone.0061537

Sarkaki A, Chehardacheric SV, Farbood Y, Mansouni SMT, Naghizadeh $B$, Basirian E (2012). Effects of fresh, aged and cooked garlic extracts on short- and long-term memory in diabetic rats. Avicenna J. Phytomed. 3(1): 45-55

Sartori C, Scherrer U (1999). Insulin, nitric oxide and the sympathetic nervous system: at the crossroads of metabolic and cardiovascular regulation. J. Hypertens. 17(11): 1517-1525

Sato A, Brace CS, Rensing N, Cliften P, Woznian DF, Herzog ED (2013). Sirt I extends lifespan and delays aging in mice through the regulation of NK2 homeobox I in the DMH and LH. Cell Metabolism 16(3): 416-430

Schauwecke PE (2012). The effects of glycaemic control on seizures and seizure-induced excitotoxic cell death. BMC Neurosci.13: 94 doi: 10.1186/1471-2202-13-94

Schenkel LC, Bragath JA, Torres CM, Martin KC, Gus-Marino G, Leistner Segal $S$ (2011). Serotonin transporter gene (5HTT) polymorphisms and temporal lobe epilepsy. Epileps. Res. 95(1-2): 152-157

Schwarz E, Prabakaran S, Whitfield P, Major H, Leweke FM, Koethe D (2008). High throughput lipidomic profiling of schizophrenic and bipolar disorder brain tissue reveal alteration of free fatty acids, phosphatidylcholines and ceramides. J. Proteom. Res. 7(10): 42664277

Schwechter EM, Veliskova J, Velisek L (2003). Correlation between extracellular glucose and seizure susceptibility in adult rats. Ann. Neurol. 53(1): 91-101

Schweiger U, Broocks A, Tuschi RJ, Pirke KM (1989). Serotonin turnover in rat brain during semi-starvation with high-protein and highcarbohydrate diets. J. Neur. Transm. 77(2-3): 131

Selley E, Kun S, Andras-Szijart I, Laczy B, Kovacs T, Fulop F (2014). Exenatide induces vasodilation increasing hydrogen sulphide, carbon monoxide and nitric oxide production. Cardiovasc. Diabetol. 13: 69

Shalam M, Harish MS, Farhana S (2006). Prevention of dexamethasone-and fructose-induced insulin resistance in rats by $\mathrm{SH}-\mathrm{OID}$, a herbal preparation. Indian J. Pharmacol. 38(6): 419-422

Shang Y, Yang X, Zhang R, Zou H, Zhao R (2010). Low aminoacid affects expression of $11 \beta$-HSD2 in BeWo cells through leptinactivated JAK-STAT and MAPK pathways. Amino Acids. 42(5): 1879-1887

Sharma A (2012). Genome-wide expression analysis in epilepsy: a synthetic review. Curr. Top. Med. Chem. 12(9): 1008-1032

Sharma S, Zhuang Y, Gomez-Pinilla F (2014). High fat diet transition reduces brain DHA levels associated with altered brain plasticity and behaviour. Scient. Rep. 2(431) doi: 10. 1038/srep00431

Shaw RJ (2009). LKB I and AMPK control of mTOR signalling and growth. Acta Physiol. (Oxford) 196(1): 65-80

Shen $\mathrm{H}-\mathrm{Y}$, Singer P, Lytle N, Wei CJ, Lan J-Q, Williams-Karnesky RL, Chen J-F (2014). Adenosine augmentation ameliorates psychotic and cognitive endophenotypes of schizophrenia. J. Clin. Investigat. doi: $10.1172 / \mathrm{JCl} 62378$

Shen K-Z, Yakhnitsa V, Munhall AC, Johason SW (2014). AMP kinase regulates K-ATP currents evoked by NMDA receptor stimuli in rat subthalamic neurons. Neurosci. 274: 138-112

Shirazi RH, Dickson SL, Skibicka KP (2013). Gut peptide GLP-I and its analogue, exendin-4, decrease alcohol intake and reward. PLoS One. 8(4): e61965

Shulman GI (2000). Cellular mechanisms of insulin resistance. J. Clin
Investig. 106: 171-176

Silva AP, Lourenco J, Xapelli S, Ferreira R, Kristiansen H, Woldbye DPD (2007). PKC activity blocks neuropeptide Y-mediated inhibition of glutamate release and contributes to excitability of the hippocampus in SE. FASEB J. 21: 671-681

Simon-Szabo L, Kokas M, Mandel J, Ken G, Csale M (2014). Metformin attenuates palmitate-induced endoplasmic reticulum stress, serine phosphorylation of IRS-I and apoptosis in rat insulinoma cells. PLoS ONE. 9(6): e97868. Doi: 10.1371/journal pone. 0097868

Singh RB, Takahashi T, Tokunagh M, Wilczyska A, Kim CJ, De Meester $F$ (2014). Effect of BDNF, in relation to diet and life-style factors, for prevention of neuropsychiatric and vascular diseases and diabetes. The Open Nutraceut. J. 7: 5-14

Sitarc KS, Elliot HR, Karaman BS, Relton C, Chinnery PE, Horvath R (2014). Valproic acid triggers increased mitochondrial biogenesis in POLG-deficient fibroblasts. Mol. Gen. Metab. 112(1): 57-63

Skaper SD, Debetto P, Giusti P (2009). P2X7 receptors in neurological and cardiovascular disorders. Cardiovasc. Psychiatr. Neurol. 2009: Art ID: 86134 doi.org/10.1155/2009/86134

Skaper SD, Giusti P (2009). P2X7 receptors as a transducer in the cooccurrence of neurologic/psychiatric and cardiovascular disorders: a hypothesis. Cardiovasc. Psychiatr. Neurol. 2009: Art ID: 545263 doi: $10.1155 / 2009 / 545265$

Skibicka KP (2013). The central GLP-I: implication for food and drug reward. Fronti. Neurosci. doi:10.3389/fnins.2013.00181

Sklar P, Smoller JW, Fen J (2008). Whole genome association studies of bipolar disorder. Mol. Psychiatr. 13: 558-569

Skov V, Cangemi C, Gram J, Chiristensen MM, Grodum E, Sorensen D (2014). Metformin, but not rosiglitazone, attenuates the increasing plasma levels of a new cardiovascular marker, fibulin-I, in patients with type 2 diabetes mellitus. Diabet. Car. 37(3): 3760-766

Soderlund J, Olsson SK, Samuelsson M, Walther-Jallow L, Johansson C, Erhardt S (2011). Elevation of CSF IL-I beta in bipolar disorder. J. Psychiatr. Neurosci. 36(2): 114-118

Sokoloff P, Le Fall B, Petachon S, Bordet R, Ridray S, Schwartz JC (2001). The dopamine $D_{3}$ receptor and drug addiction. Neurotox. Res. 3(5): 433-41

Solomonia R, Gogichaishvili N, Nozadze M, Lepsveridze E, Dzeladze D, Kiguradze T (2013). Myo-inositol treatment and GABA-A receptor subunit changes after kainite-induced SE. Cell. Mol. Neurobiol. 33(1): 119-27

Solomonia R, Mikautadze E, Nozadze M, Kuchiashvili N, Lepsveridze E, Kiguradze T (2010). Myo-inositol treatment prevents biochemical changes triggered by kainite-induced status epilepticus. Neurosci. Lett. 468(3): 277-81

Sonne SC, Brady KT (2002). Bipolar disorder and alcoholism. Alcoh. Res. Health. 20(2): 103-108

Soraya H, Clanachan AS, Rameshrad M, Mateki-Dizali N, GhaziKhansar M, Garian A (2011). Chronic treatment with metformin suppress toll-like receptor signalling and attenuates dysfunction following myocardial infarction. Eur. J. Pharmacol. 737: 77-84

Stafstrom CE (2003). Light at the end of the "Tunel"? Role of ceramide in seizure-induced programmed cell death. Epileps. Curr. 3(5): 157158

Stein D (2012). Psychiatry and mental health research in South Africa: national priorities in a low and middle income context. Afr. J. Psychiatry. (Johannesburg) 15(6): 427-31

Stellwagen D, Beattie EC, Seo JY, Malenka RC (2005). Differential regulation of AMPA receptor and GABA receptor trafficking by tumor necrosis factor-alpha. J. Neurosci. 25(12): 3219-3228

Straznicky NE, Grima MT, Sari CI, Eikelis N, Lambert EA, Nestu PJ (2012). Neuroadrenergic dysfunction along the diabetic continuum a comparative study in obese metabolic syndrome patients. Diabet. 61(10): 206-256

Suchecki D, Tufik S (2000). Social stability attenuates the stress in the modified multiple platform method for paradoxical sleep deprivation in the rat. Physiol. Behav. 68: 309-316

Suh H-S, Choi S, Khattar P, Choi N, Lee SC (2010). Histone deacetylase inhibitors suppress the expression of inflammatory and innate immune response genes in human microglia and astrocytes. J. Neuroimmun. Pharmacol. 5(4): 521-532

Sun Y, Alexander SPH, Garle MJ, Gibson CL, Hewitt K, Murphy SP 
(2007). Cannabinoid activation of PPAR alpha; novel neuroprotective mechanism. BJP. 152: 734-743

Sutherland C (2011). What are the bona fide GSK-3 substrates? Intern. J. Alzh. Dis. 2011: 505607 dx.doi.org/10.4061/2011/505607

Sutherland C, Leighton IA, Cohen P (1993). Inactivation of GSK-3beta by phosphorylation: new kinase connections in insulin and growthfactor signalling. Biochem. J. 296: 15-19

Sutin K, Cutler RG, Camandola S, Uda M, Feldman NH, Cucca $F$ (2014). Impulsivity is associated with uric acid: evidence from humans and mice. Biol. Psychiatr. 75(1): 31-7

Swann AC, Secunda S, Davis JM, Robins E, Hanin I, Koslow SH, Maas W (1983). CSF monoamine metabolites in mania. Am. J. Psychiatr. 140(4): 396-401

Szabo C (2012). Roles of hydrogen sulphide in the pathogenesis of diabetic mellitus and it complications. Antioxid. Redox. Signal. 17: $68-80$

Taghibiglou C, Martin HG, Lai TW, Cho T, Prasad S, Kojic L (2009). Role of NMDA receptor-dependent activation of SREBPI in excitotoxic neuronal injuries. Nat. Med. 15(12): 1399-1406

Takata F, Dohou S, Matsomoto J, Machida T, Kaneshima S, Matsuo M, Sakaguchi J (2013). Metformin induces upregulation of blood-brainbarrier functions by activating AMPK in rat brain microvascular cells. Biochim. Biophys. Res. Commun. 433(4): 586-590

Talbot K, Wang HY, Kazi H, Han LY, Bakshi KP, Stucky A (2012). Demonstrated brain insulin resistance in $A D$ patients is associated with IGF-I resistance, IRS-I dysregulation and cognitive decline. J. Clin. Investig. 122(4): 1316-38

Tan WQ, Chen G, Jia B, Ye M (2014). Artemisinin inhibits neuroblastoma proliferation through activation of AMPK signalling. Pharmaz. 69(6): 468-72

Tao R, Gong J, Luo X, Zang M, Guo W, Wen R, Luo Z (2010). AMPK exerts dual regulatory effects on the PI3K pathway. J. Mol. Sign. 5: 1

Taylor VH, MacQueen GM (2010). The role of adipokines in understanding the association between obesity and depression. J. Obes. 2010 (2010). Article ID 748048. Dx.doi.org//10.1155/2010/7 48048

Tedesco L, Valerio A, Cervino C, Cardile A, Pagano C, Vetton R (2008). Cannabinoid type I receptor blockade promotes mitochondrial biogenesis through eNOS expression in white adipocytes. Diabet.57(8): 2028-36

Tedesco L, Valero A, Dossena M, Cardile A, Ragai M, Pagano C (2010).Cannabinoid receptor stimulation impairs mitochondrial biogenesis in mouse white adipose tissue, muscle and liver. Diabet. 59(11): 2826- 2836

Tengholm A (2014). Purinergic P2YI receptors take centre stage in autocrine stimulation of human beta cells. Diabetolog. doi: 10.1007/s100/25-014-3392-8

Teocchi MA, Ferreira AED, de Oliveira EP de Luz, Tedeschi $H$ D'Souza-Li L (2013). Hippocampal gene expression dysregulation of Klotho, NF-kappa B and TNF in TLE patients. J. Neuropharmacol. 10. 53 doi: 10.1861/1742-2084-10-53

Theiss AL, Jenkins AK, Okoro NI, Klapproth JM, Merlin D, Sitaraman SV (2009). Prohibitin inhibits TNF-alpha-induced NF-kappa B nuclear translocation via the novel mechanism of decreasing importin alpha 3 expression. Mol. Biol. Cell. 20(20): 4412-27

Thomsen MS, Weyn A, Mikkelsn JD (2011. Hppocampal nicotinin alpha 7 acetylcholine receptor levels in patients with schizophrenia, bipolar disorder or major depressive disorder. Bipol. Disord. 13(78: 701-7

Thomson WM (2013). The physiological roles of placental corticotropnreleasing hormone in pregnancy and childbirth. J. Physiol. Biochem. 69(3): 559-573

Thorn M, Liu JY, Thompson P, Phadke R, Narkiewicz M, Martinian L (2011). Neurofibrillary tangle pathology and Braak Staging in chronic epilepsy in relation to traumatic brain injury and hippocampal sclerosis: a post-mortem study. Brain. 134(10): 29692981

Tilleux S, Hermans E (2007). Neuroinflammation and regulation of glial glutamatergic uptake in neurological disorders. J. Neurosci. Res. 85(10): 2059-2070.

Todora MT, Tandon P, Madore RA, Stafstrom CE, Seyfried TN (2000).
The ketogenic diet inhibits epileptogenesis in EL mice: a genetic model for idiopathic epilepsy. Epileps. 41(8): 933-940

Tonchev AB (2007). Fatty acids as regulators of hippocampal neurogenesis: the case of GPCR 40. Biomed. Rev. 18: 69-73

Tong JF, Yan X, Zhu MJ, Ford SP, Nathanielsz PW (2009). Maternal obesity downregulates myogenesis and beta-catenin signalling in skeletal muscle. Am. J. Physiol. Endocrinol. Metab. 296(4): E917-24

Towler MC, Hardie DG (2007). AMP-activated protein kinase in metabolic control and insulin signalling. Circ. Res. 100: 328-341

Tran POT, Gleason CE, Poitout V, Robertson RP (1999). Prostaglandin E2 mediates inhibition of insulin secretion by interleukin-I $\beta$. J. Biol. Chem. 274: 31245-31248

Tremblay-Mercier J (2012). PPAR alpha agonist: a potential tool for a healthy brain. Intech Pharmacol. 34: 130-148

Treweek JB, Dickerson TJ, Jande KM (2009). Drugs of abuse that mediated advanced glycation end products formation: a chemical link to disease pathology. Acc. Chem. Res. 42(5): 659-669

Trincavelli MR, Daniele S, Ciapparelli A, Dell'Osso MC, Massinetic D, Dell'Osso L, Martini C (2012). Changes in A2A adenosine receptor parameters in patients affected by bipolar disorders: correlation with anti-psychotic dosage and severity of illness. Op. J. Psych. doi: 10.4236/ojpsych.2012.21001

Troncone LR, Ferreira TM, Braz S, Silveiro Filho NN, Tufik S (1988). Reversal of the increase in apomorphine-induced stereotype and aggression in REM sleep deprived-rats by dopamine agonist treatments. Psychopharmacol. (Berl.) 94(1): 79-83

Tsoyi K, Jang HJ, Nizamutdinova IT, Kim YM, Lee YS, Kim HJ (2011). Metformin inhibits HMGBI release in LPS—reated RAW 267.7 cells and increases survival rate of endotoxaemic mice. BJP. 162(7): 1498-1508

Tsuchida A, Yamauchi T, Takekawa S, Hada Y, Ho Y, Maki T (2005). PPAR alpha activation increases adiponectin receptors and reduces obesity-related inflammation in adipose tissue. Diabet. 54(12): 33583370

Tufik S, Lindsey CJ, Carlini EA (1978). Does REM sleep deprivation induce a supersensitivity of dopaminergic receptors in the rat brain? Pharmacol. 16(2): 93-105

Udenze IC, Azinge EC, Adesina PA, Egbuagha E, Onyenekwu C, Ayodele O (2013). The prevalence of metabolic syndrome in persons with type 2 diabetes mellitus at LUTH, Lagos, Nigeria. Repository.unilag.edu.ng

Um JH, Yang S, Yamaki S, Kang H, Viollet B, Foretz M (2007). Activation of AMPK with diabetes drug metformin induces casein kinase-I dependent degradation of clock protein mPer2. J. Biol. Chem. 282(29): 20794-20798

Urabe H, Kojima H, Chen L, Terashima T, Ogawa N, Kataji M (2013). Haematopoietic cells produce BDNF and regulate appetite upon migration to the hypothalamus. Nat. Commun. 4: 1526 (PMID 23443554 doi: $10.1038 /$ ncomms 2536

Valenzuela M, Esler M, Ritchie K, Brodaty H (2012). Antihypertensives for combating dementia? A perspective on candidate molecular mechanisms and population-based prevention. Transl. Psychiatr. 2: e107 doi: $10.1038 / \mathrm{tp} / 2012.28$

Valladolid-Acebes I, Merino R, Principato A, Fole A, Barbas C, Lorenzo MP (2012). High-fat diets induce changes in hippocampal glutamate metabolism and neurotransmission. Am. J. Physiol-Endocrinol. Metab. 302: E396-E402

Van der Borght K, Kohnke R, Goranssen N (2011). Reduced neurogenesis in the rat hippocampus following high fructose consumption. Regulat. Pept. 167(1): 26-30

Varela RB, Valvassori SS, Lopes-Borges J, Fraga DB, Resenda WR, Arena CO (2013). Evaluation of acetylcholiesterase in an animal model of mania induced by D-amphetamine. Psychiatr. Res. 209(2): 229-34

Veldic M, Kdriu B, Maloka E, Agis-Balboa RC, Guidotti A, Davis M (2007). Epigenetic mechanisms expressed in basal ganglia GABAergic neurons differentiate schizophrenia from bipolar disorder. Schizoph. Res. 91(1-3): 51-61

Verduin ML, Tolliver BK, Brady KT (2005). Substance abuse and bipolar disorder. www.medscape.com

Vezzani A, Baram TZ (2007). New roles for IL-I beta in the mechanisms 
of epilepsy. Epileps. Curr. 7(2): 45-50

Vezzani A, Friedman A (2014). Brain inflammation as a biomarker in epilepsy. Biomark. Med. 5(5): 607-614

Vezzani A, Maroso M, Balosso S, Sanchez MA, Bartfai T (2011). IL-I receptor/toll-like receptor signalling in infection, inflammatory stress and neurodegeneration couples hyperexcitability and seizures. $\mathrm{Br}$. Beh. Immunol. 25(7): 1281-1289

Vieira $E$ (2014). The impact of metformin on circadian clock gene. J. Diabet. Metab. Disord. Contr. 1(3): 00016 dx.doi.org/10.15406/jdmdc/2014.01.00016

Vignozzi L, Filippi S, Comeglia P, Cellai I, Morelli A, Raspelli G, Maneschi E (2014). Metformin in vitro and in vivo increases adenosine signalling in rabbit corpora carvernosa. J. Sex. Med. 11(7): 1694-1708

Viviani B, Bartesaghi S, Gardoni F, Vezzani A, Behrens MM, Bartfai T (2003). Interleukin-I $\beta$ enhances NMDA receptor-mediated intracellular calcium increase through activation of the Src family of kinases. J. Neurosci. 23(25): 8692-8700

Volkow ND (2014). Drugs, brains and behaviour: the science of addiction. www.drugabuse.gov

Volkow ND, Fowler JS, Wang GJ, Baler R, Telang F (2009). Imaging dopamine's role in drug abuse and addiction. Neuropharmacol. 56(1): 3-8

Vuksan-Cusa B, Sagud M, Jakovljevic M (2010). C-reactive protein and metabolic syndrome in patients with bipolar disorder compared to patients with schizophrenia. Psychiatr. Danub. 22(2): 275-277

Wahlqvist ML, Lee MS, Chuang SY, Hsu CC, Tsai HN, Yu SH, Chang HY (2012). Increased risk of affective disorders in type 2 diabetes is minimised by slphonylureas and metformin combination: a population-based cohort study. BMC. 10: 150 doi:10.1186/17417015-10-155

Waldbaum S, Patel M (2010). Mitochondrial dysfunction and oxidative stress: a contributory link to acquired epilepsy. J. Bioenerget. Biomembr. 42(6): 449-456

Walker AJ, Kim Y, Price JB, Kale RP, McGillivrey JA, Berk M (2014). Stress, inflammation and cellular vulnerability during early stages of affective disorders: biomarker strategies and opportunities for prevention and intervention. Front. Psychiatr. doi: 10.3389/fpsyt.5212

Wang AY, Lohmann KM, Yang CK, Zimmerman El, Pantazopoulous $\mathrm{H}$, Herrina N (2011). Bipolar disorder type I and schizophrenia are accompanied by decreased density of parvalbumin- and stomatostatin- positive interneurons in the parahippocampal region. Acta Neuropathol. 122(5): 615-626

Wang D, He J, Wu M, Li S, Gao Q, Zeng Q (2015). Artemisinin mimics calorie restriction to trigger mitochondrial biogenesis and compromise telomere shortening in mice. Peer J. 31: 31: e822

Wang D, Wu M, Li S, Gao Q, Zeng Q (2014). Artemisinin mimics calorie restriction to initiate anti-oxidative responses and compromise telomere shortening. Peer J. Rev. Manusc. 10.2976

Wang H, Brown J, Martin M (2011). GSK-3: a point of convergence for the host inflammatory response. Cytok. 53(2): 130-140

Wang J, Gallagher D, De Vito LM, Cancino GI, Tsui D, He L, Keller GM (2012). Metformin activates an atypical PKC-CBP pathway to promote neurogenesis and enhance spatial memory formation. Cell Stem Cell 11(1): 23-35

Wang J, Ho L, Chen L, Zhao Z, Zhao W, Qian X, Humato N, Seror I, Bartholomew S (2007). Valsartan lowers brain beta-amyloid protein levels and improves spatial learning in a mouse model of $A D$. J. Clin. Investigat. 117(1): 3393-402

Wang J, Ono K, Dickstein DL, Ameta-Cruz I, Zhao W, Qian X (2011). Carvedilol as a potential novel agent in the treatment ofAlzheimer's disease. Neurobiol. Aging. 32(12): 2321.

Wang $M$ (2005). The role of glucocorticoid action in the pathophysiology of the metabolic syndrome. Nutri. Metab. 2: 3 doi: 10.1186/17437075-2-3

Wang S, Kaufman R (2012). The impact of the unfolded protein response on human disease. J. Cell Biol. 197(7): 857-867

Wang Z, Leng Y, Tsai LK, Leeds P, Chuang DM (2011). Valproic acid attenuates BBB disruption in a rat model of transient focal cerebral ischaemia: the roles of HDAC and MMP-9 inhibition. J. Cereb. Blood FI. Metab. 31: 152-157
Watkins CC, Sawa A, Pomper MG, (2014). Glia and immune cell signalling in bipolar disorder: insights from neuropharmacology and molecular imaging to clinical application. Transl. Psychiatr. 4 e350 doi: $10.1038 /$ tp.2013.119

Weaver-Mikaere L, Gunn AJ, Mitchell MD, Bennet L, Fraser M (2013). LPS and TNF-alpha modulate AMPA/NMDA receptor subunit expression and induce PGE2 and glutamate release in preterm fetal ovine mixed glial cultures. J. Neuroinflamm. 10: 153 doi: 10.1186/1742-2094-10-152

Weber-Hammer B, Hentschel F, Kniest A, Deuschle M, Colla M, Lederbogen $F$ (2002). Hypercortisolaemic depression is associated with increased intra-abdominal fat. Psychosom. Med. 64(2): 274277

Weisova P, Anikumar U, Ryan C, Concannon CG, Prehn JHM, Ward MW (2014). Mild mitochondrial uncoupling induced protection against neuronal excitotoxicity requires AMPK activity. Biochim. Biophys. Acta (BBA)-Bioenerg. 1817(5): 744-753

Whitfield TWJnr, Shi X, Sun WL, McGinty JF (2011). The suppressive effect of an intra-prefrontal cortical infusion of BDNF on cocaineseeking is Trk receptor and extra-cellular signal regulated protein kinase MAPK dependent. J. Neurosc. 31(3): 834-842

Whitmer R (2013). Metformin cuts dementia risk in type 2 diabetes. Alzheimer's Association International Conference 2013 Boston, MA, USA. Oral Presentation 01-05-05 Retrieved from: www.medscape.com (2011).

Wilczynski G, Konopacki FA, Wilczek E, Lasiecka Z, Gorlewicz A, Michaluk P (2008). Important role of MMP-9 in epileptogenesis. J. Cell Biol. 180(5): 1021-1035

Wildburger NC, Laezza F (2012). Control of neuronal ion channel function by GSK-3: new prospectives for an old drug. Front. Mol. Neurosci. 5: 80 doi: 10.3389/fnmol.2012.00080

Wilinski B, Wilinski J, Somogyi E, Piotrowska J, Goralska M, Macura B (2011). Carvedilol induces hydrogen sulphide tissue concentration changes in various mouse organs. Folia Biol. (Krakow). 59(3-4): 151-155

Wilinski B, Wilinski J, Somogyi E, Piotrowska J, Opoka W (2013). Metformin raises hydrogen sulphide tissue concentration in various mouse organs. Pharmacol. Rep. 65(3): 737-742.

Will MJ, Prat WE, Kelly AM (2006). Pharmacological characterization of high fat feeding induced by opioid stimulation of the ventral striatum. Physiol. Behav. 89: 226-234

Willette AA, Gallagher C, Bendlin BB, McLaren DG, Kastman EK, Canu $E$ (2012). Homocysteine, neural atrophy, and the effect of calorie restriction on rhesus monkeys. Neurobiol. Ageing. 33(4: 670-680

Winick-Ng W, Len F, Kalisch BE (2012). Nitric oxide and histone deacetylases modulate cocaine-induced $\mathrm{m} \mu$-opioid receptor levels in PC12 cells. BMC Pharmacol. Toxicol. 13:11 doi:10.1186/20506511-13-11

World Health Organisation (1999). Diagnosis and classification of diabetes mellitus. WHO. Geneva. Diabet. Care. Suppl. 2: B1-B167

Wright JB (1993). Mania following sleep deprivation. Brit. J. Psychiatr. 163: $679-680$

Wu J, McCallum SE, Glick SD, Huang Y (2011). Inhibition of the mTOR pathway by rapamycin blocks cocaine-induced locomotor sensitization. Neurosci. 172: 104-109

Xin-Long C, Zhao-Fan X, Dao-Feng B, Wei D (2011). mTOR partly mediates insulin-resistance by phosphorylation of IRS-I on serine (307) after burn. Burns. 37(1): 86-93

Xiong K, Hu X-Q, Stewart RR, Weight FF, Li C (2005). The mechanism by which ethanol inhibits rat $\mathrm{P} 2 \mathrm{X} 4$ receptors is altered by mutation of histidine 241. BJP. 145(5): 576-586

Xu C-M, Wang J, Wu P, Xue Y-X, Zhu W-L, Li Q-Q (2011). GSK-3 beta in the nucleus accumbens core is critical for methamphetamineinduced behavioural sensitization. J. Neurochem. 118(1): 126-139

Xu JN, Zeng C, Zhou Y, Peng C, Zhou YF, Xue O (2014). Metformin inhibits STAR expression in human endometriotic stroma cells via AMPK-mediated disruption of CREB-CRTC2 complex formation. J. Clin. Endocrinol. Metab. 98(8): 2795-2803

Yamamoto N, Anggadiredja K, Hiranita T (2005). New perspectives in

the studies on endocannabinoid and cannabis: a role for the endocannabinoid-arachidonic acid pathway in drug reward and long-lasting relapse to drug taking. J. Pharmacol. Sci. 96(4): 382-388 
Yamanaka M, Itakura Y, Ono-Kishino M,Tsuchido A, Nakagawa T, Taiji M (2008). Intermittent administration of BDNF ameliorates glucose metabolism and prevents pancreatic exhaustion in diabetic mice. J. Biosci. Bioener. 105: 395-404

Yan X, Zhu M, Xu W, Tong JF, Ford SP, Nathanielsz PW (2009). Upregulation of TLR4/NF-kappaB signalling is associated with enhanced adipogenesis and insulin resistance in fetal skeletal muscle of obese sheep at late gestation. Endocrinol. 151(1): 380387

Yanev S, Aloe L, Fiore M, Chaldakov GN (2013). Neurotrophic and metabophic potential of nerve growth factor and brain-derived neurotrophic factor: linking cardiometabolic and neuropsychiatric diseases. World J. Pharmacol. (wjp 2.14.92) dx.doi: org/10.5497

Yang J, Gaddock J, Hong S, Liu Z-M (2009). AMP-activated protein kinase suppresses LXR-dependent SREBP-I c transcription in rats hepatoma McA-RA7777 cells. FASEB J. 23: 522-526

Yang M, Liu C, Jiang J, Zuo G, Lin X, Yamahara J (2014). Ginger extract diminishes chronic fructose consumption-induced kidney injury through suppression of renal overexpression of proinflammatory cytokines in rats. BioMedCentral Compl. Altern. Med. 27(14): 174-180

Yang Z, Ming X-F (2010). The vascular SIRTainty. Aging. 2(6): 331-332

Yajnik CS (2010). Fetal programming of diabetes: still much to learn. Diabet. Car. 33(5): 1146-1148

Yi SS (2013). Time-dependent changes of calbindin D-28K and parvalbumin immunoreactivity in the hippocampus of rats with streptozotocin-induced type I diabetes. J. Veter. Sci. 14(14): 273300

Yin P. Yang L, Zhou HY, Sun RP (2011). Matrix metalloproteinase-9 may be a potential therapeutic target in epilepsy. Med. Hypoth. 76(2): 184-186

Yoo DY, Kim W, Nam SM, Yoo KY, Lee CH, Choi JH (2011). Reduced cell proliferation and neuroblast differentiation in the dentate gyrus of high-fat diet fed mice are ameliorated by metformin and glimepiride treatment. Neurochem. Res. 36: 2401-2408

Young LT (2007). Is bipolar disorder a mitochondrial disease? J. Psychiatr Neurosci. 32(3): 160-161

Yumuru M, Gergerliogli HS, Savas HA, Basarah K, Kalenderogli A, Buyukbas $S$ (2012). Serum resistin levels and metabolic changes in bipolar disorder. J. Mood Disord. 2(2): 47-50

Zeggini E, Scott LJ, Saxena R (2008). Meta-analysis of genome-wide association data and large scale replication identifies additional susceptibility loci for type 2 diabetes mellitus. Nat. Gene. 40(5): 638-645

Zeman M, Jirak R, Jachymova M, Vecka M, Tzicka E, Zak A (2009). Leptin, adiponectin, leptin to adiponectin ratio and insulin resistance in depressive women. Neuroendocrin. Lett. 30(3): 309-395

Zeng T, Zhang C-L, Song F-Y, Zhao X-L, Yu L-H, Zhu Z-P (2013). The activation of $\mathrm{HO}-\mathrm{I} / \mathrm{Nrf}-2$ contributes to protective effects of diallyl disulphide (DADS) against ethanol-induced oxidative stress. BBAGen. Subj. 1830(10): 4848-4859

Zhang H-Y, Gao M-L, Liu Q-R, Bi G-H, Li X, Yang H-J (2014). Cannabinoid CB2 agonists modulate midbrain dopamine neuronal activity and dopamine-related behaviour in mice. Sci. (gov) US. 2014-11-18

Zhang JG, Liu JX, Li ZH, Wang LZ, Jiang YD, Wang SR (2007). Dysfunction of endothelial nitric oxide system originated from homocysteine-induced aberrant methylayion pattern in promoter region of DDAN2 gene. Chin. Med. (Eng.) 120(23): 2132-7

Zhang M, Xu S, Maitland-Toolan KA, Zuccollo A, Hou X, Jiang B (2006). Polyphenols stimulate AMP-activated protein kinase, lower lipids, and inhibit accelerated atherosclerosis in diabetic LDL receptordeficient mice. Diabet. 55(8): 2180-2191

Zhang XY, Chen D-C, Tan Y-L, Tan S-P, Luo X, Zuo L (2015). A functional polymorphism in the interleukin-I beta and severity of nicotine dependence in male schizophrenia: a case control study. J. Psychiatri. Res. 64: 51-58
Zhang ZJ, Koifman J, Shin DS, Ye H, Florez CM, Zhang L (2012). Transition to seizure, ictal discharge is preceded by exhausted presynaptic GABA release in the hippocampal CA3 region. J. Neurosci. 32(7): 2499-2512

Zhao M, Sun L, Yu J, Miao Y, Liu J-J, Wang H, Ren J, Zhang W-J (2013). Acetylcholine mediates AMPK-dependent autophagic cytoprotection in $\mathrm{H} 9 \mathrm{C} 2$ cells during hypoxia/reoxygenation injury. Cell Physiol. Biochem. 32: 601-661

Zhao RR, Xu XC, Xu F, Zhang WL, Zhang WL, Liu LM (2014). Metformin protects against seizures, learning and memory impairments and oxidative damage induced by pentylenetetrazolinduced kindling in mice. Biochim. Biophys. Res. Commun. 448(4): 414-417

Zhao WQ, De Felice FG, Fernandez S, Chen H, Lambert MP, Quon MU (2008). Amyloid beta oligomers induce impairment of neuronal insulin receptors. FASEB J. 22(1): 246-266

Zheng $X$, Sun T, Wang $X$ (2013). Activation of type 2 cannabinoid receptors (CB2R) promotes fatty acid oxidation through the SIRT I/PGC-I alpha pathway. Biochem. Biophys. Res. Comm. 436(3): 373-81

Zheng Z, Zeng Y, Huang H, Xu F (2013). MicroRNA-132 may play a role in co-existence of depression and cardiovascular diseases: A hypothesis. Med. Sci. Monit. 19: 438-443

Zhong Q, Kowluru RA (2013). Regulation of MMP-9 by epigenetic modifications and the development of diabetic retinopathy. Diabet. 62: 2559-2568

Zhong Y, Zhang X, Cai X, Wang K, Chen Y, Deng Y (2014). Puerarin attenuated early diabetic kidney injury through down-regulation of MMP-9 in STZ-induced diabetic rats. PLoS One doi. 10: $1371 /$ journal pone/0085690

Zhou $L$ (2012). Genetic dissection of the role of casein kinase-l epsilon in sleep, mood and metabolism. www. gradworks.umi.com Ph.D dissertation 3605804

Zhou R, Yuan P, Wang Y, Hunsberger JG, Elkahloun A, Wei Y (2009). Evidence for selective microRNAs and their effectors as common long-term targets for the actions of mood stabilisers. Neuropsychopharmacol. 34: 1395-1405

Zhou Y, Colombo G, Carai MAM, Ho A, Gessa GL, Kreek MJ (2012). Involvement of arginine vasopressin and VIb receptor in alcohol drinking in Sardinian alcohol-preferring rats. Alcohol Clin. Expt. Res. 35(10): 1876-1883

Zhou Y, Colombo G, Gessa GL, Kreek MJ (2013). Effects of voluntary alcohol drinking on CRF and preprodynorphin mRNA level in the central amygdala of Sardinian alcohol-preferring rats. Neurosci. Lett. 554: 110-4

Zhou Y, Leri F, Cummins E, Hoeschele M, Kreek MJ (2008). Involvement of arginine vasopressin and $\mathrm{VIb}$ receptor in heroin withdrawal and heroin seeking precipitated by stress and by heroin. Neuropsychopharmacol. 33(2): 226-36

Zhu CB, Blakeley RD, Hewlett WD (2006). The proinflammatory cytokines interleukin-I beta and TNF-alpha activate serotonin transporters. Neuropsychopharmacol. 31(10): 2121-2131

Zhu J-N, Fu Y-H, Lin Q-X, Huang S, Guo LL, Zhang M-Z (2013). Smad inactivation and MiR-29b upregulation mediate the effect ofcarvedilol inattenuating the acute myocardium infarctioninducedmyocardial fibrosis in rat. PLoS One. 8(9): e75557.

Zhuang X, Oosting RS, Jones SR, Gainetdinov RR, Miller GW, Caron MG (2001). Hyperactivity and impaired response habituation in hyperdopaminergic mice. PNAS. US. 98(4): 1982-1987

Zorilla EP, Logrip ML, Koob GF (2014). CRF: a key role in the neurobiology of addiction. Front. Neurosci. 35(2): 234-244 